\title{
Systematic dissection of phenotypic, functional, and tumorigenic heterogeneity of human prostate cancer cells
}

\author{
Xin Liu ${ }^{1, *}$, Xin Chen ${ }^{1, *}$, Kiera Rycaj ${ }^{1, *}$, Hsueh-Ping Chao ${ }^{1,3}$, Qu Deng ${ }^{1,3}$, Collene Jeter ${ }^{1}$, \\ Can Liu ${ }^{1}$, Sofia Honorio ${ }^{1}$, Hangwen Li $^{1}$, Tammy Davis ${ }^{1}$, Mahipal Suraneni ${ }^{1}$, Brian \\ Laffin $^{1}$, Jichao Qin ${ }^{1}$, Qiuhui Li ${ }^{1}$, Tao Yang ${ }^{2}$, Pamela Whitney ${ }^{1}$, Jianjun Shen ${ }^{1}$, Jiaoti \\ Huang ${ }^{4}$, Dean G. Tang ${ }^{1,2,3,5}$ \\ ${ }^{1}$ Department of Epigenetics and Molecular Carcinogenesis, University of Texas MD Anderson Cancer Center, Science Park, \\ Smithville, TX 78957, USA \\ ${ }^{2}$ Cancer Stem Cell Institute, Research Center for Translational Medicine, East Hospital, Tongji University School of Medicine, \\ Shanghai 200120, China \\ ${ }^{3}$ Program in Molecular Carcinogenesis, University of Texas Graduate School of Biomedical Sciences (GSBS), Houston, TX \\ 77030, USA \\ ${ }^{4}$ Department of Pathology and Laboratory Medicine, David Geffen School of Medicine, UCLA, Los Angeles, CA 90095, USA \\ ${ }^{5}$ Centers for Cancer Epigenetics, Stem Cell and Developmental Biology, RNA Interference and Non-Coding RNAs, and \\ Molecular Carcinogenesis, University of Texas MD Anderson Cancer Center, Houston, TX 77030, USA \\ *These authors have contributed equally to this work
}

Correspondence to:

Dean G. Tang, e-mail: dtang@mdanderson.org

Keywords: prostate cancer, cancer stem cells, stem cells, differentiation, heterogeneity

Received: April 15, $2015 \quad$ Accepted: June 12, $2015 \quad$ Published: June 24, 2015

\section{ABSTRACT}

Human cancers are heterogeneous containing stem-like cancer cells operationally defined as cancer stem cells (CSCs) that possess great tumor-initiating and long-term tumor-propagating properties. In this study, we systematically dissect the phenotypic, functional and tumorigenic heterogeneity in human prostate cancer ( $\mathrm{PCa}$ ) using xenograft models and $>\mathbf{7 0}$ patient tumor samples. In the first part, we further investigate the $\mathrm{PSA}^{-/ 10}$ PCa cell population, which we have recently shown to harbor self-renewing long-term tumor-propagating cells and present several novel findings. We show that discordant $A R$ and PSA expression in both untreated and castration-resistant PCa (CRPC) results in $\mathrm{AR}^{+} \mathrm{PSA}^{+}, \mathrm{AR}^{+} \mathrm{PSA}^{-}, \mathrm{AR}^{-} \mathrm{PSA}^{-}$, and $\mathrm{AR}^{-} \mathrm{PSA}^{+}$subtypes of $\mathrm{PCa}$ cells that manifest differential sensitivities to therapeutics. We further demonstrate that castration leads to a great enrichment of $\mathrm{PSA}^{-/ 10} \mathrm{PCa}$ cells in both xenograft tumors and CRPC samples and systemic androgen levels dynamically regulate the relative abundance of $\mathrm{PSA}^{+}$versus $\mathrm{PSA}^{-/ 10}$ PCa cells that impacts the kinetics of tumor growth. We also present evidence that the $\mathrm{PSA}^{-/ 10} \mathrm{PCa}$ cells possess distinct epigenetic profiles. As the $\mathrm{PSA}^{-/ 10} \mathrm{PCa}$ cell population is heterogeneous, in the second part, we employ two PSA- (Du145 and PC3) and two PSA $^{+}$(LAPC9 and LAPC4) PCa models as well as patient tumor cells to further dissect the clonogenic and tumorigenic subsets. We report that different PCa models possess distinct tumorigenic subpopulations that both commonly and uniquely express important signaling pathways that could represent therapeutic targets. Our results have important implications in understanding PCa cell heterogeneity, response to clinical therapeutics, and cellular mechanisms underlying CRPC.

\section{INTRODUCTION}

Cellular heterogeneity represents an omnipresent feature in human tumors, which contain cells with diverse morphology, cytogenetic markers, growth kinetics, immunological characteristics, metastatic ability, and sensitivity to therapeutics [1]. Clonal evolution, driven by genetic instability of tumor cells, and phenotypic maturation and diversification, driven by cancer stem cells (CSCs), operate hand-in-hand to generate tumor cell 
heterogeneity [2]. Specifically, clonal evolution creates genetic diversity and drives clonal competition between multiple subclones in the tumor whereas CSC-directed differentiation and maturation generates phenotypic diversity within individual subclones [2].

One of the key biological properties of CSCs is the 'stemness', which confers on a subpopulation of cancer cells two fundamental traits of normal stem cells, i.e., self-renewal and differentiation ability. Like normal stem cells, whose self-renewal and multi-lineage differentiation (i.e., pluripotency) are regulated by an intricate network of transcription factors, CSC stemness is also bestowed by critical signaling pathways (e.g., Notch, HH, and Wnt) and transcription factors and epigenetic regulators such as Nanog, Bmi-1, and Polycomb proteins [3-5]. It has now become clear that intra-clonally, genetic mutations, epigenetic changes and tumor microenvironment converge on regulating the CSC stemness to generate the phenotypic diversity and functional heterogeneity of tumor cells [2].

Many different experimental strategies and approaches have been adopted and developed to purify and enrich CSC populations. These include cell surface marker-based flow sorting, marker-independent strategies such as holoclone, clonogenic sphere formation and label-retaining assays, functional assays such as Side Population (SP; which measures the drug-effluxing ability in CSCs) and Aldefluor assay (which measures the aldehyde dehydrogenase [ALDH] mediated detoxification capability), and in vitro and in vivo lineage tracing assays [1]. To study the stemness properties, a 'gold-standard' functional assay is to xenotransplant candidate human CSC populations in immunodeficient mice at decreasing cell doses, an assay often called limiting dilution (tumor) assay or LDA [1]. The LDA measures tumor-regenerating or tumor-initiating capacity, which, when combined with serial tumor transplantations, would measure the self-renewal ability of the candidate CSCs [1].

Prostate cancer $(\mathrm{PCa})$ is extremely heterogeneous but the cellular basis for PCa cell heterogeneity remains largely unknown. Understanding PCa cell heterogeneity is of clear clinical importance as it likely underlies differential $\mathrm{PCa}$ cell response to androgen-deprivation therapy (ADT) and other therapeutics such as docetaxel and helps explain $\mathrm{PCa}$ recurrence and metastasis. Work from our lab in the past 10 years has generated important clues to understanding the cellular heterogeneity of PCa. We have demonstrated that PCa cell SP and holoclones, as well as $\mathrm{CD} 44^{+}$and $\mathrm{CD} 44^{+} \alpha 2 \beta 1^{+}$subpopulations in some $\mathrm{PCa}$ models are enriched in prostate CSCs (PCSCs) with high tumorigenic and metastatic potential [6-12]. Using a PSA promoter (PSAP) driven EGFP lentiviral tracing reporter, we have recently provided evidence that the undifferentiated $\left(\mathrm{PSA}^{-/ 10}\right)$ PCa cell population harbors long-term tumor-propagating PCSCs that preferentially express stem cell-associated genes and can self-renew to generate $\mathrm{PSA}^{+} \mathrm{PCa}$ cells by asymmetric cell division [13]. Of clinical significance, $\mathrm{PSA}^{-1 \mathrm{lo}} \mathrm{PCa}$ cells can initiate robust tumor regeneration in fully castrated hosts, survive androgen deprivation, and mediate tumor recurrence [13]. Many other groups have also reported PCSC subpopulations [14-24].

One of the issues in PCSC studies is that different research groups often use divergent $\mathrm{PCa}$ models and different phenotypic markers or experimental approaches to enrich for putative PCSCs, making direct comparison of the results difficult. The main goals of our current study are to systematically dissect the $\mathrm{PCa}$ cell heterogeneity via assessing a spectrum of PCa cell line and xenograft models as well as primary tumor cells and samples, to address the relationship between and among different PCSC subpopulations, and dissect the relationship between PCSCs and AR, PSA, and castration resistance. The results presented here greatly advance our understanding of $\mathrm{PCa}$ cell heterogeneity and help to illuminate cellular mechanisms of $\mathrm{PCa}$ therapy resistance.

\section{RESULTS}

\section{PCa cell heterogeneity: Inverse correlation between tumor $P S A$ mRNA levels with clinical parameters and discordant $A R$ and $P S A$ mRNA expression in PCa samples}

We started our studies by systematically analyzing 27 'eligible' Oncomine data sets of PCa cDNA microarrays (Supplementary Table 1) and by correlating tumor PSA mRNA levels versus Gleason grade, hormone-refractory and metastatic status, and patient survival. The results revealed several interesting points. FIRST, an inverse correlation was observed between tumor PSA mRNA and tumor grade in all data sets with information on PSA mRNA and Gleason grade of the tumors and with sufficient number of cases (Figure 1A-1C; 13). Reduced PSA mRNA was also noted in high-grade (i.e., Gleason 8-10) tumors in the data sets of Best 2, Holzbeierlein, and Wallace (not shown). SECOND, reduced PSA levels were observed in hormone-refractory PCa in data sets of Best 2 (Figure 1D), and of Tamura and Tomlins (not shown). THIRD, we observed reduced tumor PSA mRNA in PCa metastases in all 11 data sets that contained $\geq 5$ metastatic samples (Figure 1E-1H). Interestingly, although the draining lymph node (LN) only occasionally showed reduced PSA mRNA (e.g., in the Chandran data set; Figure 1H), distant metastases, e.g., those to the adrenal gland, bone, and liver, generally exhibited consistent reduction in PSA mRNA (Figure 1H). Distant metastases also tended to express lower PSA mRNA than the benign/normal $(\mathrm{B} / \mathrm{N})$ tissues (Figure 1H). FINALLY, overall patient survival correlated with high intra-tumoral PSA mRNA levels in the data sets of Nakagawa [13], Setlur, Grasso, and Taylor (Figure 1I).

Strikingly, we frequently observed a discordant relationship between $P S A$ and $A R$ in individual primary (Figure 1A-1C), hormone-refractory (Figure 1D) and metastatic (Figure 1E-1F) samples. PSA mRNA was decreased across all data sets (Figure 1A-1F; data not 

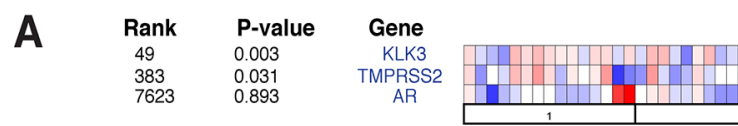

Yu

B

GS 6 (15)

GS 7 (27)

GS 8 (7) GS 9 (12)

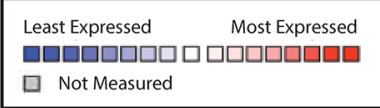

$\begin{array}{llc}\text { Rank } & \text { P-value } & \text { Gene } \\ 87 & 5.25 \mathrm{E}-5 & \text { KLK3 } \\ 3124 & 0.523 & \text { AR }\end{array}$

\begin{tabular}{|c|c|}
\hline Rank & P-value \\
\hline 1614 & 0.003 \\
\hline 2265 & 0.006 \\
\hline 4221 & 0.034 \\
\hline Rank & P-value \\
\hline 67 & 0.001 \\
\hline 3726 & 0.201 \\
\hline 7672 & 0.54 \\
\hline Rank & P-value \\
\hline 377 & 9.93E-11 \\
\hline 11675 & 0.999 \\
\hline 13011 & 1.000 \\
\hline
\end{tabular}
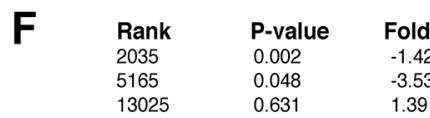

3.88 AR

-1.74 KLK3

-7.47 TMPRSS2

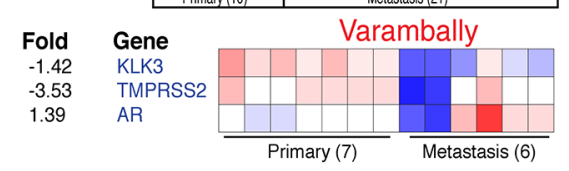

Setlur

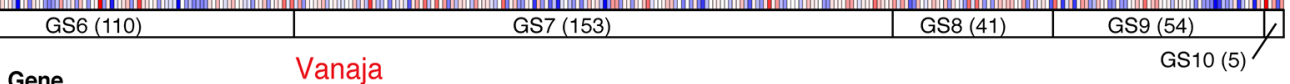

$\begin{array}{ll}-2.62 & \text { KLEK3 } \\ -2.37 & \text { TMPRSS }\end{array}$

AR

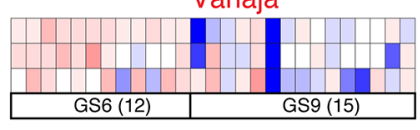

G

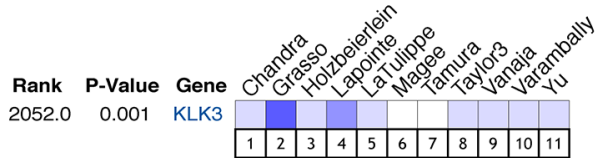

Best 2

KLK3

TMPRSS

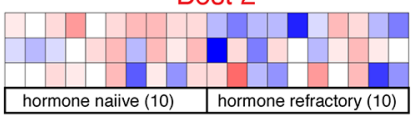

$H$
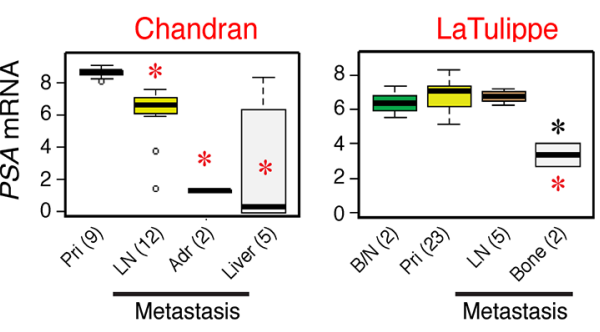

I
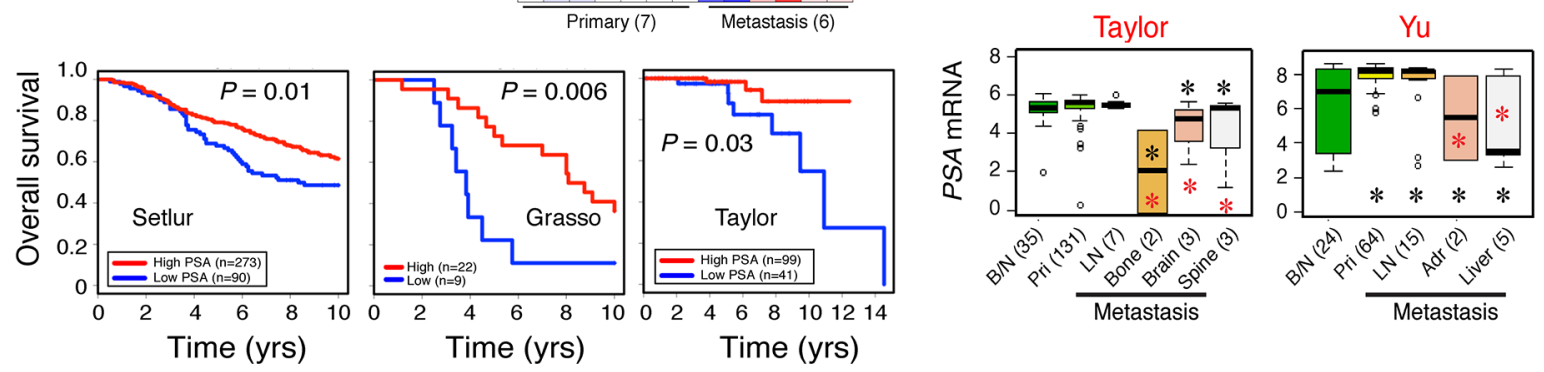

Figure 1: Inverse correlation between tumor PSA mRNA levels and clinical parameters. A-C. Heat map presentation of the mRNA levels of PSA, AR, and/or TMPRSS2 in relation to tumor grade (GS, Gleason score) in three representative Oncomine data sets (indicated above; see Supplementary Table 1 for information). Note that in individual samples, the $A R$ and $P S A$ expression patterns are frequently discordant. The legend on the right applies to all heat maps. D-F. Heat map showing discordant $A R$ and $P S A$ expression and reduced PSA mRNA levels in CRPC (D) and/or in metastases (E-F). G. Reduced PSA mRNA levels in PCa metastases across all 11 eligible data sets. H. Examples of reduced PSA mRNA levels in PCa metastasis. B/N, benign/normal; pri, primary tumor; LN, lymph node; Adr., adrenal gland. Red asterisk, $P<0.05$ in comparison with primary tumors; black asterisk, $P<0.05$ compared to B/N samples. I. Overall patient survival positively correlates with high PSA mRNA levels in 3 data sets.

shown) except the Setlur data set in which PSA reduction was not statistically significant although the decreasing trend was clear (Figure 1E). Another AR target, TMPRSS2, was also reduced in most data sets analyzed (Figure 1A, 1C-1F; 13). In contrast, the $A R$ mRNA levels were not correlated with tumor grade, hormone refractoriness, or metastasis (Figure 1A-1F; 13; data not shown). In one data set (Vanaja), the $A R$ mRNA levels were actually decreased in Gleason 9 tumors compared to Gleason 6 tumors (Figure 1C).

\section{PCa cell subtypes in untreated patient tumors, enrichment of PSA ${ }^{-/ 10}$ PCa cells in CRPC and castration-resistant xenograft tumors, and differential drug responses in PCa cell subtypes}

Discordant mRNA expression patterns between $A R$ and PSA suggest 4 subpopulations of PCa cells, i.e., $\mathrm{AR}^{+} \mathrm{PSA}^{+}, \mathrm{AR}^{-} \mathrm{PSA}^{+}, \mathrm{AR}^{+} \mathrm{PSA}^{-}$, and $\mathrm{AR}^{-} \mathrm{PSA}^{+}$cells.
Immunofluorescence (IF) analysis of AR and PSA proteins in 11 untreated primary patient tumors $(\mathrm{HPCa}$; Supplementary Table 2) directly supports this premise as the 4 subpopulations of PCa cells could be identified in all samples, although, as expected, the $\mathrm{AR}^{+} \mathrm{PSA}^{+} \mathrm{PCa}$ cells represented the major subpopulation (Figure 2A-2B; Supplementary Figure 1 and 2). In these analyses, AR showed typical nuclear staining with a spectrum of intensities (negative, weak, intermediate, and strong) whereas PSA generally showed cytoplasmic staining (Figure 2A; Supplementary Figure 1 and 2). Occasionally, nuclear PSA (Supplementary Figure 1C; Supplementary Figure 2B) and secreted PSA in the lumen of the prostatic glands (Supplementary Figure 2C) were observed.

Next, we analyzed AR and PSA protein expression in 23 CRPC samples including 20 samples (CRPC120 ) in a tissue microarray (TMA) and 3 regular CRPC (CRPC21-23) samples (Figure 2C; Supplementary Figure 
3A-3B). AR expression showed wide variability in these CRPC samples. For example, CRPC5 and CRPC12 showed apparently increased $\mathrm{AR}$ expression and $\mathrm{AR}^{+} \mathrm{PCa}$ cells compared to untreated PCa but many CRPC samples (e.g., CRPC9, 16, and 20-23) significantly lacked $\mathrm{AR}^{+}$ PCa cells (Figure 2C; Supplementary Figure 3, Ab, B). Furthermore, in all $\mathrm{AR}^{+} \mathrm{CRPC}$ samples, $\mathrm{AR}^{-} \mathrm{PCa}$ cells could be readily identified, e.g., in CRPC8 (Figure 2C) and CRPC2 and 7 (Supplementary Figure 3B). In sharp contrast to the AR expression patterns, the majority of the 23 CRPC samples mostly lacked appreciable PSA expression or PSA ${ }^{+} \mathrm{PCa}$ cells (Figure 2C; Supplementary Figure 3A-3B). Only one sample (CRPC12) was found to have somewhat concordant AR and PSA expression and only CRPC19 (the patient was treated with Lupron for $\sim 2$ weeks) expressed high intratumoral PSA (Supplementary Figure 3A). The IHC studies in this cohort of 23 CRPC samples indicate that $P S A^{-/ l o} \mathrm{PCa}$ cells (which can be $\mathrm{AR}^{+}$ or $\mathrm{AR}^{-}$) are enriched in patient CRPC samples.

Subsequently, we investigated the relative abundance of the 4 subtypes of PCa cells in 3 AD (androgen-dependent) and AI (androgen-independent) PCa xenograft models, LNCaP, LAPC4 and LAPC9 (13). In all 3 models, the AI tumors were highly enriched in $\mathrm{PSA}^{-/ 1 \mathrm{o}}$ PCa cells (Figure 2D-2E; Supplementary Figure $3 \mathrm{C}-3 \mathrm{D}$; data not shown). In LNCaP AD tumors, $\sim 80 \%$ of the cells were $\mathrm{AR}^{+} \mathrm{PSA}^{+}$and the other 3 subtypes of cells represented the minority (Figure 2D-2E; Supplementary Figure 3C). In contrast, the LNCaP AI tumors showed greatly reduced $\mathrm{AR}^{+} \mathrm{PSA}^{+}$cells and dramatically increased $\mathrm{PSA}^{-/ \mathrm{lo}}\left(\mathrm{AR}^{+} \mathrm{PSA}^{-/ \mathrm{lo}}\right.$ and $\left.\mathrm{AR}^{-} \mathrm{PSA}^{-/ \mathrm{lo}}\right)$ cells (Figure 2D-2E; Supplementary Figure 3C). Similarly, $\mathrm{PSA}^{-/ 10} \mathrm{PCa}$ cells were significantly increased in LAPC4 (Supplementary Figure 3D) and LAPC9 (not shown) AI tumors. Interestingly, in LAPC4 AI tumors, most AR localized to the cytoplasm (Supplementary Figure 3D).

To explore potential differences between subtypes of $\mathrm{PCa}$ cells in response to therapeutics, we performed a preliminary study in three types of $\mathrm{LNCaP}$ cells (Figure $2 \mathrm{~F}$ ), i.e., $\mathrm{AR}^{+} \mathrm{PSA}^{+}$wild-type $\mathrm{LNCaP} \mathrm{AR}^{+} \mathrm{PSA}^{-}$ LNCaP-abl [25], and $\mathrm{AR}^{-} \mathrm{PSA}^{-}$LNCaP-CDSS and LNCaP-MDV cells, the two castration-resistant LNCaP sublines we recently established (Rycaj et al., manuscript submitted). We treated these 3 LNCaP cell types with two antiandrogens, i.e., bicalutamide and MDV3100 (MDV; Enzalutamide), two chemotherapeutic drugs (etoposide and docetaxel), and two molecularly targeted drugs, i.e., ABT-199, which selectively inhibits Bcl-2 [26, 27], and AEW541, an inhibitor of IGF-1R [28], which is important for the $\mathrm{PSA}^{-/ \mathrm{lo}} \mathrm{PCa}$ cells [13]. In this relatively short (72 h) cytotoxicity assay, the three LNCaP cells manifested differential responses to the 6 drugs (Figure 2G). The $\mathrm{AR}^{+} \mathrm{PSA}^{+}$wild-type $\mathrm{LNCaP}$ cells displayed responses to all 6 drugs except Bicalutamide whereas $\mathrm{AR}^{+} \mathrm{PSA}^{-} \mathrm{LNCaP}-$ abl cells behaved overall similarly to wild-type LNCaP cells and showed only resistance to $10 \mu \mathrm{M}$ ABT-199
(Figure 2G). In contrast, the $\mathrm{AR}^{-} \mathrm{PSA}^{-} \mathrm{LNCaP}-\mathrm{CDSS}$ and LNCaP-MDV cells manifested prominent resistance to both etoposide and docetaxel as well as to MDV and ABT-199 (Figure 2G). Interestingly, LNCaP-abl cells showed higher sensitivity to $10 \mu \mathrm{M}$ AEW541 than both wild-type LNCaP and LNCaP-CDSS and LNCaP-MDV cells (Figure 2G). This pilot experiment establishes the proof-of-principle that subtypes of PCa cells with distinct $\mathrm{AR}$ and PSA expression profiles may respond differently to anticancer therapeutics.

\section{PSA $^{-/ 10}$ PCa cells: Heterogeneity in AR expression, quiescence, and resistance to antiandrogens and other therapeutics}

The converging findings from the above studies are that: 1) the $\mathrm{PSA}^{-/ \mathrm{lo}} \mathrm{PCa}$ cells pre-exist in untreated $\mathrm{HPCa}$; 2) $\mathrm{PSA}^{-/ \mathrm{lo}} \mathrm{PCa}$ cells become enriched in patient CRPC and AI xenograft models; and 3) $\mathrm{PSA}^{-/ l o}$ PCa cells respond to antiandrogens and several other therapeutics differently than the $\mathrm{PSA}^{+} \mathrm{PCa}$ cells. We recently employed a series of lentiviral GFP/RFP reporters to separate $\mathrm{PSA}^{-/ 10}$ from $\mathrm{PSA}^{+} \mathrm{PCa}$ cells to compare their molecular, cell biological, and tumorigenic properties [13]. Herein, we continue to use this system to further explore the cellular and molecular distinctions between these cell subsets, investigate their differential responses to therapeutics in vitro and to systemic androgen levels in vivo, and interrogate the relationship between the $\mathrm{PSA}^{-/ \mathrm{lo}} \mathrm{PCa}$ cells vs. several other PCSC populations.

Infection of LNCaP cells with the PSAP-GFP lentivector at an MOI of 20 led to $100 \%$ infection and GFP positivity faithfully reported the endogenous PSA expression [13]. Consistent with earlier results [13], all $\mathrm{PSA}^{+}$(i.e., $\mathrm{GFP}^{+}$) LNCaP cells were nuclear $\mathrm{AR}^{+}$whereas only $\sim 30 \% \mathrm{PSA}^{-/ \mathrm{lo}}$ (i.e., $\mathrm{GFP}^{-/ 10}$ ) LNCaP cells had strong nuclear AR (Supplementary Figure 4A). Similar results were obtained in LAPC9 and LAPC4 xenografts [13; data not shown]. These observations suggest that the $\mathrm{PSA}^{-/ 10} \mathrm{PCa}$ cell population is heterogeneous with respect to $\mathrm{AR}$ expression, consistent with the above IHC-based immunophenotypic analysis of AR and PSA expression in both untreated HPCa and CRPC samples.

We have previously demonstrated [13] that under time-lapse videomicroscopy, single $\mathrm{PSA}^{+} \mathrm{PCa}$ cells exclusively undergo symmetrical cell divisions (SCD) whereas $\mathrm{PSA}^{-/ \mathrm{lo}} \mathrm{PCa}$ cells undergo both $\mathrm{SCD}$ and asymmetrical cell division (ACD). Here we employed time lapse-based single-cell tracking to determine cell-cycle transit times in two populations of LNCaP cells (Figure $3 \mathrm{~A}-3 \mathrm{E}$ ). As observed previously [13], the $\mathrm{PSA}^{+}$(i.e., $\mathrm{GFP}^{+}$) LNCaP cells underwent rapid and exclusive SCD to generate more $\mathrm{PSA}^{+}$cells (Figure 3A; Figure 3D, top). In contrast, many $\mathrm{PSA}^{-/ \mathrm{lo}}$ (i.e., $\mathrm{GFP}^{-}$) $\mathrm{LNCaP}$ cells underwent ACD during the first cell division (Figure 3B; Figure 3D, middle). Very occasionally, we observed rare $\mathrm{PSA}^{-/ \mathrm{lo}}$ 
A
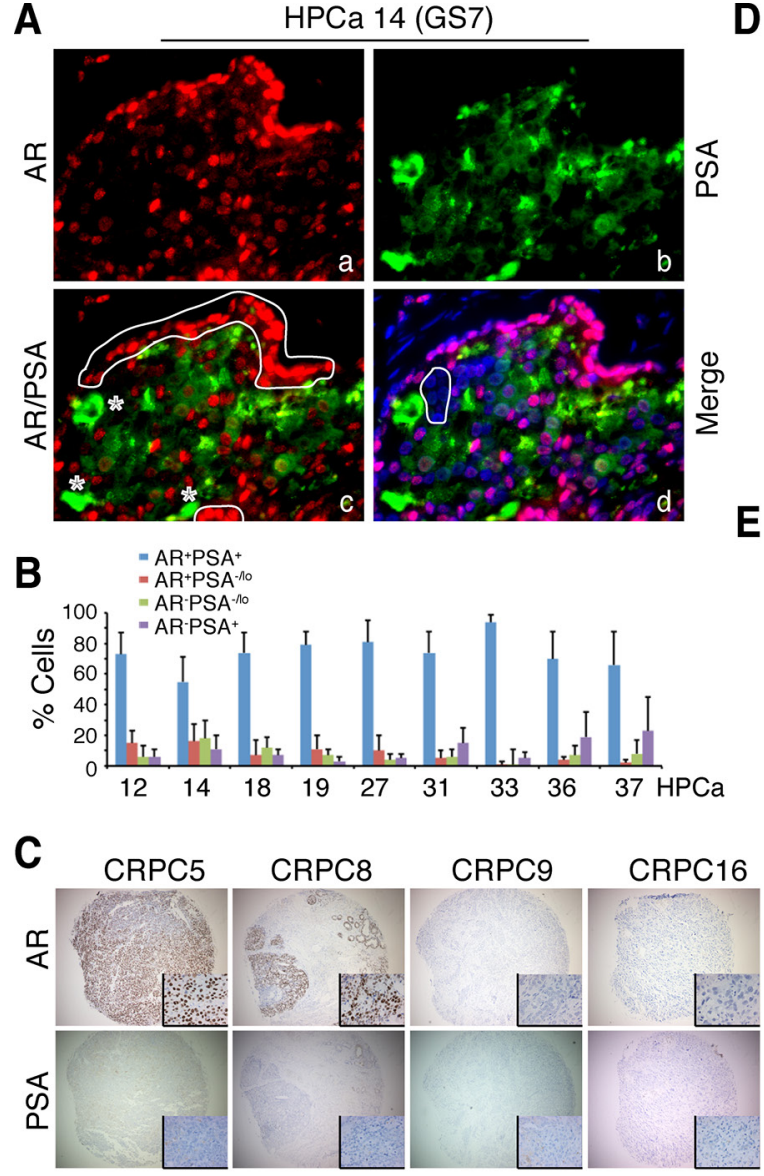

D

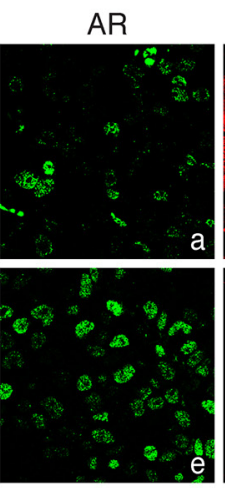

E

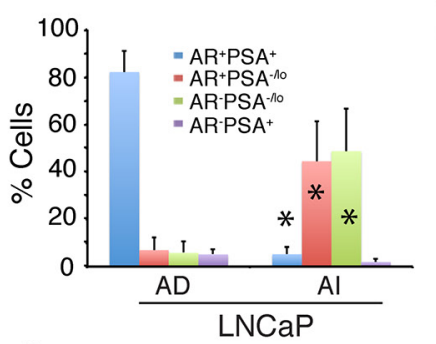

G

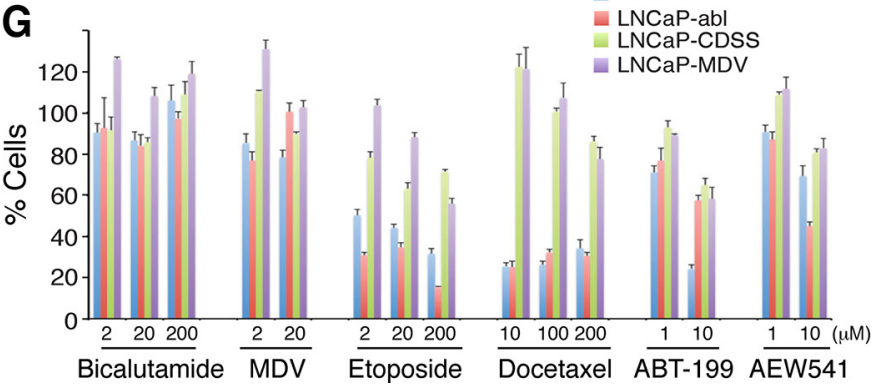

Figure 2: Discordant PSA and AR protein expression in PCa, 4 subtypes of PCa cells, enrichment of PSA ${ }^{-/ 0}$ PCa cells in CRPC, and differential drug responses in subtypes of PCa cells. A-B. Representative immunofluorescence images $(\times 400)$ illustrating discordant PSA and AR protein expression in HPCa 14 (A) and quantification of 4 subpopulations of PCa cells in the 9 HPCa samples (B). In A, $\mathrm{AR}^{+} \mathrm{PSA}^{+} \mathrm{PCa}$ cells are marked by red nuclei and green cytosplasm, $\mathrm{AR}^{+} \mathrm{PSA}^{-10}$ cells by red alone (panel $\mathrm{c}$, white circled areas), $\mathrm{AR}^{-} \mathrm{PSA}^{+}$cells by green alone (panel c, asterisks), and $\mathrm{AR}^{-} \mathrm{PSA}^{-10}$ cells by being negative (or low) for both red and green staining (panel d, white circled area). C. IHC analysis of AR and PSA in the TMA samples. Shown are 4 CRPC samples illustrating homogeneous loss of PSA in all 4 samples and heterogeneous expression of AR (insets: 400×). D. Double immunofluorescence staining of AR and PSA in AD vs. AI LNCaP xenograft tumors. In panel c, the white line demarcates $3 \mathrm{AR}^{+} \mathrm{PSA}^{+}$cells and the arrows point to $2 \mathrm{AR}^{+} \mathrm{PSA}^{-10}$ cells. In panel d, the white circle demarcates several $\mathrm{AR}^{-} \mathrm{PSA}^{-1 / 0}$ cells and the arrows point to $3 \mathrm{AR}^{-} \mathrm{PSA}^{+}$cells. In panel h, the arrows illustrate several $\mathrm{AR}^{-} \mathrm{PSA}^{-10}$ cells. Shown are representative confocal images (original magnification; $\times 400$ ). E. Quantification of the 4 subtypes of PCa cells in AD and AI LNCaP xenograft tumors. A total of 809 and 907 cells were counted from several $\mathrm{AD}$ and AI tumors, respectively. ${ }^{*} P<0.001$ in AI compared in AD tumors. F. Western blotting analysis of AR and PSA. PC3 and IGR1 cells, which are known to be negative for both proteins, were used as controls. Note that the wild-type LNCaP cells (lane 3) were $\mathrm{AR}^{+} \mathrm{PSA}^{+}$whereas LNCaP-abl cells AR ${ }^{+} \mathrm{PSA}^{-}$(lane 2). $\mathrm{LNCaP}^{-C D S S}$ and LNCaP-MDV cells were both $\mathrm{AR}^{-} \mathrm{PSA}^{-}$ (lanes 5-6). The arrow indicates the $\sim 114 \mathrm{kD}$ full-length $\mathrm{AR}$ and lower bands might represent AR splice variants (top panel). G. Drug responses in subtypes of $\mathrm{LNCaP}$ cells. $\mathrm{LNCaP}\left(\mathrm{AR}^{+} \mathrm{PSA}^{+}\right)$, $\mathrm{LNCaP}-\mathrm{abl}\left(\mathrm{AR}^{+} \mathrm{PSA}^{-}\right)$, and $\mathrm{LNCaP}-\mathrm{CDSS}$ and $\mathrm{LNCaP}-\mathrm{MDV}\left(\mathrm{AR}^{-} \mathrm{PSA}^{-}\right)$cells were treated with the drugs at the indicated concentrations for $72 \mathrm{~h}$. Relative cell numbers were determined by Alamar Blue assays (see Methods). For Bicalutamide, at 2 and $20 \mu \mathrm{M}$, only LNCaP-MDV cells showed partial resistance $(P<0.05)$. At $200 \mu \mathrm{M}$, Bicalutamide even slightly promoted wild-type LNCaP cell growth probably due to its well-known agonist effects. For MDV3100, at $2 \mu \mathrm{M}$, LNCaP-CDSS and LNCaP-MDV but not LNCaP-abl cells showed partial resistance $(P<0.05)$. At $200 \mu \mathrm{M}$ of MDV, all $3 \mathrm{LNCaP}$ sublines showed partial resistance $(P<0.05)$ in comparison to wild-type cells. Note prominent resistance in LNCaP-CDSS and LNCaP-MDV cells to etoposide and docetaxel $(P<0.001$ for all comparisons between these two cell types vs. either wild-type or LNCaP-abl cells). All LNCaP cell types responded similarly to $1 \mu \mathrm{M} \mathrm{ABT}$ 199 but the 3 LNCaP sublines (LNCaP-abl, -CDSS, and -MDV) showed common resistance to $20 \mu$ M ABT-199 $(P<0.01)$. LNCaP-CDSS and LNCaP-MDV but not LNCaP-abl cells showed partial resistance to $1 \mu \mathrm{M}$ of AEW541 $(P<0.05)$ and this resistance phenotype dissipated at 10 $\mu \mathrm{M}$ AEW541, at which LNCaP-abl cells showed higher sensitivity than wild-type cells $(P<0.05)$.

cells that underwent SCD during the first cell division followed by complex division modes during subsequent divisions (Figure 3C; Figure 3D, bottom). Strikingly, the
$\mathrm{PSA}^{+}$daughter cells derived from ACD in most cases underwent rapid SCD whereas the $\mathrm{PSA}^{-/ 10}$ mother cells rarely divided again (Figure 3B), suggesting that the $\mathrm{PSA}^{-/ 10}$ 
A

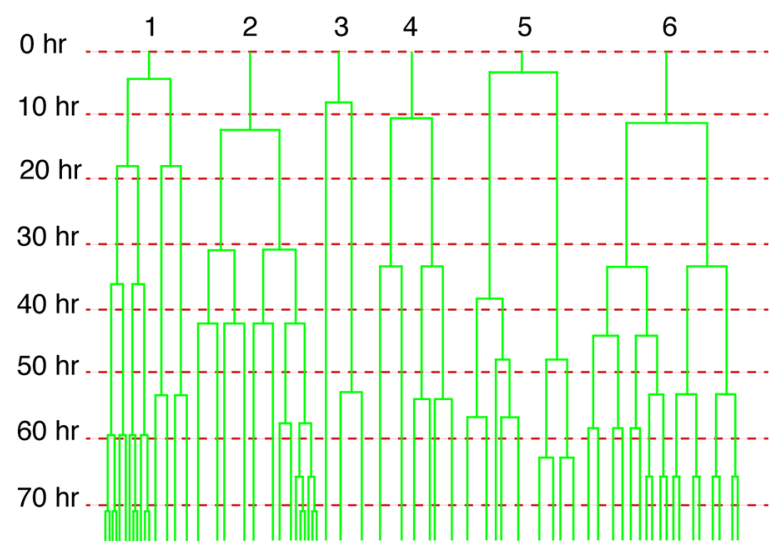

$80 \mathrm{hr}$
B

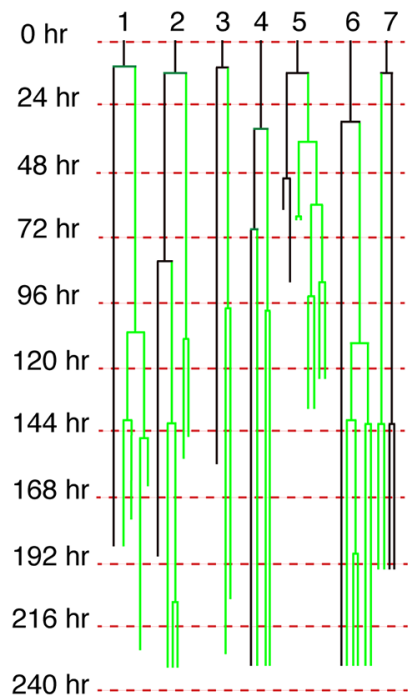

C GFP cell

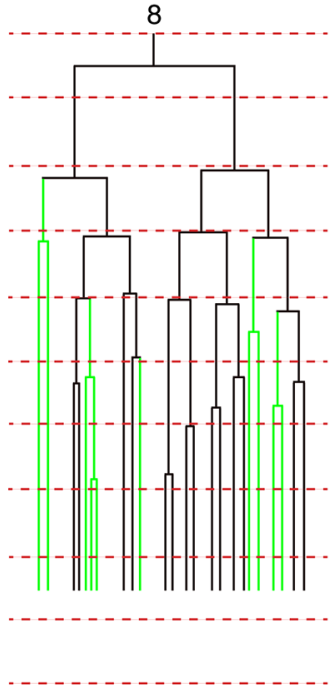

D

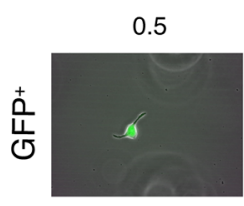

1

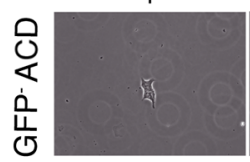

10

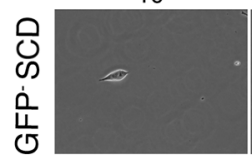

E

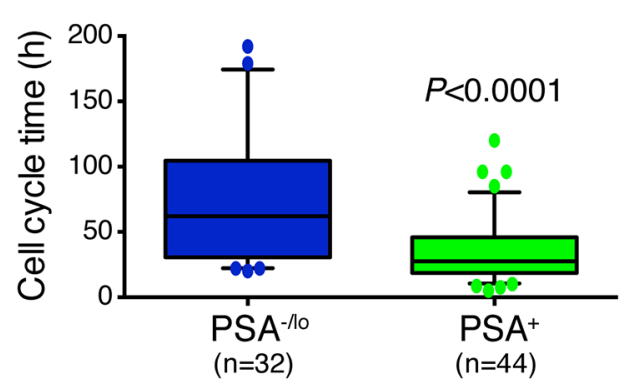

34

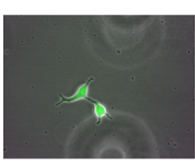

80

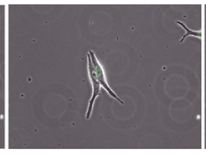

30

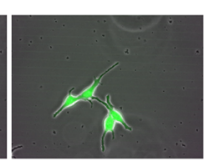

112

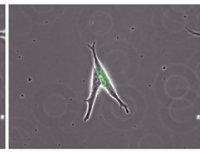

73
49

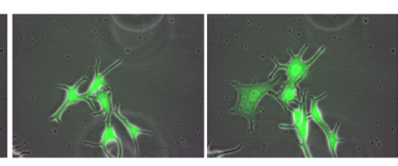

118

127
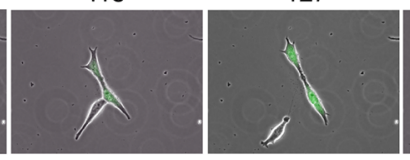

110

120
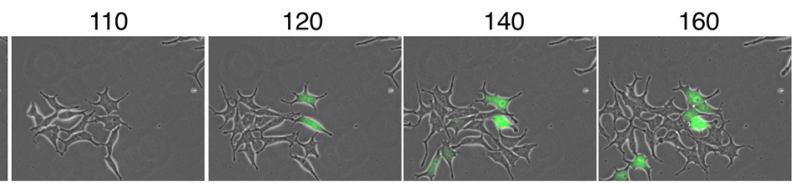

91

109 hrs

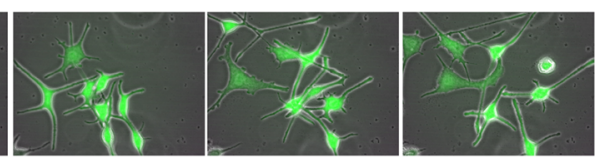

$153 \mathrm{hrs}$

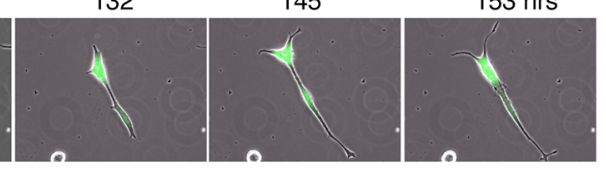

$176 \mathrm{hrs}$

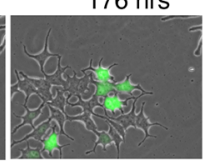

G

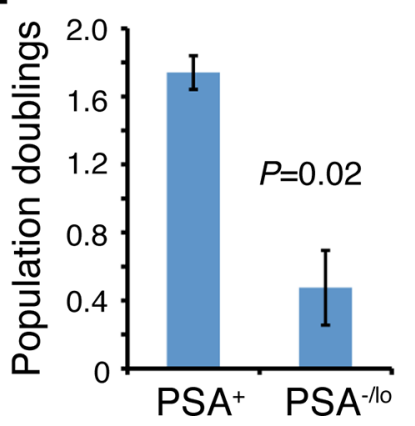

Figure 3: PSA $^{-/ 10}$ LNCaP cells are more quiescent than PSA $^{+}$cells. A-C. Cell division mode and cell-cycle transit times in LNCaP cells in regular serum-containing culture medium as determined by time-lapse videomicroscopy. Shown in A are six representative GFP ${ }^{+}$ LNCaP cells that underwent symmetrical cell divisions. Shown in B are seven representative $\mathrm{GFP}^{-} \mathrm{LNCaP}$ cells that underwent asymmetric cell divisions. Shown in $\mathrm{C}$ is one $\mathrm{GFP}^{-} \mathrm{LNCaP}$ cell that underwent complex cell divisions (see Text). Time scale is shown on the left for each cell recorded. D. Time-lapse images showing one $\mathrm{GFP}^{+} \mathrm{LNCaP}$ cell undergoing symmetrical cell divisions in the first round and all subsequent rounds (top panels), one $\mathrm{GFP}^{-}$cell undergoing ACD during the first cell division (middle panels), and one GFP ${ }^{-}$cell undergoing symmetrical cell division during the first cell division followed by complex division modes in the progeny (bottom panels). E. Graphical presentation of cell-cycle transition times in $\mathrm{PSA}^{-/ 10}$ vs. PSA ${ }^{+}$LNCaP cells based on the time-lapse tracking of the 2 cell types. F. PSA ${ }^{+}$and PSA ${ }^{-/ 10} \mathrm{LNCaP}$ cells were FACS-purified and plated in quadruplicate in 96-well plate (1,500 cells/well) and cultured in regular serum-containing medium. Live cells were enumerated 3 days after plating and presented are the population doublings. G. PSA ${ }^{+}(+\mathrm{ve})$ and PSA ${ }^{-/ 10}(-\mathrm{ve}) \mathrm{LNCaP}$ cells were plated at clonal density (100 cells/well in triplicate) and cultured in RPMI-5\% FBS plus $10 \mathrm{nM} \mathrm{R} 1881$ for 2 weeks. At the end, holoclones were enumerated. Shown are the bar graphs (mean \pm S.D) pooled from three repeat experiments and a representative Giemsa-stained image (inset). 
cells overall divided more slowly than the isogenic $\mathrm{PSA}^{+}$ cells. Indeed, quantification of time-lapse images indicated that the $\mathrm{PSA}^{-/ \mathrm{lo}} \mathrm{LNCaP}$ cells had longer average cell-cycle transit times than $\mathrm{PSA}^{+}$cells (Figure $3 \mathrm{E}$ ). Consistent with the single cell analysis, $\mathrm{PSA}^{-/ \mathrm{lo}} \mathrm{LNCaP}$ cells demonstrated lower cumulative population doublings (Figure 3F) and holoclone [10] forming efficiency (Figure 3G) in regular medium containing serum (which contained small amount of steroid hormones) than the corresponding $\mathrm{PSA}^{+}$cells. In another holoclone assay, in which we sorted single $\mathrm{PSA}^{+}$ and $\mathrm{PSA}^{-/ l o}$ LNCaP cells into 96-well plates and cultured them in serum-containing medium. 18 days later, 19 holoclones developed in 36 single $\mathrm{PSA}^{+}$LNCaP cells (i.e., cloning efficiency $=53 \%$ ) whereas 24 clones developed in 83 single $\mathrm{PSA}^{-/ \mathrm{lo}}$ cells (cloning efficiency $=29 \%$ ). Taken together, these results suggest that the $\mathrm{PSA}^{-/ 10} \mathrm{PCa}$ cells, in the presence of androgen, are more quiescent than $\mathrm{PSA}^{+}$ PCa cells.

Are there any differences between $\mathrm{PSA}^{-/ 10}$ and $\mathrm{PSA}^{+}$ PCa cells in the absence of androgen or in the presence of stresses? In our earlier studies [13], we performed cDNA microarray analyses comparing gene expression profiles in $\mathrm{PSA}^{-/ \mathrm{lo}}$ and $\mathrm{PSA}^{+} \mathrm{LNCaP}$ as well as xenograft LAPC9 cells. A total of 570 probesets representing 337 genes (see Methods) were commonly upregulated $(1.5$ fold; $P<0.05)$ in $\mathrm{PSA}^{-/ \mathrm{lo}}$ cells in both cell types (Supplementary Figure 4B). Remarkably, when we performed Gene Ontology (GO) analysis on the 337 genes using DAVID, the top $10 \mathrm{GO}$ terms were all related, in some ways, to cellular responses to stress and wound healing (Supplementary Figure 4C). Preferential enrichment of anti-stress and regeneration genes coupled with their quiescent nature would render the PSA ${ }^{-/ l o}$ PCa cells resistant to stresses and therapeutics. Several experiments confirmed this prediction. First, when acutely purified $\mathrm{PSA}^{+}$and $\mathrm{PSA}^{-/ l o} \mathrm{LNCaP}$ cells were cultured in androgen-deficient conditions, i.e., in medium containing charcoal dextran-stripped serum (CDSS), the $\mathrm{PSA}^{-/ \mathrm{lo}}$ cells underwent significant expansion (Figure 4A), sharply contrasting with the scarce growth observed in androgen-proficient conditions (Figure 3F). As a matter of fact, only the $\mathrm{PSA}^{-/ \mathrm{lo}} \mathrm{LNCaP}$ cells showed significant survival and expansion during continued culture of up to 1 month (Figure 4B). Importantly, the suppressive effects of CDSS on PSA ${ }^{+}$LNCaP cells could be dose-dependently relieved by exogenous R1881 (Figure 4C). In another set of experiments, we treated the two purified populations of LNCaP cells side-by-side with CDSS plus bicalutamide $(20 \mu \mathrm{M})$, etoposide $(1 \mu \mathrm{M})$, paclitaxel $(20 \mathrm{nM})$, or H2O2 $(1 \mu \mathrm{M})$ for 4 days and then analyzed for apoptosis. As shown in Figure 4D, the $\mathrm{PSA}^{-/ \mathrm{lo}} \mathrm{LNCaP}$ cells were more resistant to all these treatments. Finally, we performed yet another set of side-by-side experiments with the two purified populations using the MTT assays to measure the cells that survived treatments. As shown in Figure 4E, $\mathrm{PSA}^{-/ l o}$ cells survived better than $\mathrm{PSA}^{+}$LNCaP cells in response to both Taxol and $\mathrm{H} 2 \mathrm{O} 2$. Since we employed two purified populations of
LNCaP cells to directly compare their apoptotic sensitivities (Figure 4), the results excluded the possibility that treatments caused de-differentiation in turning $\mathrm{PSA}^{+} \mathrm{LNCaP}$ cells to $\mathrm{PSA}^{-/ \mathrm{lo}}$ cells during the treatment period (i.e., 4 days). In support, we observed that all live PSA ${ }^{+}$LNCaP cells $48 \mathrm{~h}$ after treatments remained $\mathrm{GFP}^{+}$(not shown).

\section{Systemic androgen levels regulate the relative abundance of $\mathrm{PSA}^{+}$and $\mathrm{PSA}^{-/ 10} \mathrm{PCa}$ cells in tumors}

We next explored how systemic androgen levels dynamically affect the relative abundance of $\mathrm{PSA}^{-/ \mathrm{lo}}$ vs. $\mathrm{PSA}^{+}$cells in the tumors (Figure 5). LAPC9 tumors continuously maintained in male mice (i.e., the 'AD' tumors) contained $20.9 \% \pm 10.3 \%(n=10) \mathrm{PSA}^{-/ l o}$ cells with the majority being $\mathrm{PSA}^{+}$cells (Figure 5A, and $5 C)$. When bulk LAPC9 cells from these AD tumors were transferred to androgen-deficient hosts (i.e., either castrate male or female mice) for $\sim 2$ months, $\mathrm{PSA}^{+}$cells declined significantly whereas $\mathrm{PSA}^{-1 / 0}$ cells increased to $\sim 50 \%$ (Figure 5A, and 5C). When LAPC9 tumors were maintained in androgen-deficient hosts for $\sim 2$ years (i.e., the 'AI' tumors), $\mathrm{PSA}^{-/ l o}$ cells increased to $89.3 \% \pm 9.8 \%$ $(n=12)$ (Figure 5B). When unsorted LAPC9 cells from such AI tumors were put back in intact male mice, $\mathrm{PSA}^{+}$ LAPC9 cells in the tumors again increased (Figure 5B). These results are remarkably similar to what we observed earlier in AD/AI LNCaP and LAPC4 systems and suggest that systemic androgen levels dynamically regulate the abundance of $\mathrm{PSA}^{+}$vs. PSA ${ }^{-/ 10}$ cells in prostate tumors.

When unsorted LAPC9 cells from the AD tumors, in which 70-90\% cells were PSA ${ }^{+}$, were implanted in different hosts, they initiated much larger tumors in male mice than in castrated male or female mice (Figure 5D). In contrast, when bulk LAPC9 cells from the AI tumors, in which 90\% cells were $\mathrm{PSA}^{-/ \mathrm{lo}}$, were implanted in different hosts, they initiated larger tumors in androgen-deficient hosts (Figure $5 \mathrm{E})$. These results indicate that the relative abundance of $\mathrm{PSA}^{+}$versus $\mathrm{PSA}^{-/ 10}$ cells greatly influences tumor growth rate in hosts with different levels of androgen.

\section{Evidence that $\mathrm{PSA}^{-/ 10} \mathrm{PCa}$ cells possess distinct epigenetic profiles: Analysis of bivalent chromatin domains in several genes}

The above observations that systemic androgen levels regulate the relative abundance of the two populations of PCa cells in vivo implicate epigenetic mechanisms. Previous microarray analyses showed that the $\mathrm{PSA}^{-/ \mathrm{lo}} \mathrm{PCa}$ (LAPC9, LNCaP, as well as HPCa) cells overexpressed several dozens of stem cell-associated genes [13]. Of importance, the PSA ${ }^{-/ l o}$ LNCaP cells, compared to $\mathrm{PSA}^{+}$cells, also overexpressed some (e.g., EED, HDAC4, PHF8) whereas under-expressed other (e.g., DNMT3B, PHF19) chromatin modifiers/ epigenetic regulators [13]. Embryonic stem cells (ESCs) are 
A
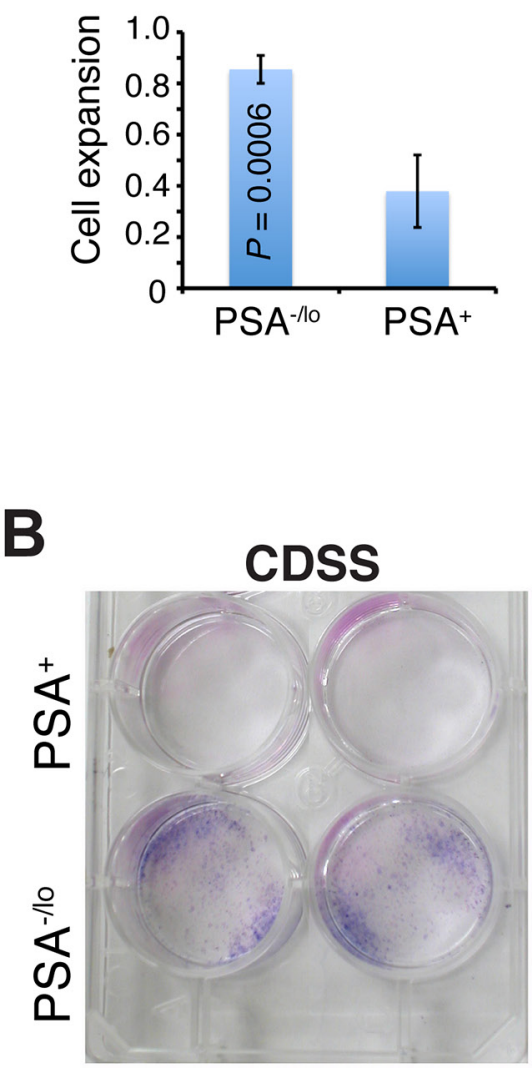

D

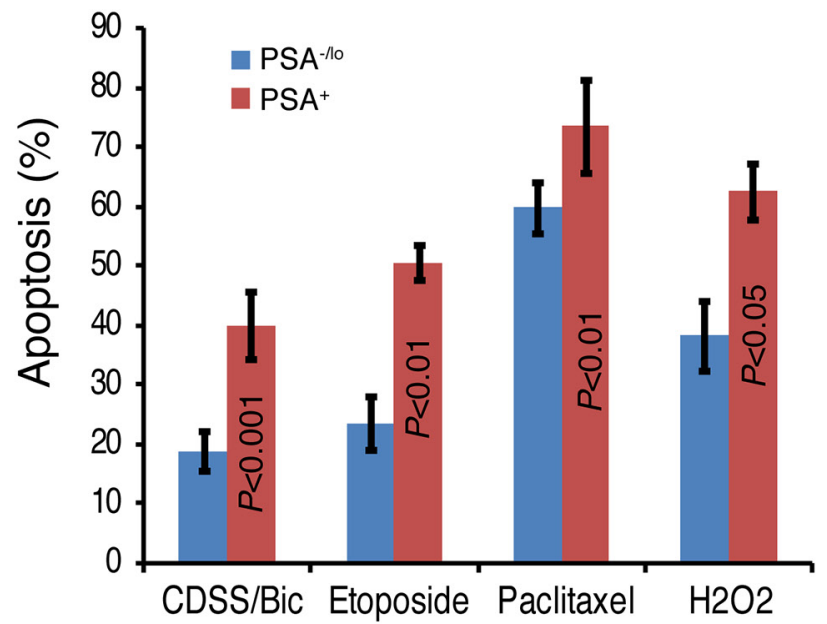

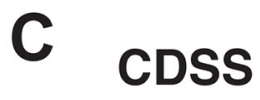

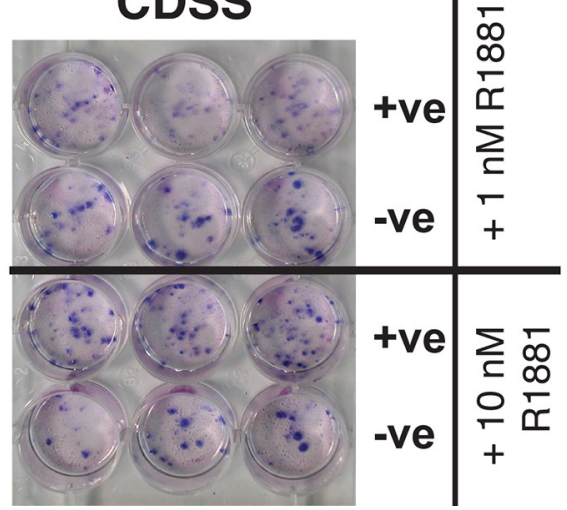

$\mathbf{E}$

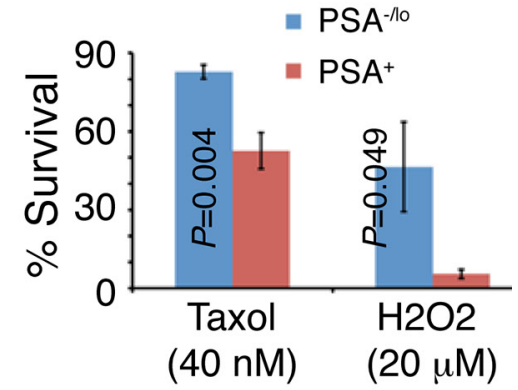

Figure 4: Differential apoptotic responses of $\mathbf{P S A}^{-/ 10}$ and $\mathbf{P S A}^{+} \mathbf{L N C a P}$ cells to therapeutics. A. PSA ${ }^{+}$and PSA ${ }^{-/ 10}$ LNCaP cells were plated (1,500/well) in quadruplicate in RPMI containing either $7 \%$ regular FBS or 7\% charcoal dextran stripped serum (CDSS). 11 days later, live cells were measured by MTT assays. The results are presented as the cell growth (expansion) of each population in CDSS medium RELATIVE to the corresponding FBS medium (which is 1). B. PSA ${ }^{+}$and PSA ${ }^{-/ l o}$ LNCaP cells (10,000/well) were cultured in

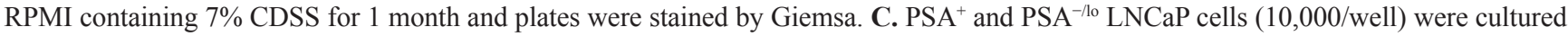
in RPMI-7\% CDSS plus either $1 \mathrm{nM}$ or $10 \mathrm{nM}$ R1881 for 25 days and plates were stained by Giemsa. Note that R1881 dose-dependently 'overcame' the CDSS effect and promoted the clonal expansion of PSA ${ }^{+}$LNCaP cells. D. Apoptosis assessed by the Vybrant apoptosis assays. Unsorted bulk LNCaP cells infected with PSAP-GFP lentiviral reporter were plated at $120 \mathrm{k}$ cells/well in 6-well plates. Cells were treated for 4 days with either DMSO, 2\% CDSS plus $20 \mu \mathrm{M}$ Bicalutamide (CDSS/Bic), $20 \mathrm{nM}$ Paclitaxel, $1 \mu \mathrm{M}$ etoposide, or $1 \mu \mathrm{M}$ H2O2. The $\%$ apopotsis represents the mean \pm S.D $(n=3)$ and $P$ values determined by Student's $t$-test. No difference in apoptosis was observed in the two populations in response to vehicle DMSO (not shown). E. PSA ${ }^{-/ 10} \mathrm{LNCaP}$ cells preferentially survive stress treatments. Purified PSA ${ }^{-1 / 0}$ and $\mathrm{PSA}^{+}$cells were plated (1,000/well) in 96-well plate in regular serum-containing medium containing Taxol (Docetaxel) or H2O2 for $48 \mathrm{~h}$. At the end of treatments, live cells were measured by MTT assays and cell survival normalized to vehicle control DMSO (which is $100 \%$ ).

enriched in genes associated with bivalent chromatin marks consisting of large regions of the repressive H3 lysine 27 trimethylation (H3K27me3) harboring smaller regions of $\mathrm{H} 3$ lysine 4 trimethylation (H3K4me3) [29]. To explore whether $\mathrm{PSA}^{-/ \mathrm{lo}} \mathrm{PCa}$ cells may also be epigenetically different from the differentiated isogenic $\mathrm{PSA}^{+}$cells, we performed ChIP and re-ChIP (also called ChIP and sequential ChIP) analysis using the Bernstein protocol [30]. We purified $\mathrm{PSA}^{-/ \mathrm{lo}}$ and $\mathrm{PSA}^{+}$LNCaP and LAPC9 cells and analyzed 8 genes whose promoters have been associated with the bivalent marks in ESCs [29] including FGF5, NKX3.1, BCL2, CDH2 (i.e., $\mathrm{N}$-cadherin), CD61 (i.e., integrin $\beta 3$ ), AR, ASCL1, and PPP2R4. We first performed regular ChIP assays using rabbit polyclonal antibodies to pan-histone 3 (panH3), H3K4me3, or $\mathrm{H} 3 \mathrm{~K} 27 \mathrm{me} 3$ in purified $\mathrm{PSA}^{+} / \mathrm{PSA}^{-/ \mathrm{lo}} \mathrm{LNCaP}$ (Figure $6 \mathrm{~A}$ ) or LAPC9 (Figure 6B) cells. We then performed sequential ChIP on the first ChIP products using a mAb to H3K27me3.

The results revealed that in LNCaP cells, 4 genes, i.e., NKX3.1, FGF5, BCL2, and CDH2 showed bivalent binding patterns preferentially in the $\mathrm{PSA}^{-/ \mathrm{lo}}$ cell population (Figure 6C). In contrast, the other 4 genes (i.e., CD61, ASCL1, AR, and PPP2R4) showed overall similar re-ChIP profiles, which did not differ significantly between $\mathrm{PSA}^{-/ \mathrm{lo}}$ vs. $\mathrm{PSA}^{+}$ cells (Figure 6C; data not shown). In LAPC9 cells, 4 genes, i.e., FGF5, BCL2, CDH2 and CD61 showed bivalent binding patterns preferentially in $\mathrm{PSA}^{-/ 10}$ cells (Figure 6D) whereas $N K X 3.1$ showed similarly low levels of bivalency in both populations. The other 3 genes (ASCL1, 


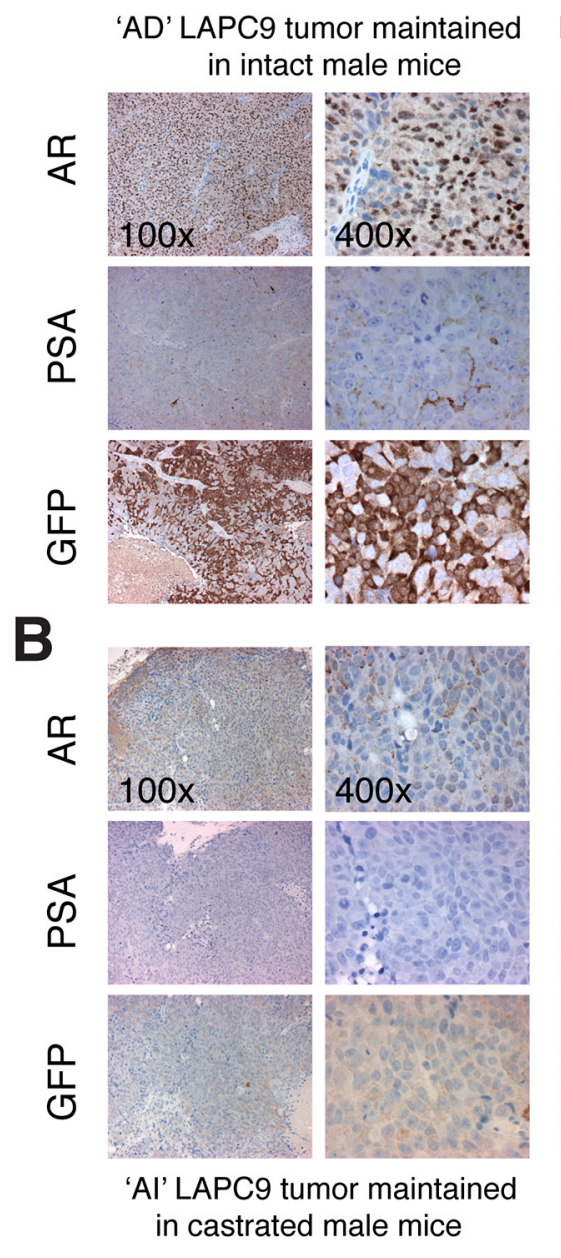

\section{LAPC9 'AD' tumors transferred to castrated male mice}
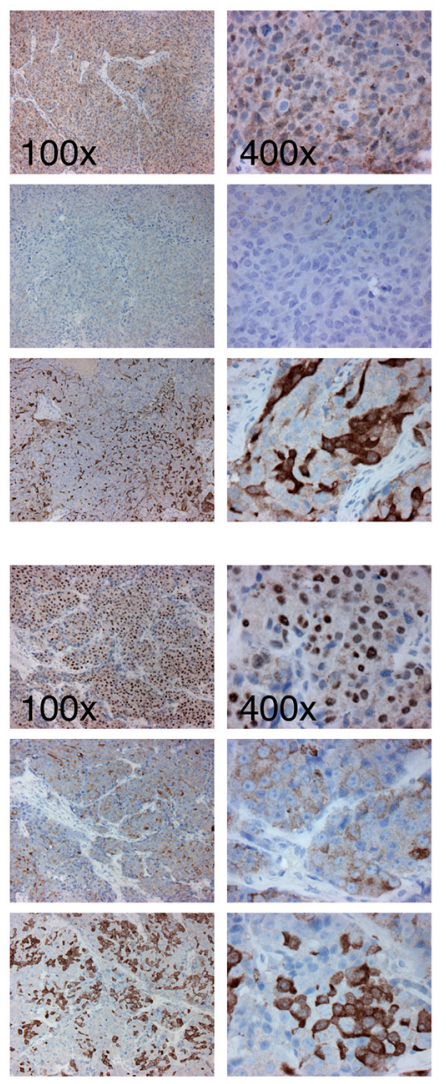

LAPC9 'Al' tumors transferred to intact male mice
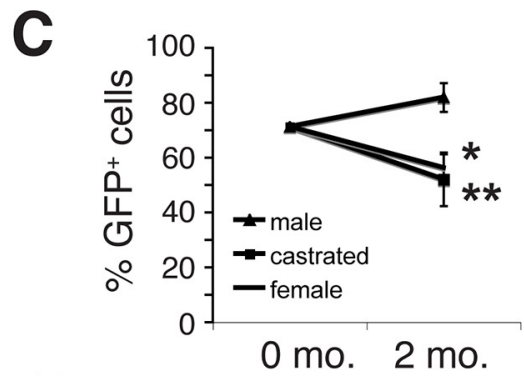

D
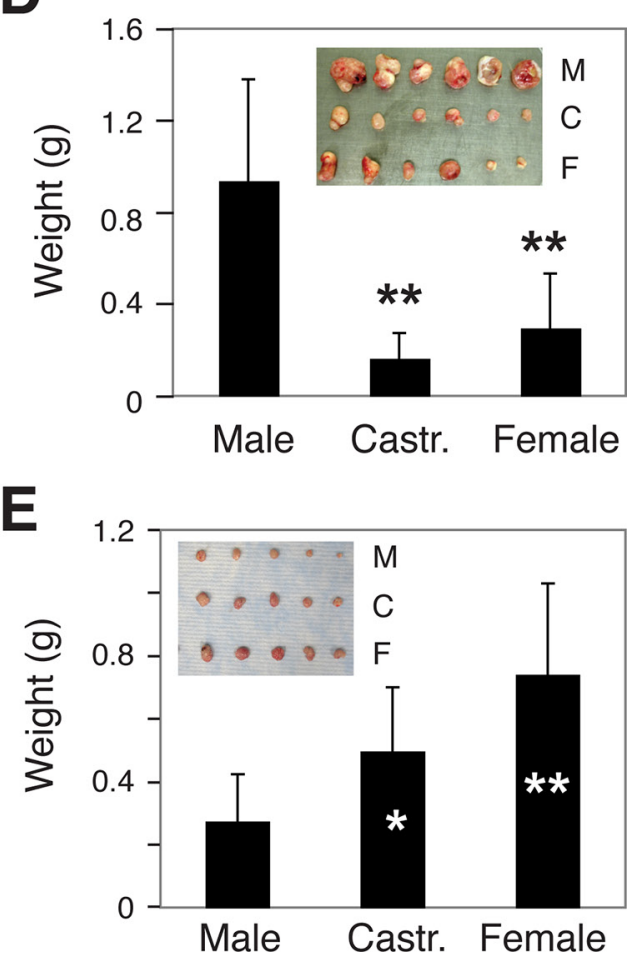

Figure 5: Systemic androgen levels regulate the relative abundance of $\mathrm{PSA}^{+}$and $\mathrm{PSA}^{-/ 10}$ cells in the tumors. A-B. Systemic androgen regulates the abundance of PSA ${ }^{+}$PCa cells in LAPC9 tumors. (A) The majority of PCa cells in LAPC9 reporter tumors maintained in intact male NOD-SCID mice expressed nuclear AR, PSA, and GFP (the left panel; note less sensitive PSA staining than corresponding GFP staining). When LAPC9 tumors in male mice were transferred to castrated mice, AR became excluded from nucleus (which was expected due to lack of the ligand), PSA staining was reduced, and $\% \mathrm{GFP}^{+}$cells significantly decreased (right panels). (B) Tumor cells in the LAPC9 reporter tumors maintained in castrated male mice showed dramatically reduced numbers of $\mathrm{AR}^{+}$and $\mathrm{PSA}^{+}$, and $\mathrm{GFP}^{+}$cells (the left panel; note that in these tumors GFP sequence could be readily detected by PCR analysis of genomic DNA; not shown); however, when the LAPC9 tumors in castrated mice were transferred back to intact male mice, many tumor cells again displayed nuclear AR as well as PSA/GFP positivity (right panels). C. LAPC9 tumor cells were purified from a maintenance reporter tumor maintained in intact male NOD/SCID mice). The bulk tumor cells contained $\sim 72 \% \mathrm{GFP}^{+}$LAPC9 cells as assessed by FACS (i.e., at 0 month). Then 100,000 unsorted LAPC9 cells were injected subcutaneously, in 50\% Matrigel, in intact male mice, castrated male mice (castrated $\sim 2$ weeks earlier), or female mice ( $n=4$ for each), respectively. Two months after tumor cell implantation, tumors were harvested and the $\%$ of GFP ${ }^{+}$ cells in each tumor was determined by FACS. $* P<0.05$ and ${ }^{*} P<0.01$, when compared to the tumors in male mice. D-E. Bulk LAPC9 cells purified from maintenance tumors in male (D) or castrated (E) mice were injected $(200,000$ cells/injection) s.c in three different types of hosts (M, male; C, castrated; F, female). Tumor weights (mean \pm S.D) were presented. ${ }^{*} P<0.05$; ${ }^{* *} P<0.01$. Insets: tumor images.

AR, and PPP2R4) did not show significant differences in bivalent patterns between PSA ${ }^{-10}$ vs. PSA ${ }^{+}$LAPC9 cells (data not shown). It is interesting that LNCaP and LAPC9 cells showed similar bivalent chromatin marks on 3 gene promoters (i.e., FGF5, BCL2, and $\mathrm{CDH} 2$ ) but differed in NKX3.1 and CD61. Also of interest, LNCaP cDNA microarray analysis revealed higher levels of $N K X 3.1$ and
FGF5 mRNAs in $\mathrm{PSA}^{-/ \mathrm{lo}}$ cells [13] and correspondingly, our ChIP assays showed high H3K4me3 association with the NKX3.1 and FGF5 gene promoters also in $\mathrm{PSA}^{-10}$ cells (Figure 6C), supporting the preferential activation of these two genes in $\mathrm{PSA}^{-10} \mathrm{LNCaP}$ cells. These preliminary ChIP/ re-ChIP results provide evidence that the $\mathrm{PSA}^{-10}$ and $\mathrm{PSA}^{+}$ $\mathrm{PCa}$ cells may possess different epigenetic profiles. 
A

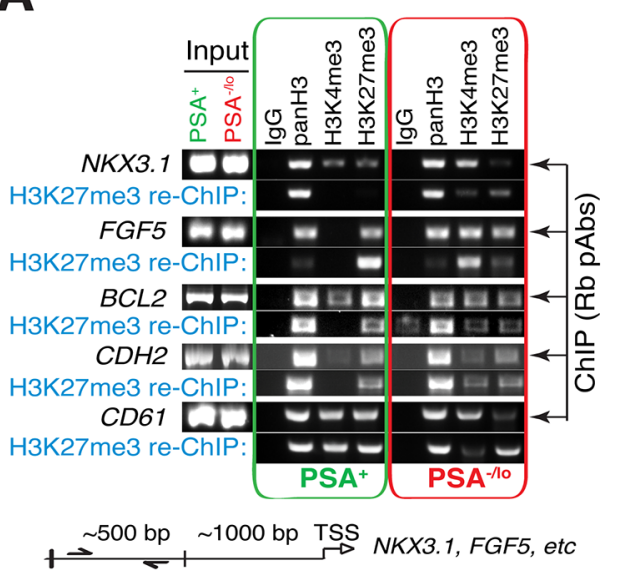

B

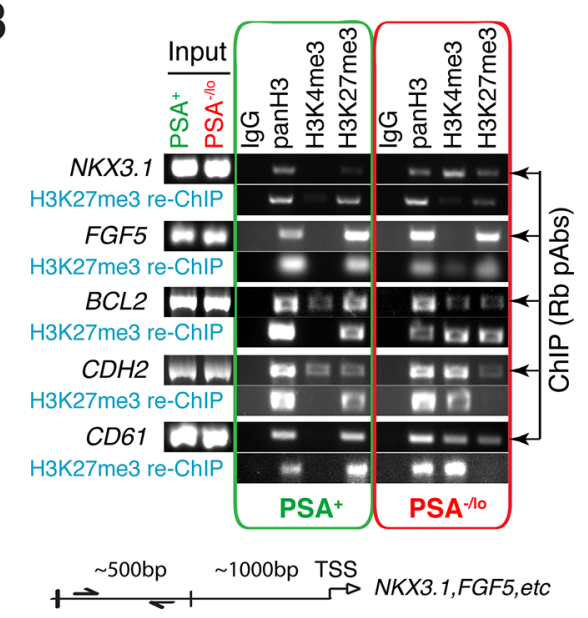

C
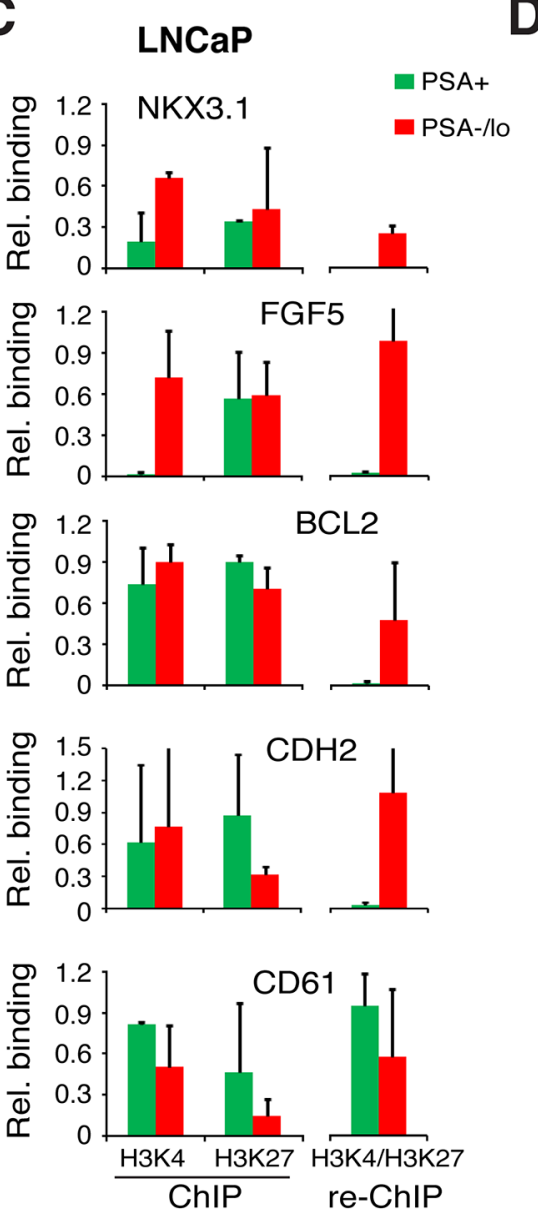

D
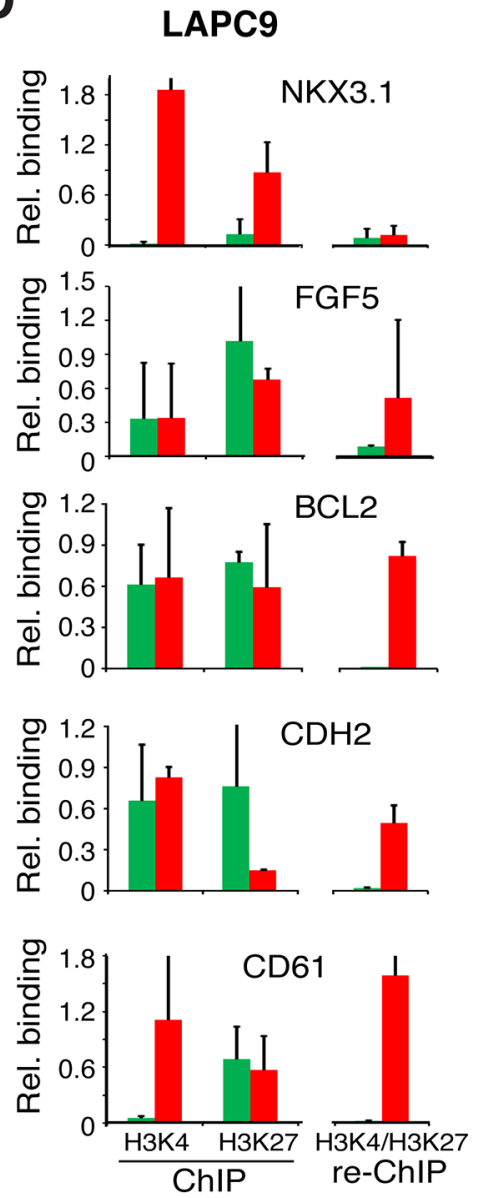

Figure 6: $\mathrm{PSA}^{-10} \mathrm{PCa}$ cells show preferential gene promoter association with bivalent chromatin marks. ChIP/re-ChIP experiments were performed in purified PSA ${ }^{-10}$ and $\mathrm{PSA}^{+} \mathrm{LNCaP}(\mathbf{A}$ and $\mathbf{C})$. and LAPC9 (B and $\left.\mathbf{D}\right)$ ). cells. ChIP was performed with individual rabbit polyclonal antibodies (Rb pAbs) and re-ChIP was performed with a monoclonal anti-H3K27me3 antibody. Shown are representative gel images (A and $\mathrm{B}$ ) and quantification ( $\mathrm{C}$ and $\mathrm{D} ; n=3)$ normalized to panH3. The re-ChIP bar graphs (C and $\mathrm{D}$; right) represent bivalent marks.

\section{Relationship between PSA ${ }^{-/ 10}$ PCa cells and other tumorigenic $P C$ a cell subsets}

In our previous studies, cDNA microarray analysis revealed that the $\mathrm{PSA}^{-1 / 0}$ LAPC9 cells expressed higher mRNA levels of several CSC markers including CD44, integrin $\alpha 2 \beta 1$, and $A L D H 1 A 1$ in comparison to PSA ${ }^{+}$LAPC9 cells [13]. Indeed, using $\mathrm{PSA}^{+} / \mathrm{PSA}^{-/ \mathrm{lo}}$ LAPC9 cells freshly purified from xenograft reporter tumors [13], we observed lower levels of $P S A$ and $A R$ mRNAs (Supplementary Figure $5 \mathrm{~A}$ ) but higher levels of CD44 mRNA (Supplementary Figure 5B) in $\mathrm{PSA}^{-1 / 0}$ cells. Tumors initially derived from $\mathrm{PSA}^{-/ 10}$ LAPC9 cells, even after 3 passages in intact male mice, still expressed high levels of $\alpha 2 \beta 1, \mathrm{CD} 44$, and ALDH1A1 proteins compared to similarly passaged tumors initially derived from the $\mathrm{PSA}^{+}$cells (Supplementary Figure 5C). These results suggest an opposite relationship between PSA expression and the three phenotypic PCSC markers. Indeed, double IF staining in benign prostate tissues showed basal expression of CD44, ALDH1 A1, and $\alpha 2 \beta 1$ but luminal expression of PSA (Supplementary Figure 5D-5E). Similar experiments in HPCa samples also revealed mutually exclusive expression patterns between PSA versus the three PCSC markers (Figure 7A). Differential quantification demonstrated that $\alpha 2 \beta 1^{+}$(Figure 7B) and ALDH1A1 ${ }^{+}$ (Figure 7C) cells were mainly PSA ${ }^{-1 /}$. Strikingly, when we performed the opposite experiments by purifying out $\mathrm{CD} 44^{+} /$ CD44- primary tumor cells from 12 untreated tumor samples (Supplementary Table 2) and analyzing $A R$ and $P S A$ mRNAs in the two populations, we found that the PSA mRNA was preferentially expressed in $\mathrm{CD}^{-} 4^{-} \mathrm{HPCa}$ cells in 10 samples whereas $A R$ mRNA expression pattern was more complex with preferential enrichment in CD44- HPCa cells in only 6 samples (Figure 7D). In 4 samples, $A R$ mRNA was actually higher in $\mathrm{CD}_{4} 4^{+} \mathrm{HPCa}$ cells (Figure 7D).

\section{Comprehensive dissection of tumorigenic subsets in PCa culture and xenograft models}

The above studies in primary human PCa (HPCa) samples (Figure 7; Supplementary Figure 5) suggest a concordant relationship between $\mathrm{PSA}^{-/ \mathrm{lo}}$ cells and 

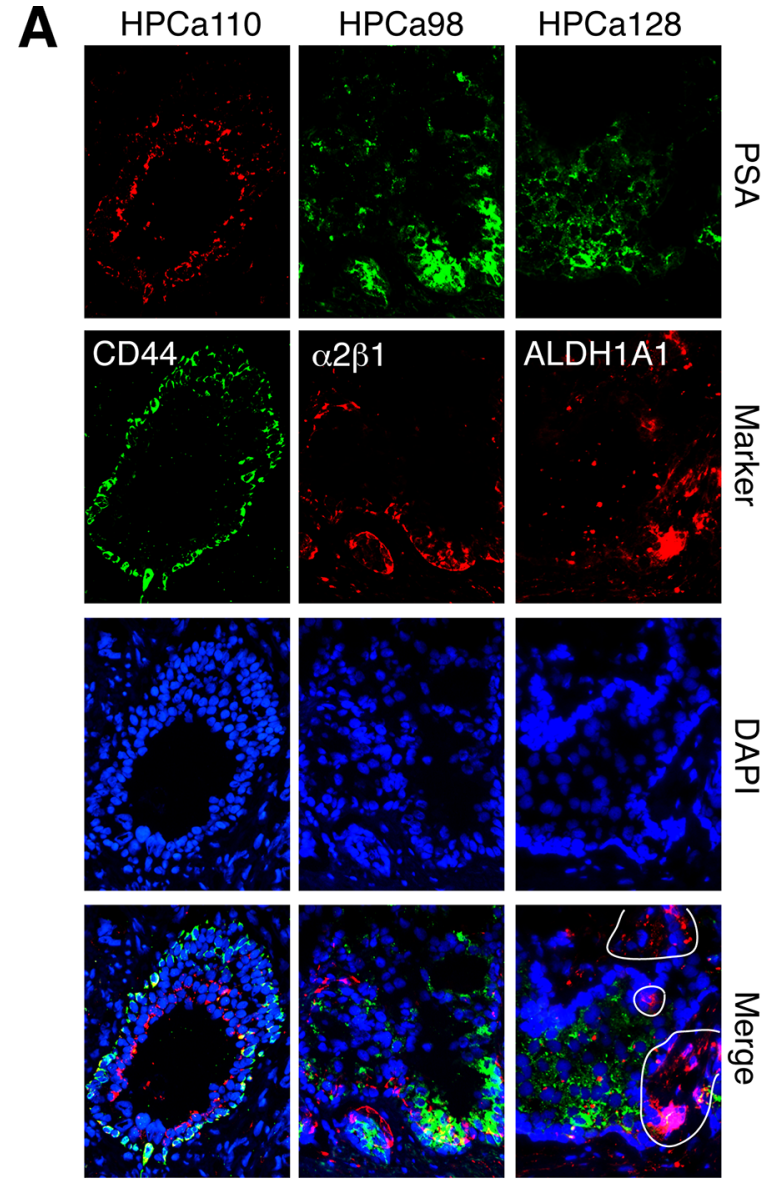

B
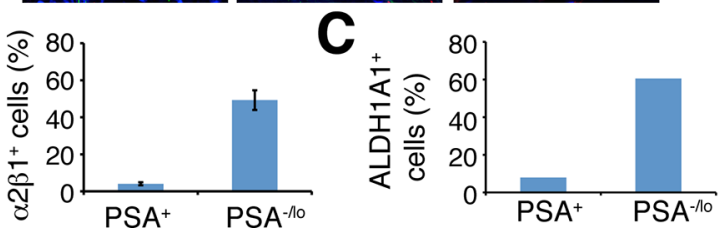

D
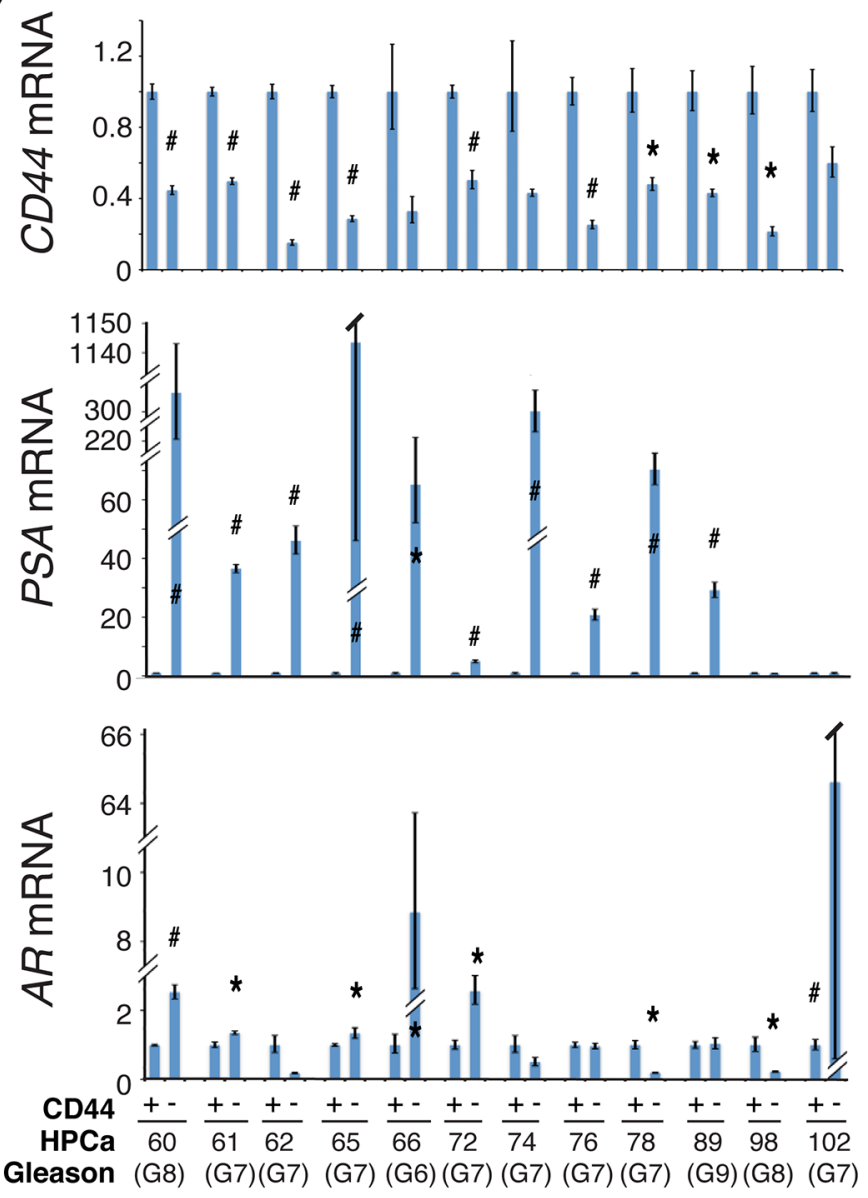

Figure 7: Relationship of PSA ${ }^{-10}$ PCa cells and other PCSC marker-expressing subpopulations in HPCa. A. Representative IF images ( $\times 400)$ illustrating reciprocal expression patterns of ALDH1A1, $\alpha 2 \beta 1$, and CD44 versus PSA in the 3 HPCa samples (indicated on top). Note the mutually exclusive staining patterns of PSA versus ALDH1A1 (right; circled areas were ALDH1 A1 ${ }^{+}$but PSA ${ }^{-}$), $\alpha 2 \beta 1$ (middle), or CD44 (left). B-C. Quantification of marker-positive cells in PSA ${ }^{-1 /}$ vs. PSA ${ }^{+} \mathrm{HPCa}$ cells. The results for $\alpha 2 \beta 1$ were data pooled from counting > 500 cells each in HPCa96, HPCa98, and HPCa110 (B). The PSA ${ }^{-1 / 0}$ cells contained significantly more $\alpha 2 \beta 1^{+}$cells (mean \pm S.D; $P<0.0001$ ). The bar graph for ALDH1A1 was obtained from counting ALDH1A1-postive cells in $\sim 1,000$ each of PSA ${ }^{+}$and PSA $^{-10}$ cells in HPCa128. D. qPCR analysis of CD44, $A R$, and $P S A$ mRNAs in $\mathrm{CD}_{4} 4^{+}$and $\mathrm{CD}^{-} 4^{-} \mathrm{HPCa}$ cells freshly purified from untreated primary prostate tumors. The results are expressed as relative levels in $\mathrm{CD}_{4} 4^{+} \mathrm{HPCa}$ cells to those in the matched CD44- HPCa cells. ${ }^{*} P<0.05 ; \# P<0.01$.

PCa cells expressing CSC markers CD44, $\alpha 2 \beta 1$, and ALDH1A1. Unfortunately, primary HPCa cells, and even primary HPCa pieces, are well-known to be very difficult to regenerate tumors in immunocompromised mice $[11,31]$. Therefore, to further dissect the PCa cell heterogeneity, in this part of the project, we employed both surface markers (CD44, $22 \beta 1$, and, for comparison, $\mathrm{ABCG} 2$ ) and functional (i.e., SP and Aldefluor) assays to dissect the tumorigenicity of $\mathrm{PCa}$ cell subpopulations in three PSA $^{-}$(Du145, PPC-1 and PC3; all three models do not express AR and PSA and contain only PSA ${ }^{-}$cells) and three $\mathrm{PSA}^{+}$(LNCaP, LAPC4 and LAPC9; all 3 models contain $\mathrm{PSA}^{+}$and $\mathrm{PSA}^{-1 / 0}$ cells) PCa models. It should be noted that although we have previously reported tumorinitiating cells in some of these models [6-12], those studies were conducted in by different investigators and at different time points. Herein, we aim to conduct sideby-side, in-depth dissection of PCa cell heterogeneity in the same models. We performed a spectrum of functional assays in vitro and (serial) tumor transplantations by implanting 1 to $5 \times 10^{5}$ cells in NOD/SCID mice followed by determining and comparing the tumor-initiating 
frequency (TIF) of matched PCa cell subpopulations. As we describe below, the results revealed distinct phenotypic profiles of tumor-initiating cells in individual PCa models.

In vitro studies in the $4 \mathrm{PCa}$ cell lines ( $\mathrm{LNCaP}$, Du145, PPC-1 and PC3) showed (Supplementary Figure 6; Supplementary Table 3) that they all expressed the luminal cell marker cytokeratin 18 (CK18) but only LNCaP cells expressed the differentiation markers AR and PSA. In contrast, the basal/stem cell markers CD44, $\alpha 2 \beta 1$, and CK5 were not detected in LNCaP cells but observed in a fraction of Du145 cells and expressed in the majority of PC3 and PPC-1 cells. We also measured telomerase activity in these cells, which mirrored the expression pattern of basal/stem cell markers (Supplementary Table 3). Interestingly, the clonogenic, tumorigenic, and metastatic capacity of the $4 \mathrm{PCa}$ cells positively correlated with their telomerase activity and the abundance of basal/ stem cell markers.

Subsequently, we performed limiting-dilution tumor-regeneration assays (LDA) in Du145 and PC3 cells, two surrogate PSA ${ }^{-}$PCa models, using both markerbased and functional assays (Table 1; Figure $8 \mathrm{~A}-8 \mathrm{E}$; Supplementary Figure 7-8). Among the 3 single surface marker (ABCG2, CD44, and $\alpha 2 \beta 1)$ profiles, the $\mathrm{ABCG}^{+}$ Du145 cell population (from either cultures or xenografts) manifested significantly higher tumor-regenerating activity than the $\mathrm{ABCG}^{-}$population (Table 1 ). Consistent with our earlier results (7), the CD44 ${ }^{+}$Du145 cells were $>30$ fold more tumorigenic than the $\mathrm{CD}_{4} 4^{-}$counterparts (Table 1). The integrin $\alpha 2 \beta 1^{+}$Du145 cells were also much more tumorigenic than the $\alpha 2 \beta 1^{-}$Du145 cells (Table 1; Supplementary Figure 7). Interestingly, when we sorted out Du145 cells double positive for CD44 and $\alpha 2 \beta 1$, there was only $\sim 2$ fold difference in TIF between $\mathrm{CD} 44^{+} \alpha 2 \beta 1^{+}$vs. $\mathrm{CD}_{4} 4^{-} \alpha 2 \beta 1^{-}$populations, which was not statistically significant (Table 1 ; see below). In the two functional (i.e., SP and Aldefluor) assays performed, Du145 cells did not show a detectable SP (not shown), as we previously reported [6]. In contrast, $\sim 20 \%$ Du145 cells had high Aldefluor activity (i.e., $\mathrm{ALDH}^{+}$; Figure 8A; Supplementary Figure 8A). The $\mathrm{ALDH}^{+}$Du145 cells demonstrated relatively higher clonogenic capacity (Supplementary Figure 8B) and significantly higher tumorigenicity (Supplementary Figure 8C; Table 1) than $\mathrm{ALDH}^{-}$cells. In secondary $\left(2^{\circ}\right)$ tumor transplantation experiments (Figure 8B), the $\mathrm{ALDH}^{+} \mathrm{Du} 145$ cells purified from the first generation $\left(1^{\circ}\right)$ tumors were greatly enriched in tumor-regenerating activity giving rise to a striking TIF of $1 / 1$ (Figure $8 \mathrm{C}$; Table 1), suggesting that nearly every single $\mathrm{ALDH}^{+}$cell was tumorigenic. $\mathrm{ALDH}^{+} \mathrm{Du} 145$ cells self-renewed in vivo as both the $1^{\circ}$ (Supplementary Figure $8 \mathrm{D})$ and $2^{\circ}$ (not shown) tumors, like the parental cultures, harbored only a fraction of $\mathrm{ALDH}^{+}$cells with the majority being $\mathrm{ALDH}^{-}$.

PC3 cells, unlike Du145, were nearly all positive for CD44 and $\alpha 2 \beta 1$ (Supplementary Figure 6A;
Supplementary Table 3). Therefore, these two surface markers would not be able to stratify tumorigenic vs. nontumorigenic subsets. On the other hand, $\sim 40 \%$ PC 3 cells were $\mathrm{ALDH}^{+}$(Figure 8A; Supplementary Figure 8A) and purified $\mathrm{ALDH}^{+} \mathrm{PC} 3$ cells showed much higher clonal (Figure 8D), sphere-formation (Figure 8E), and tumorregeneration (Table 1) capacities than the corresponding $\mathrm{ALDH}^{-} \mathrm{PC} 3$ cells.

Next, we studied LAPC9 and LAPC4, two xenograft models that contain both $\mathrm{AR}^{+} / \mathrm{AR}^{-}$and $\mathrm{PSA}^{+} /$ $\mathrm{PSA}^{-}$cells [13]. Unlike what we observed in Du145 cells, $\mathrm{ABCG}^{+}$and $\mathrm{ABCG} 2^{-}$LAPC9 cells did not show any difference in tumorigenic capacities (Table 2). The $\alpha 2 \beta 1^{+}$and $\alpha 2 \beta 1^{-}$LAPC9 cells, whether implanted subcutaneously or in the DP, also did not manifest any difference in tumor-regenerating activity (Table 2). $\mathrm{CD}_{4} 4^{+}$LAPC9 cells, however, when implanted subcutaneously or orthotopically in the dorsal prostate (DP), exhibited $\sim 6-$ and 19-fold, respectively, higher tumor-initiating potential than corresponding CD44 LAPC9 cells (Table 2). The higher tumor-initiating capacity of CD44+ LAPC9 cells was corroborated in an independent orthotopic LDA experiment (Supplementary Figure 9A). Importantly, the in vivo self-renewal ability of the $\mathrm{CD}_{4} 4^{+}$LAPC9 cells was revealed in $2^{\circ}$ transplantation experiments (Supplementary Figure 9B). Remarkably, however, the CD $44^{+} \alpha 2 \beta 1^{+}$LAPC9 cells, unlike $\mathrm{CD}_{4} 4^{+} \alpha 2 \beta 1^{+}$Du145 cells, demonstrated $>900$ fold enrichment in tumor-initiating capacity compared to the double-negative cells (Table 2). In fact, we even observed tumor development with a single CD $44^{+} \alpha 2 \beta 1^{+}$ LAPC9 cell (Table 2; see discussion below). In the two functional assays we performed, the LAPC9 SP cells, as we observed earlier [6], constituted $\sim 0.05-1 \%$ of the total (not shown) and possessed much higher tumor-initiating capacity than the non-SP cells (Table 2; Supplementary Figure 9C). Like the $\mathrm{CD}_{4} 4^{+}$and CD $44^{+} \alpha 2 \beta 1^{+}$cells, the LAPC9 SP cells self-renewed in vivo and a single LAPC9 SP cell was able to establish a $2^{\circ}$ tumor (Supplementary Figure 9C and 9D). The $\mathrm{ALDH}^{+}$LAPC9 cells in regular AD tumors constituted $\sim 10 \%$ of the total (Figure 8A; Supplementary Figure 8A) and displayed higher sphere-forming (Supplementary Figure 8E) and tumor-regenerating (Table 2) activities than the corresponding $\mathrm{ALDH}^{-}$cells. Interestingly, the $\mathrm{ALDH}^{+}$LAPC9 cells purified from AI tumors, which were enriched in $\mathrm{ALDH}^{+}$cells (not shown), also manifested higher sphere-forming capacity than $\mathrm{ALDH}^{-}$ cells (Figure 8F).

When we purified out $\mathrm{CD} 44^{+} / \mathrm{CD} 44^{-}$and $\alpha 2 \beta 1^{+} / \alpha 2 \beta 1^{-}$ LAPC4 cells from the xenografts and performed similar LDA tumor experiments, surprisingly, the marker-positive and marker-negative subpopulations appeared similarly tumorigenic (Table 2). LAPC4 cells did not have a detectable $\mathrm{SP}$ (data not shown) but had $\sim 35 \% \mathrm{ALDH}^{+}$cells (Figure $8 \mathrm{~A}$; Supplementary Figure 8A). The ALDH ${ }^{+}$LAPC4 cells again 


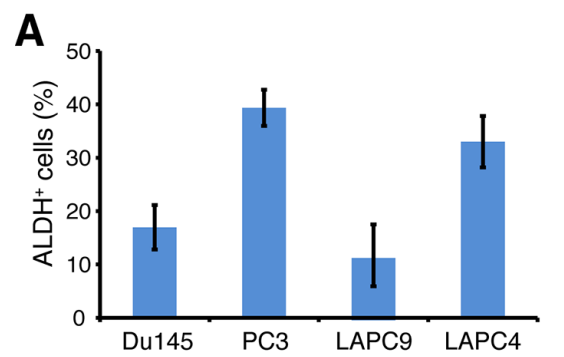

\section{B}

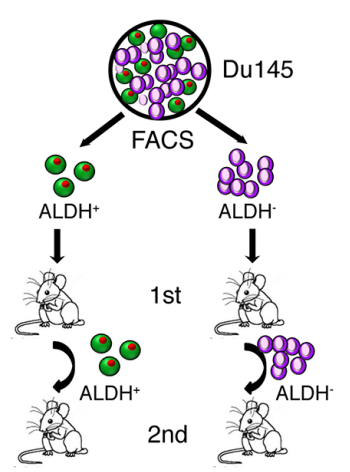

D
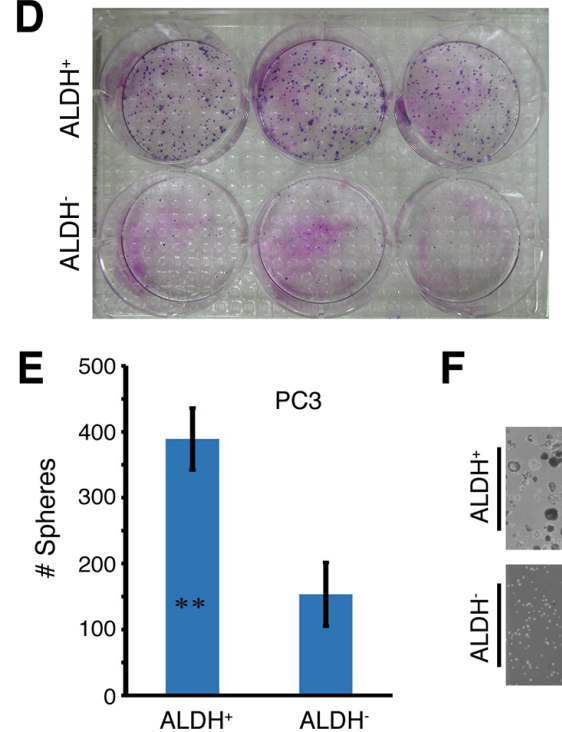

$\mathbf{F}$
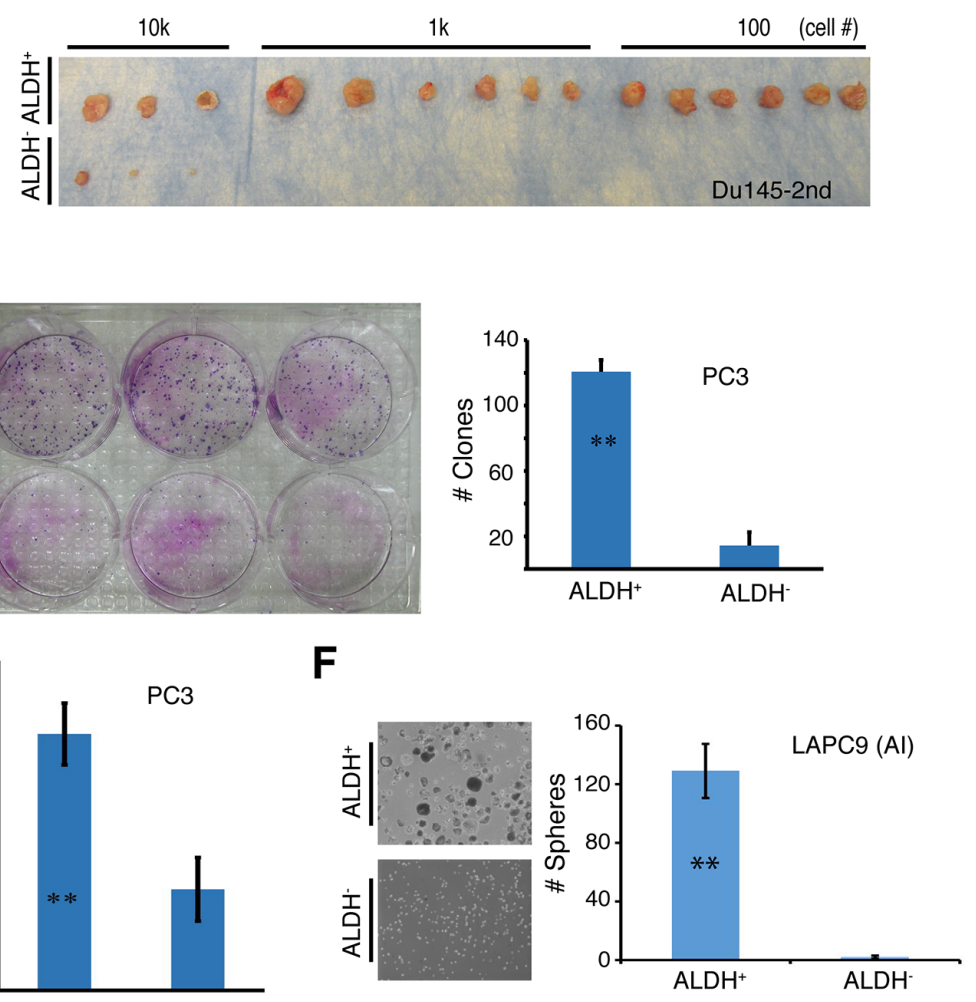

Figure 8: The $\mathrm{ALDH}^{+} \mathrm{PCa}$ cell subpopulations are enriched in self-renewing tumor-initiating cells. A. The percentage of $\mathrm{ALDH}^{+}$cells in four PCa models. ALDH activity was measured by the ALDEFLUOR assay and analyzed by flow cytometry. Tumor cells purified from Du145 and PC3 cultures or LAPC9 and LAPC4 xenografts were incubated in ALDEFLUOR assay buffer containing ALDH substrate and analyzed by FACS. Cells treated with DEAB were used as negative control. Shown is the bar graph derived from at least 3 independent experiments (mean $\pm \mathrm{SEM}$ ). B. Experimental scheme for Du145 serial tumor transplantation assays. $\mathrm{ALDH}^{+}$and $\mathrm{ALDH}^{-}$Du145 cells were purified and used for LDA in intact male NOD/SCID mice. The $1^{\circ}$ tumors derived from $\mathrm{ALDH}^{+}$and $\mathrm{ALDH}^{-}$ were harvested and utilized to purify $\mathrm{ALDH}^{+}$and $\mathrm{ALDH}^{-}$cells, respectively, for $2^{\circ}$ transplantation. $\mathrm{C}_{\text {. }} \mathrm{ALDH}^{+}$and $\mathrm{ALDH}^{-} \mathrm{Du}_{145}$ cells were sorted from $1^{\circ}$ tumors derived from $\mathrm{ALDH}^{-}$and $\mathrm{ALDH}^{+}$cells, respectively, and LDA was performed in NOD/SCID male mice (see also Table 1). Shown were $2^{\circ}$ tumor transplantation images at the cell doses indicated. D. PC 3 cells were sorted by FACS for ALDH ${ }^{+}$and $\mathrm{ALDH}^{-}$cells, and plated at clonal density (400 cells/well in 6-well dishes) in triplicate. Nine days after plating, holoclones were counted. Shown is the bar graph (mean \pm S.D; $n=3 ; * * P<0.001$ ) and clone images. E. ALDH ${ }^{+}$and ALDH ${ }^{-}$PC3 cells were sorted and cultured in anchorage-independent conditions. 10 days later, spheres were counted. Presented are the mean $\pm \mathrm{S} . \mathrm{D}(n=3 ; * * P<0.01)$. F. ALDH ${ }^{+}$and $\mathrm{ALDH}^{-}$cells were purified from a LAPC9 xenograft tumor long-term maintained in castrated male mice (AI) and cultured in ultra-low attachment plates. Shown are the representative sphere images (left) and bar graphs (mean \pm S.D; $n=4,{ }^{*} P<0.001$ ).

did not exhibit any difference in tumor-regenerating activity compared to the $\mathrm{ALDH}^{-}$cells (Table 2; Supplementary Figure 8F). If anything, the $\mathrm{ALDH}^{-} \mathrm{LAPC} 4$ cells appeared to be slightly more tumorigenic than the $\mathrm{ALDH}^{+}$cells (Supplementary Figure 8F). However, CD $44^{+} \alpha 2 \beta 1^{+}$LAPC4 cells displayed (statistically) higher tumor-regenerating activity than the corresponding CD $44^{-} \alpha 2 \beta 1^{-}$LAPC4 cells (Table 2; Supplementary Figure 10).

\section{Further dissection of phenotypic and functional heterogeneity of PCSC subpopulations}

The above exhaustive side-by-side tumor studies in two $\mathrm{PSA}^{-}$and two $\mathrm{PSA}^{+}$tumor systems (summarized in
Supplementary Table 4) demonstrate that tumor-initiating Du145 cells can be enriched by all three surface markers (ABCG2, $\alpha 2 \beta 1$, and CD44) as well as Aldefluor assay but not SP analysis as this model lacks the SP. Tumorigenic LAPC 9 cells can be enriched by CD $44^{+}, \mathrm{CD} 44^{+} \alpha 2 \beta 1^{+}$, and $\mathrm{SP}$ and $\mathrm{ALDH}^{+}$phenotypes but not the $\alpha 2 \beta 1^{+}$or $\mathrm{ABCG} 2^{+}$ phenotypes. Tumorigenic PC3 cells may be enriched by the $\mathrm{ALDH}^{+}$phenotype but not ABCG2 whereas only the $\mathrm{CD} 44^{+} \alpha 2 \beta 1^{+}$phenotype can enrich tumor-initiating cells in the LAPC4 model (Supplementary Table 4). Serial tumor transplantation experiments have established that the Du145 $\mathrm{ALDH}^{+}$, and LAPC9 CD44 ${ }^{+}, \mathrm{CD}_{4}{ }^{+} \alpha 2 \beta 1^{+}$, and SP populations all can self-renew in vivo, attesting to their true CSC properties. These results, collectively, 
Table 1. Tumor-initiating frequecy (TIF) of Du145 and PC3 cells

\begin{tabular}{|c|c|c|c|c|c|c|c|}
\hline \multirow[t]{2}{*}{ Phenotype* } & \multicolumn{5}{|c|}{ Cell dose } & \multirow[t]{2}{*}{ TIF (range) ${ }^{\mathrm{s}}$} & \multirow{2}{*}{$\begin{array}{c}\text { P value }^{\#} \\
\text { (fold differ.) }\end{array}$} \\
\hline & $10^{5}$ & $10^{4}$ & $10^{3}$ & $10^{2}$ & 10 & & \\
\hline \multicolumn{8}{|l|}{ Du145 } \\
\hline $\mathrm{ABCG}^{+}$(cells) & & & $2 / 6$ & $3 / 8$ & & $1 / 1,100(1 / 415-1 / 2,915)$ & \multirow[t]{4}{*}{$6.44 \mathrm{e}-119(10 \mathrm{x})$} \\
\hline ABCG2 (cells) & & $2 / 6$ & $1 / 6$ & $2 / 6$ & & $1 / 10,897(1 / 4060-1 / 29,246)$ & \\
\hline $\mathrm{ABCG}^{+}$(xenografts) & & & $1 / 2$ & $2 / 6$ & & $1 / 623(1 / 165-1 / 2,347)$ & \\
\hline ABCG2- (xenografts) & & $1 / 4$ & $2 / 6$ & $2 / 6$ & & $1 / 7,891(1 / 2,686-1 / 23,183)$ & \\
\hline $\mathrm{CD}_{4} 4^{+}$ & & & $5 / 8$ & $5 / 8$ & & $1 / 530(1 / 245-1 / 1,146)$ & \multirow[t]{2}{*}{$7.6 e-210(33 x)$} \\
\hline CD44- & & $3 / 8$ & $0 / 6$ & $1 / 8$ & & $1 / 17,584(1 / 6,395-1 / 48,350)$ & \\
\hline$\alpha 2 \beta 1^{+}$ & $8 / 8$ & $7 / 8$ & $3 / 8$ & & & $1 / 3,744(1 / 1,694-1 / 8,275)$ & \multirow[t]{2}{*}{$8.47 \mathrm{e}-09(31 \mathrm{x})$} \\
\hline$\alpha 2 \beta 1^{-}$ & $2 / 5$ & $2 / 8$ & $0 / 8$ & & & $1 / 115,913(1 / 40,331-1 / 333,137)$ & \\
\hline $\mathrm{CD} 44^{+} \alpha 2 \beta 1^{+}$ & & $4 / 8$ & $2 / 8$ & $1 / 7$ & \multirow{4}{*}{$\begin{array}{l}0 / 8 \\
0 / 8 \\
0 / 8\end{array}$} & $1 / 9,152(1 / 4,034-1 / 20,765)$ & \multirow{4}{*}{ F $\quad 0.0396$} \\
\hline $\mathrm{CD} 44^{+} \alpha 2 \beta 1^{-}$ & & $1 / 8$ & $1 / 7$ & $0 / 8$ & & $1 / 41,048(1 / 9,936-1 / 169,575)$ & \\
\hline $\mathrm{CD}_{4}{ }^{-} \alpha 2 \beta 1^{+}$ & & $0 / 3$ & $1 / 8$ & $0 / 8$ & & $1 / 38,298(1 / 4,922-1 / 298,016)$ & \\
\hline $\mathrm{CD}^{\circ} 4^{-} \alpha 2 \beta 1^{-}$ & & $2 / 4$ & $0 / 8$ & $0 / 8$ & & $1 / 18,963(1 / 4,832-1 / 74,420)$ & \\
\hline $\mathrm{ALDH}^{+}$ & & & $3 / 4$ & $1 / 4$ & & $1 / 615(1 / 205-1 / 1,842)$ & $2.62 \mathrm{e}-77(64 \mathrm{x})$ \\
\hline $\mathrm{ALDH}^{-}$ & & $1 / 4$ & $0 / 4$ & $0 / 4$ & & $1 / 39,188(1 / 5,558-1 / 276,314)$ & \\
\hline $\operatorname{ALDH}^{+}\left(2^{\circ}\right)$ & & $3 / 3$ & $6 / 6$ & $6 / 6$ & & $1 / 1(1 / 1-1 / 108)$ & $1.07 \mathrm{e}-141(6,025 \mathrm{x})$ \\
\hline $\operatorname{ALDH}^{-}\left(2^{\circ}\right)$ & $3 / 4\left(0.5 \times 10^{4}\right)$ & $0 / 4$ & $0 / 4$ & & & $1 / 6,025(1 / 1,995-1 / 18,195)$ & \\
\hline \multicolumn{8}{|l|}{ PC3 } \\
\hline $\mathrm{ABCG}^{+}$ & & $5 / 5$ & $6 / 8$ & $2 / 8$ & & $1 / 615(1 / 283-1 / 1,336)$ & \multirow[t]{2}{*}{0.253} \\
\hline ABCG2 & & $7 / 8$ & $8 / 8$ & $5 / 8$ & & $1 / 1,071(1 / 457-1 / 2,512)$ & \\
\hline $\mathrm{ALDH}^{+}$ & & $10 / 10$ & $4 / 7$ & $5 / 8$ & & $1 / 552(1 / 245-1 / 1,245)$ & \multirow[t]{2}{*}{$0.00869(4 x)$} \\
\hline $\mathrm{ALDH}^{-}$ & & $10 / 11$ & $7 / 12$ & $2 / 6$ & & $1 / 2,003(1 / 944-1 / 4,250)$ & \\
\hline
\end{tabular}

Table 2. Tumor-initiating frequency of LAPC9 and LAPC4 cells

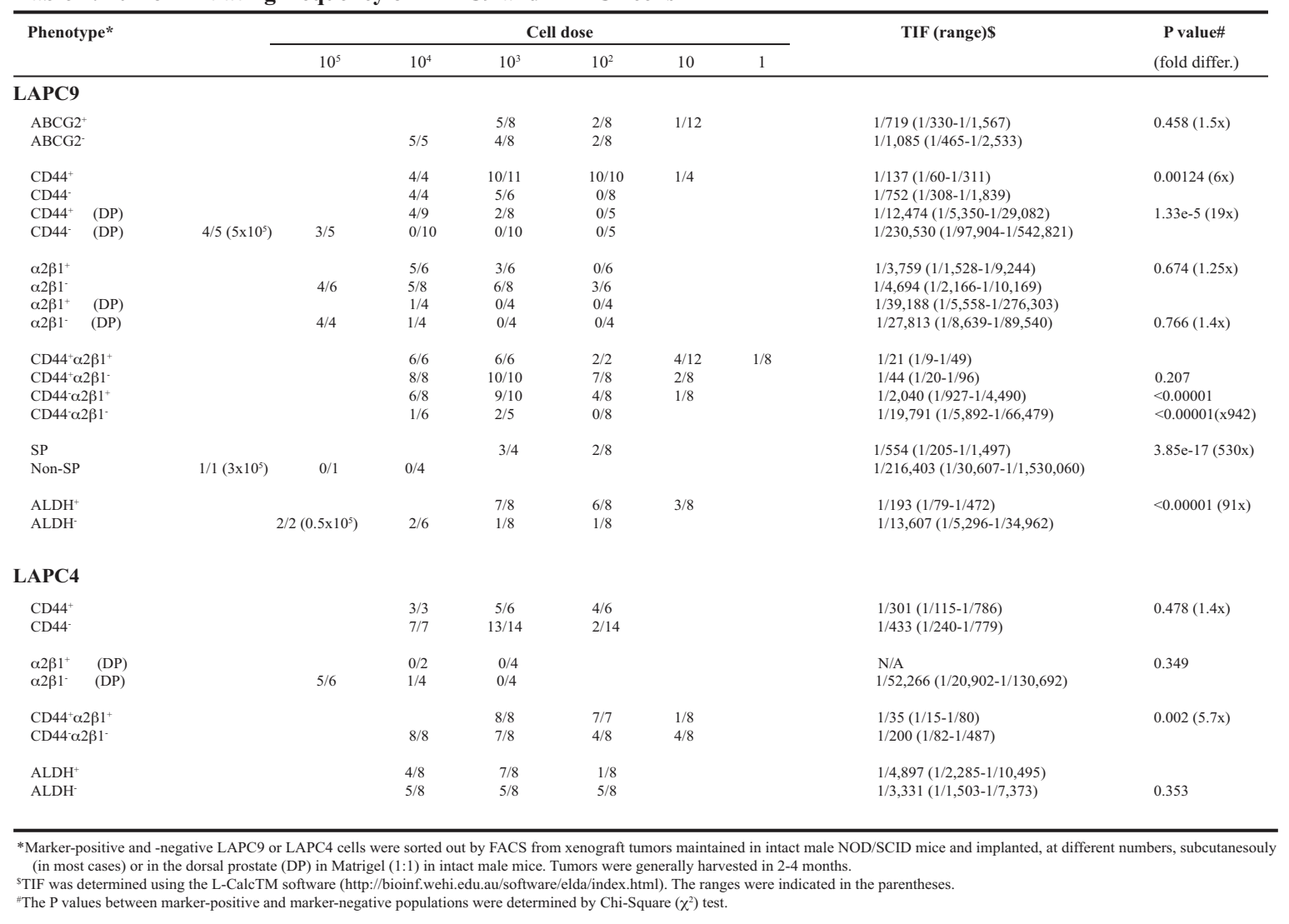


A

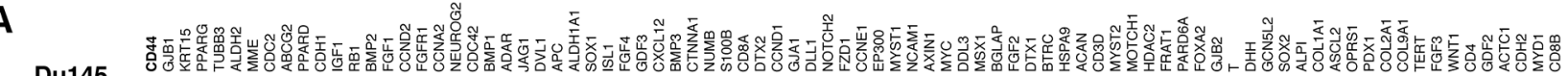

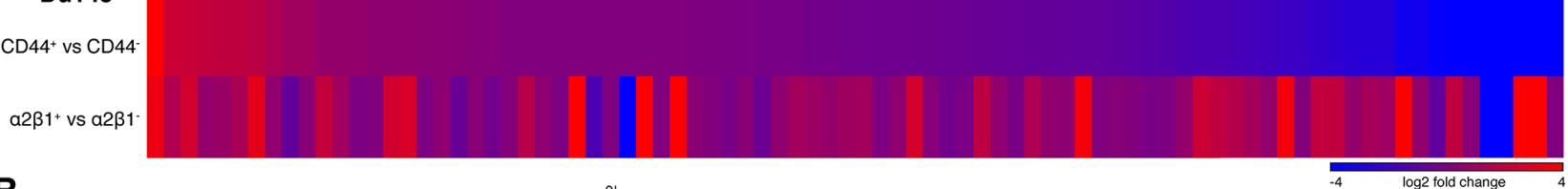
B

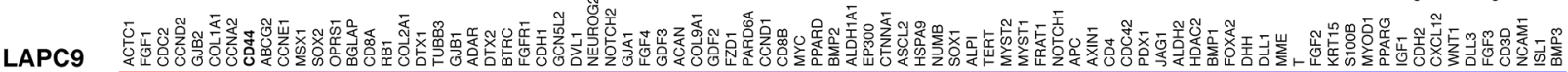
$\mathrm{CD} 44^{+} \mathrm{vs} \mathrm{CD} 44$ -
$\mathrm{CD} 44^{+} \mathrm{\alpha} 2 \beta 1^{+} \mathrm{vs}$
$\mathrm{CD} 44^{\circ} \mathrm{\alpha} \beta 1^{-}$

C

\section{Du145} CD44+vs CD44 $\alpha_{2} \beta 1^{+}$vs $\alpha 2 \beta 1$

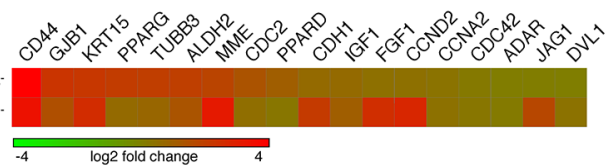

D

\section{LAPC9}

CD44+ vs CD44 $\mathrm{CD} 44^{+} \alpha 2 \beta 1^{+}$vs CD44 $\alpha 2 \beta 1$.

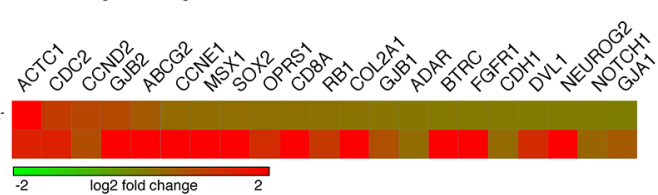

E

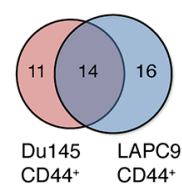

G

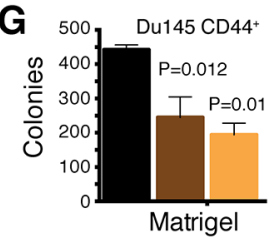

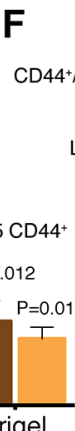
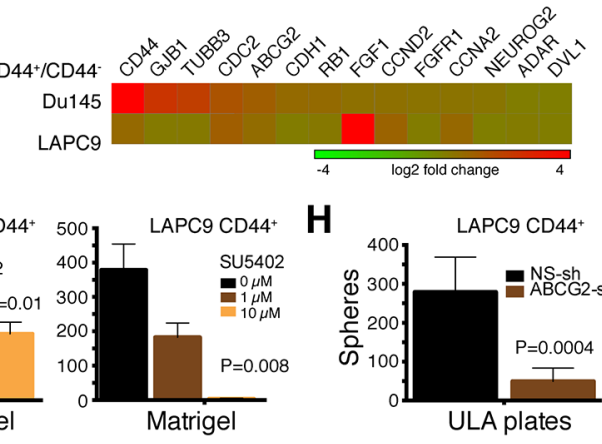

H

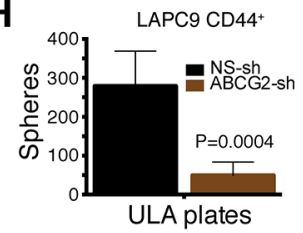

Figure 9: Gene expression profiles and functional studies in PCa cell subpopulations. A-B. Expression of 84 SC-related genes in the indicated marker-positive and corresponding marker-negative Du145 (A) and LAPC9 (B) cells. Relative expression levels were normalized to the average expression levels of 5 internal controls (B2M, HPRT1, RPL13A, GAPDH and ACTB). Scale bars depict fold changes (in $\log 2$ ratio), centered at 0 . For both Du145 and LAPC9, genes were presented from the highest to lowest in the CD44 population. Note that CD44 gene (bold) was the highest expressed gene in Du145 and was among the highest in LAPC9. C-D. Heat map of representative genes commonly overexpressed in the two indicated PCa cell populations in Du145 (C) and LAPC9 (D) models. E-F. Venn diagram (E) and heat map (F) presenting the genes that were commonly overexpressed in the CD44+ Du145 and LAPC9 cells. G. Blocking FGFR signaling compromised clonogenic capacity of CD44 ${ }^{+} \mathrm{PCa}$ cells. Freshly purified Du145 and LAPC9 CD44 $4^{+}$cells were plated in Matrigel-coated 12-well plates (3,000 cells/well) and treated with $0-10 \mu \mathrm{M}$ FGFR inhibitor SU5402. Colonies were enumerated 2 weeks after plating. H. Knocking down ABCG2 reduced sphere formation in CD44 LAPC9 cells. Freshly purified CD44 LAPC9 cells were infected with non-silencing (NS) or ABCG2 shRNAs (MOI 20) and 48 later, plated in 6-well ULA plates (2,000 cells/well). Spheres were counted 2 weeks after plating.

suggest that different PCa models possess distinct profiles of tumorigenic subpopulations.

To investigate the potential relationship between single marker-positive versus double marker-positive PCa cells with respect to their tumor-regenerating activity, we compared $\mathrm{CD}_{4} 4^{+} \alpha 2 \beta 1^{+}$versus $\mathrm{CD} 44^{+}$and $\alpha 2 \beta 1^{+}$cells in Du145 and LAPC9 models. Interestingly, the CD $44^{+} \alpha 2 \beta 1^{+}$ Du145 cell population was only slightly enriched in tumorinitiating cells and its tumor-initiating capacity was actually lower than in $\mathrm{CD}_{4} 4^{+}$Du145 cells (TIF 1/9, 152 vs. TIF $1 / 530, P=1.27 \mathrm{e}-07$ ) (Table 1). Also, the CD44 ${ }^{+} \alpha 2 \beta 1^{+}$ Du145 cells exhibited only $\sim 2$ fold higher tumorigenic potential than $\mathrm{CD}_{4} 4^{-} \alpha 2 \beta 1^{-}$cells $(1 / 9,152$ vs. $1 / 18,963, P$ $=0.343)($ Table 1$)$. In sharp contrast to the Du145 model, the CD $44^{+} \alpha 2 \beta 1^{+}$LAPC9 cells were highly tumorigenic in that as few as 1 double-positive cell was able to regenerate a tumor (Table 1) and the regenerated tumor contained only a small $\%$ of CD $44^{+} \alpha 2 \beta 1^{+}$LAPC9 cells and could be serially passaged (not shown). Significantly, the $\mathrm{CD} 44^{+} \alpha 2 \beta 1^{+}$ LAPC9 cell population was more tumorigenic than either
$\mathrm{CD}_{4} 4^{+}(1 / 21$ vs $1 / 137 ; P=0.0014)$ or $\alpha 2 \beta 1^{+}(1 / 21$ vs. $1 / 3$, $759 ; P=5.12 \mathrm{e} 14$ ) cell population (Table 1 ). The contrasting results observed in Du145 and LAPC9 models with respect to the tumorigenicity of $\mathrm{CD} 44^{+} \alpha 2 \beta 1^{+}$cells suggest that the ability of combinatorial marker-sorting strategy to further enrich CSCs over single marker strategies is dependent on the cancer model analyzed.

To further dissect PCSC heterogeneity at the molecular level, we custom-made a $\mathrm{RT}^{2}$ Profiler ${ }^{\mathrm{TM}}$ qPCR Human Stem Cell Superarray that contained 84 stem cell-associated genes (Supplementary Table 5) and analyzed their expression levels in $\mathrm{CD} 44^{+}, \alpha 2 \beta 1^{+}$, and/or $\mathrm{CD} 44^{+} \alpha 2 \beta 1^{+}$Du 145 and LAPC9 cell populations (Figure 9A-9F; Supplementary Figure 11A-1B). The results revealed several interesting findings. First, we observed both overexpressed and downregulated genes in markerpositive in comparison to the corresponding markernegative populations in both models. Second, we observed similarities as well as differences in gene expression both between different subpopulations of cells in the same cell 
type and between the same subpopulations of different $\mathrm{PCa}$ cell types. For instance, the CD44 ${ }^{+}$Du145 cells displayed a gene expression pattern that was overall different from that in the $\alpha 2 \beta 1^{+}$Du145 cells (Figure 9A). Gene expression patterns in $\mathrm{CD}_{4} 4^{+}$versus CD $44^{+} \alpha 2 \beta 1^{+}$LAPC9 cells were also dissimilar (Figure 9B). Third, the two subpopulations from the same cell type, however, did share some gene expression patterns. For example, the CD $44^{+}$and $\alpha 2 \beta 1^{+}$ Du145 cells (Figure 9C) and the $\mathrm{CD}_{4} 4^{+}$and $\mathrm{CD} 44^{+} \alpha 2 \beta 1^{+}$ LAPC9 cells (Figure 9D) shared many overexpressed genes. Fourth, the CD $44^{+} \alpha 2 \beta 1^{+}$LAPC9 cells, which were among the most tumorigenic and were more tumorigenic than CD44 ${ }^{+}$LAPC9 cells (Table 2), showed more upregulated genes (Figure 9B and 9D; Supplementary Figure 11A). Among the most highly upregulated genes in $\mathrm{CD} 44^{+} \alpha 2 \beta 1^{+}$ LAPC9 cells were MME (CD10), CCNE1, COL2A1, and those involved in Wnt signaling (FRAT1, BTRC, APC, WNT1), growth factor signaling (FGFR1, IGF1, BMP2, FGF4, NEUROG2), and pluripotency (SOX2) (Supplementary Figure 11A). Many of these molecules are well-known stem cell regulators and have been implicated in PCa etiology and progression [e.g., 32-36].

The qPCR analysis provided clues about potential involvement of certain signaling pathways in commonly regulating several PCSC populations. For example, the CD44 ${ }^{+}$Du145 and LAPC9 cell populations, both of which were tumorigenic, shared 14 upregulated genes including developmental (FGF1, FGFR1, and DVL1), cell-cycle related (RB1, CDC2, CCND2, and CCNA2), and neuronal (TUBB3 and NEUROG2) genes (Figure 9E-9F). As an example of interrogating the functional significance of the signaling pathways, we treated freshly purified CD44 ${ }^{+}$Du145 and LAPC9 cells with SU5402, a specific FGFR inhibitor and then performed colony formation assays in Matrigel and sphere formation assays in ultra-low attachment (ULA) plates (6-13). SU5402 dose-dependently compromised colony (Figure 9G) and sphere (Supplementary Figure 11C) forming capabilities of both $\mathrm{CD} 44^{+} \mathrm{PCa}$ cell populations.

The qPCR results also provided clues about potential relationships between different $\mathrm{PCa}$ cell subpopulations. For instance, the $\mathrm{CD}_{4} 4^{+}$Du145 cell population was enriched not only in CD44 mRNA but also mRNAs of $A B C G 2$ and two ALDH isoforms ( $A L D H 1 A 1$ and $A L D H 2$ ) and the $\alpha 2 \beta 1^{+}$Du145 cells expressed high levels of CD44 and $A L D H 1 A 1$ mRNAs (Supplementary Figure 11B). These results suggest that in the Du145 model, CD44 ${ }^{+}, \alpha 2 \beta 1^{+}, \mathrm{ABCG}^{+}$, and $\mathrm{ALDH}^{+}$cell populations identify overlapping subsets of tumorigenic cells, which is congruent with phenotypic analysis (Supplementary Figure 12A). Similarly, in the LAPC9 model, $A B C G 2$ mRNA was enriched in both $\mathrm{CD} 44^{+}$and $\mathrm{CD} 44^{+} \alpha 2 \beta 1^{+}$cell populations (Supplementary Figure 11B), again suggesting that these markers identify overlapping cell populations as corroborated by the flow analysis (Supplementary Figure 12B). Interestingly, the
mRNAs of $A L D H 1 A 1$ and $A L D H 2$ were not enriched in the two CD44 ${ }^{+}$LAPC9 populations (Supplementary Figure $11 \mathrm{~B}$ ) but the $\mathrm{ALDH}^{+}$cells were nearly completely encompassed in the $\mathrm{CD}_{4} 4^{+}$population of LAPC9 cells (Supplementary Figure 12B), suggesting that other ALDH isoform(s) might be involved in mediating the Aldefluor phenotype in the LAPC9 model.

Finally, we employed lentiviral-mediated knockdown to investigate the functions of CD44, integrin $\alpha 2$, and ABCG2 in purified CD44 ${ }^{+}$Du145 and/or LAPC9 cells. CD44 knockdown did not affect the colony or sphere formation in either model (Supplementary Figure 11D; data not shown). These results are consistent with our earlier studies demonstrating that antiCD44 antibodies did not interfere with the clonal and clonogenic properties of CD44 ${ }^{+} \mathrm{PCa}$ cells [7]. In contrast to $\mathrm{CD} 44, \mathrm{ABCG} 2$ knockdown inhibited clonogenic activities of both LAPC9 (Figure 9H; Supplementary Figure 11E) and Du145 (not shown) CD $44^{+}$cells, which is consistent with ABCG2 enrichment and also suggests its functional significance in the two CD $44^{+} \mathrm{PCa}$ cell populations. Interestingly, knocking down integrin $\alpha 2$ also strongly suppressed the clonogenicity of LAPC9 CD $44^{+}$cells (Supplementary Figure 11D).

\section{Clonogenic and tumorigenic subpopulations in untreated patient tumors}

We showed earlier that untreated primary human $\mathrm{PCa}$ (i.e., HPCa) contained CD44 ${ }^{+}, \alpha 2 \beta 1^{+}$, and $\mathrm{ALDH}^{\mathrm{A}} 1^{+}$cells that were mostly $\mathrm{PSA}^{-/ 10}$ (Figure 7; Supplementary Figure $5 \mathrm{E})$. Here, we quantitatively analyzed the expression and, importantly, potential functions of PCSC marker-positive $\mathrm{HPCa}$ cells, i.e., $\mathrm{CD} 44^{+}, \alpha 2 \beta 1^{+}, \mathrm{CD}_{4} 4^{+} \alpha 2 \beta 1^{+}$, and $\mathrm{ALDH}^{+}$, as well as CD133 [15] in a large cohort $(\sim 50)$ of HPCa samples (Figure 10; Supplementary Figure 13; Supplementary Table $2)$. The majority of the HPCa samples we examined (44/46, $96 \%$ ) contained $\mathrm{CD}_{4} 4^{+}$cells, although the percentages varied widely (Figure 10A; Supplementary Table 2). When CD44 HPCa cells, which were all negative for AR and PSA proteins (Supplementary Figure 13A) as we previously observed [8, $37,38]$, were purified out, plated on fibroblast feeders or collagen, and analyzed for their proliferative potential, we observed higher population doublings (PDs) for the CD44 ${ }^{+}$ cell population than $\mathrm{CD}_{4} 4^{-}$population in HPCa41 (Figure 10Ba), HPCa43 (Figure 10Bb), HPCa44 (Figure 10Bc), HPCa50 (Supplementary Figure 13C), and HPCa51 (not shown) samples. In fact, most HPCa44 (Figure 10Bc) and HPCa50 (Supplementary Figure 13C) CD44- cells initially attached but did not proliferate and soon died off whereas the corresponding $\mathrm{CD}_{4} 4^{+}$cells expanded exponentially, suggesting that the CD $44^{+} \mathrm{HPCa}$ cells also possess greater survival advantage. On the other hand, as we observed in the xenograft systems, not all patient-derived CD $44^{+} \mathrm{HPCa}$ cells manifested higher proliferative potential than their CD44counterparts (e, g., Supplementary Figure 13D). 


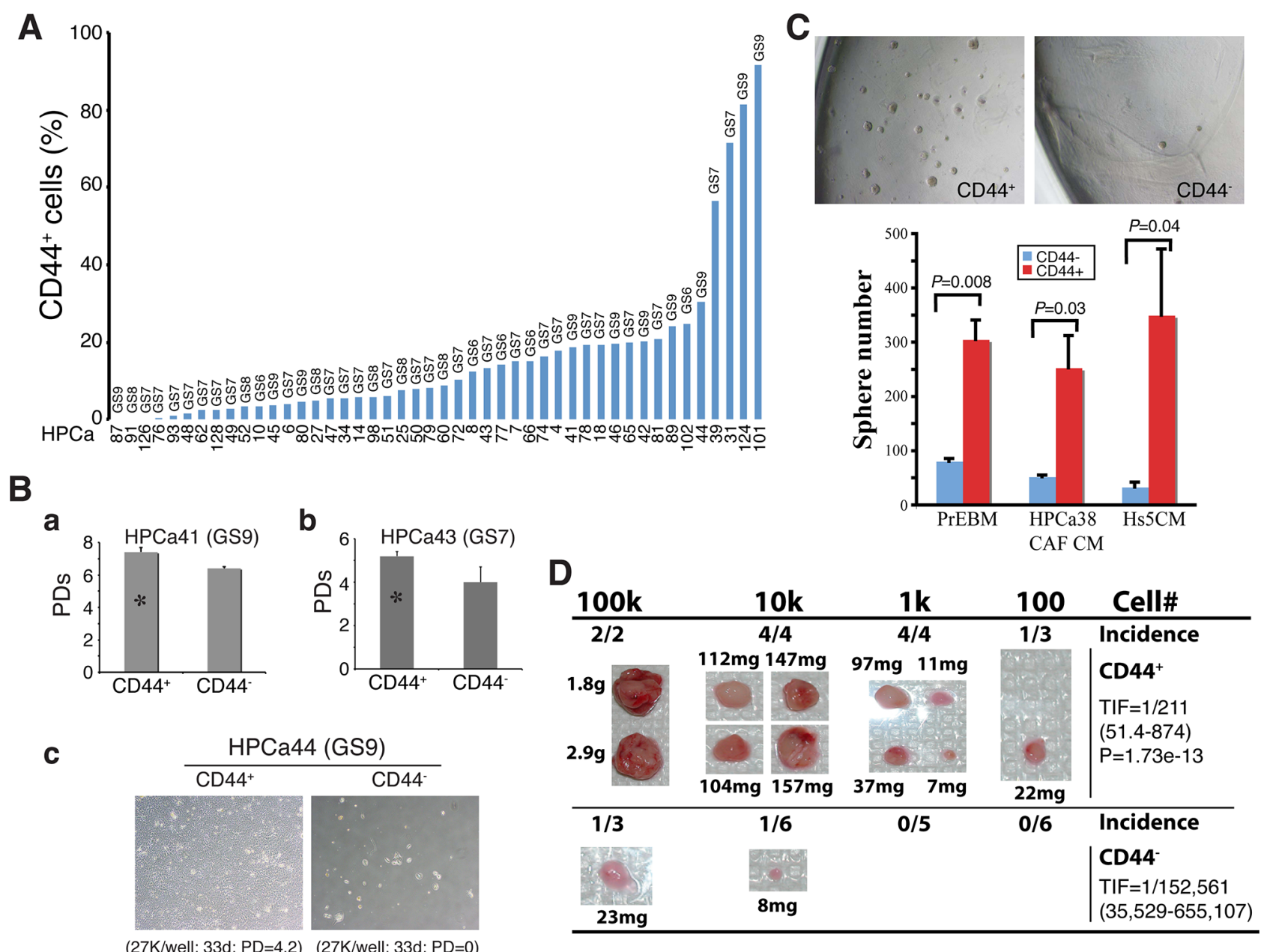

Figure 10: $\mathrm{CD}^{+}{ }^{+} \mathrm{HPCa}$ cells possess high proliferative, survival, clonogenic, and tumorigenic potential. A. Percentage of $\mathrm{CD}_{4} 4^{+}$cells in HPCa samples. The combined Gleason score (GS) for each tumor is indicated on top and the patient ID\# at the bottom. B. $\mathrm{CD} 44^{+} \mathrm{HPCa}$ cells possess higher proliferative and survival advantages than the corresponding CD44- $\mathrm{HPCa}$ cells. a. $\mathrm{CD}_{4} 4^{+}$and CD44 HPCa41 cells were plated in triplicate on Swiss 3T3 feeder layer (1,000 cells/well) and cell numbers determined 29 days after plating. Shown are the cumulative population doublings (PDs; ${ }^{*} P<0.05$ ). b. CD $44^{+}$and $\mathrm{CD} 44^{-} \mathrm{HPCa} 43$ cells were plated in triplicate on Swiss $3 \mathrm{~T} 3$ feeder layer $(5,000$ cells/well) and cell numbers determined 41 days after plating. Shown are the cumulative PDs $(* P<0.01)$. c. Purified $\mathrm{CD}_{4}{ }^{+}$and $\mathrm{CD}_{4}{ }^{-} \mathrm{HPCa} 44$ cells were plated in triplicate on collagen-coated 6-well dishes. Shown below are the cell numbers plated, time when surviving cells were enumerated, and the cumulative PDs. C. CD44 ${ }^{+} \mathrm{HPCa}$ cells possess high clonogenic potential. CD44 ${ }^{+}$ CD44- HPCa51 cells were plated, in triplicate, in Matrigel-coated 12-well plates (10, 000 cells/well). Shown are representative images $(40 \times)$ of spheres (top) and quantifications of spheres plated in 3 different media (PrEBM, prostate epithelial basal medium; HPCa38 CAF $\mathrm{CM}$, conditioned medium from HPCa38 carcinoma-associated fibroblasts or CAFs; Hs5 CM, conditioned medium from Hs5 immortalized human mesenchymal stem cells) 15 days after plating. D. CD $44^{+} \mathrm{HPCa}$ cells possess high tumorigenic potential. $\mathrm{CD}^{-} 4^{+} / \mathrm{CD}_{4} 4^{-} \mathrm{HPCa} 52$ cells were acutely MACS-purified from the patient tumor (GS8) and co-injected, at the indicated cell numbers, with 100k Hs5 cells in 50\% Matrigel s.c into irradiated NOD/SCID- $\gamma$ mice. The $10 \mathrm{k}$ and 100k tumors were harvested at $\sim 4$ months whereas 100 and $1 \mathrm{k}$ tumors were harvested at 7 months after implantation. Shown on the right are the TIF for the two populations and the $P$ value for TIF comparison.

We also compared the clonogenic potential of $\mathrm{CD} 44^{+} /$ CD44- HPCa cells by plating them, at clonal density, in Matrigel in several variations of serum-free medium. The results revealed significantly higher sphere-forming ability of the $\mathrm{CD} 44^{+}$cells from HPCa50 (not shown) and HPCa51 (Figure 10C) than the respective CD44- HPCa cells. The above clonal and clonogenic assays indicate that primary CD44+ HPCa cells possess certain stem/progenitor cell properties, which was supported by the expression of stem cell marker hTERT (Supplementary Figure 13A; data not shown). Importantly, in a pilot in vivo experiment, we purified out $\mathrm{CD} 44^{+} / \mathrm{CD} 44^{-}$cells from HPCa52 (GS8) and co-injected them, at increasing cell numbers, with the Hs5 mesenchymal cells [31], subcutaneously in irradiated male NOD/SCID- $\gamma$ mice supplemented with the exogenous testosterone. As shown in Figure 10D, the CD44 ${ }^{+} \mathrm{HPCa} 52$ cells demonstrated higher tumor-regenerating capacity than corresponding $\mathrm{CD}_{4} 4^{-}$cells. This was quite a remarkable finding for the bulk primary HPCa cells are known to be extremely indolent in tumor regeneration [11,31]. 
HPCa also expressed other PCSC markers including CD133 [15]. In general, the $\%$ of CD $133^{+} \mathrm{HPCa}$ cells was lower than that of $\mathrm{CD}_{4} 4^{+} \mathrm{HPCa}$ cells (Supplementary Figure 13E; Supplementary Table 2). The CD133+ LAPC4 (Supplementary Figure 13F) and HPCa (Supplementary Figure $13 \mathrm{G}-13 \mathrm{H}$ ) cells showed higher proliferative and sphere-forming potential than the corresponding CD133cells. Interestingly, in a pilot study we observed higher CD44 and integrin $\alpha 2$ mRNA levels in $\mathrm{CD}_{133^{+}} \mathrm{HPC} 40$ cells than the corresponding CD133- cells (Supplementary Figure 13I), suggesting a potentially overlapping relationship among the 3 subpopulations in HPCa samples.

Together, these results suggest that untreated primary tumors contain subsets of HPCa cells that express the phenotypic markers of PCSCs and possess enhanced clonal, clonogenic, and even tumorigenic potential.

\section{DISCUSSION}

To our knowledge, the present study represents the most comprehensive efforts to dissect the phenotypic, functional, and tumorigenic heterogeneities in human $\mathrm{PCa}$ cells using multiple xenograft models and $>70$ patient tumor samples. In the first part, we further investigate the $\mathrm{PSA}^{-/ \mathrm{lo}} \mathrm{PCa}$ cell population, which we have recently shown to harbor self-renewing long-term tumor-propagating cells [13]. We demonstrate that 1) tumor cell PSA mRNA levels inversely correlate with grade, metastasis, and patient survival; 2) discordant AR and PSA expression in both untreated and castration-resistant PCa (CRPC) results in $\mathrm{AR}^{+} \mathrm{PSA}^{+}, \mathrm{AR}^{+} \mathrm{PSA}^{-}, \mathrm{AR}^{-} \mathrm{PSA}^{-}$, and $\mathrm{AR}^{-} \mathrm{PSA}^{+}$ subtypes of $\mathrm{PCa}$ cells that manifest differential sensitivities to therapeutics; 3) the $\mathrm{PSA}^{-/ \mathrm{lo}} \mathrm{PCa}$ cells pre-exist in untreated primary tumors and castration leads to a great enrichment of $\mathrm{PSA}^{-/ \mathrm{lo}} \mathrm{PCa}$ cells in both xenograft tumors and CRPC samples; 4) the PSA ${ }^{-/ l o}$ PCa cells are quiescent and resistant to castration and other stress treatments; 5) systemic androgen levels dynamically regulate the relative abundance of $\mathrm{PSA}^{+}$versus $\mathrm{PSA}^{-/ \mathrm{lo}} \mathrm{PCa}$ cells in the tumors that impacts the kinetics of tumor growth; 6) the $\mathrm{PSA}^{-/ 10}$ PCa cells seem to possess distinct epigenetic profiles; and 7) the $\mathrm{PSA}^{-/ \mathrm{lo}} \mathrm{PCa}$ cell population is enriched in several CSC markers including CD44, integrin $\alpha 2 \beta 1$, and ALDH1A1.

Heterogeneous and discordant AR and PSA expression in $\mathrm{PCa}$ cells has been reported in numerous earlier studies [39-61]; however, our study, for the first time, has proposed and presented the evidence for the 4 subtypes of $\mathrm{PCa}$ cells, i.e., $\mathrm{AR}^{+} \mathrm{PSA}^{+}, \mathrm{AR}^{-} \mathrm{PSA}^{+}, \mathrm{AR}^{+} \mathrm{PSA}^{-}$, and $\mathrm{AR}^{-} \mathrm{PSA}^{+}$that pre-exist in untreated $\mathrm{HPCa}$. We have shown preliminary evidence that $3 \mathrm{LNCaP}$ sublines representing 3 subtypes of $\mathrm{PCa}$ cells, i.e., $\mathrm{AR}^{+} \mathrm{PSA}^{+}$(regular $\mathrm{LNCaP}), \mathrm{AR}^{+} \mathrm{PSA}^{-}$(LNCaP-abl) and $\mathrm{AR}^{-} \mathrm{PSA}^{-}$(LNCaPCDSS and LNCaP-MDV) exhibit differential responses to antiandrogens, chemodrugs, and targeted therapeutics. Of clinical significance, the $\mathrm{PSA}^{-/ \mathrm{lo}}$ cell population, which encompasses both $\mathrm{AR}^{+} \mathrm{PSA}^{-/ 10}$ and $\mathrm{AR}^{+} \mathrm{PSA}^{-/ 10}$ cells, becomes strikingly enriched in all CRPC samples examined and in castration-resistant xenograft model. These analyses, taken together with evidence of distinct epigenetic profiles of $\mathrm{PSA}^{-/ \mathrm{lo}}$ vs. $\mathrm{PSA}^{+}$subsets, suggest that castration selects for undifferentiated $\mathrm{PSA}^{-/ \mathrm{lo}} \mathrm{PCa}$ cells.

Our previous work has demonstrated that the $\mathrm{PSA}^{-/ \mathrm{lo}}$ PCa cell population harbors self-renewing long-term tumorpropagating PCSCs that resist castration [13]. The present study follows up on the earlier work by further showing that the $\mathrm{PSA}^{-/ \mathrm{lo}} \mathrm{PCa}$ cells are much more quiescent than the $\mathrm{PSA}^{+}$cells, based on time-lapse tracking of single cells and clonal analysis. Purified $\mathrm{PSA}^{-/ \mathrm{lo}} \mathrm{PCa}$ cells, like the bulk $\mathrm{AR}^{-} \mathrm{PSA}^{-/ \mathrm{lo}} \mathrm{LNCaP}$ subline, are also refractory to antiandrogens and other drugs. We further demonstrate that the relative abundance of both $\mathrm{PSA}^{-/ l o}$ and $\mathrm{PSA}^{+} \mathrm{PCa}$ cells in tumors are regulated dynamically by systemic androgen levels, which in turn impacts tumor regeneration and growth in androgen-proficient versus androgen-deficient conditions. These latter observations implicate differential epigenetic mechanisms in regulating the two populations of $\mathrm{PCa}$ cells. In support, targeted $\mathrm{ChIP} / \mathrm{re}-\mathrm{ChIP}$ assays on 8 gene promoters known to be associated with bivalent chromatin domains in ES cells reveal 4 genes possessing bivalent features but preferentially in $\mathrm{PSA}^{-/ \mathrm{lo}} \mathrm{PCa}$ cells, consistent with these cells possessing stem cell gene expression profiles and biological characteristics [13]. A genome-wide ChIP-Seq analysis of several histone marks in purified $\mathrm{PSA}^{-/ \mathrm{lo}}$ and $\mathrm{PSA}^{+} \mathrm{PCa}$ cells is under way.

The $\mathrm{PSA}^{-/ \mathrm{lo}} \mathrm{PCSC}$ population is heterogeneous [13]. Therefore, in the second part of this project, we carried out exhaustive tumor-regeneration and serial transplantation studies in $2 \mathrm{AR}^{+} / \mathrm{PSA}^{+}$(LAPC9 and LAPC4) and $2 \mathrm{AR}^{-} /$ $\mathrm{PSA}^{-}$(PC3 and Du145) PCa models. The results provide indisputable evidence that 1) different $\mathrm{PCa}$ models possess distinct profiles of tumorigenic subpopulations; 2), some PCa (e.g., LAPC9 and Du145) may possess several populations of CSCs whereas others (e.g., LAPC4) seem to have a paucity of CSC populations; 3) no single marker profile can track tumor-propagating cells in all models; and 4) the ability of combinatorial marker-sorting strategy to further enrich CSCs over single marker strategies is dependent on the cancer models analyzed (Supplementary Table 2). Therefore, the $\mathrm{CD}_{4} 4^{+}$phenotype enriches CSCs in Du145 and LAPC9 but not in LAPC4 models whereas the $\mathrm{ALDH}^{+}$phenotype enriches tumor-initiating cells in all 4 models except LAPC4. Similarly, the CD $44^{+} \alpha 2 \beta 1^{+}$phenotype enriches CSCs in LAPC9 and LAPC4 but not in Du145 models. These results provide essential foundation for understanding CSC heterogeneity $[1,2]$ and also explanations to why different groups, working on individual PCa models, have often reported divergent PCSC phenotypes.

That tumorigenic subpopulations can be enriched by several different markers and functional strategies implies that some tumors contain a CSC pool with heterogeneous tumorigenic subsets that possess distinct tumor-initiating and tumor-propagating properties. In support, the LAPC9 
model harbors tumorigenic subpopulations that can be prospectively enriched using $\mathrm{CD}_{4} 4^{+}$and $\mathrm{CD} 44^{+} \alpha 2 \beta 1^{+}$ profiles as well as the SP and ALDH assays with the $\mathrm{CD} 44^{+} \alpha 2 \beta 1^{+}$subpopulation being the most tumorigenic (i.e., $\sim 1$ tumor-initiating cell in every 20 cells; Table 2 ). Detailed phenotypic and molecular profiling in Du145 and LAPC9 models shows that the $\mathrm{CD}_{4} 4^{+}, \alpha 2 \beta 1^{+}, \mathrm{ABCG}^{+}$, and $\mathrm{ALDH}^{+}$ cell populations identify overlapping subsets of tumorinitiating cells. Functional interrogation demonstrates that integrin $\alpha 2$ and ABCG2 but not CD44 are causally important for the clonal and clonogenic properties of the $\mathrm{CD} 44^{+} \mathrm{PCa}$ cells. The results with CD44 suggest that the molecule probably regulates PCSC properties in some other ways. Indeed, we have recently shown that CD44 plays a critical role in facilitating the invasive and metastatic behavior of PCSCs [12]. Of significance, the tumorigenic CD44 cell populations in both Du145 and LAPC9 commonly upregulate 14 genes involved in development (FGF1, FGFR1, and DVL1), cell cycle (RB1, CDC2, CCND2, and CCNA2), and neuronal activity (TUBB3 and NEUROG2), providing potential therapeutic targets for the $\mathrm{CD} 44^{+} \mathrm{PCa}$ cells. Similar molecular profiling reveals genes preferentially expressed in the most tumorigenic CD $44^{+} \alpha 2 \beta 1^{+}$LAPC9 cells including Wnt (FRAT1, BTRC, APC, WNT1), growth factor (FGFR1, IGF1, BMP2, FGF4, NEUROG2), and pluripotency (SOX2) signaling molecules. As a proof of principle, an FGFR inhibitor potently blocks the clonal and clonogenic activity in CD44 ${ }^{+}$LAPC9 and Du145 cells.

Our observations in $\mathrm{PCa}$ are consistent with the phenotypic heterogeneity and functional diversity of CSCs recently reported in other tumor systems including cancers of the breast, pancreas, and colon as well as acute myeloid leukemia and glioblastoma [1, 2, 25, 62-67]. Our results also support but greatly extend earlier efforts in using CD antigen phenotyping to study PCa cell heterogeneity [68]. Importantly, phenotypic analysis combined with functional studies in $~ 50 \mathrm{HPCa}$ samples demonstrate that untreated HPCa samples also heterogeneously express CSC markers including CD44, CD133, $\alpha 2 \beta 1$, and ALDH and that prospectively purified $\mathrm{CD} 44^{+}$and $\mathrm{CD} 133^{+} \mathrm{HPCa}$ cells in most (though not all) samples manifest high proliferative, clonal and clonogenic capacities.

Results from the present study reinforce the intrinsic stem cell nature and castration-resistant properties of the $\mathrm{PSA}^{-/ \mathrm{lo}} \mathrm{PCa}$ cells. Then what is the relationship between the $\mathrm{PSA}^{-/ \mathrm{lo}} \mathrm{PCa}$ cell population and several other populations of PCSCs including CD $44^{+}, \alpha 2 \beta 1^{+}$and $\mathrm{ALDH}^{+} \mathrm{PCa}$ cells? IF staining combined with molecular profiling indicate that the 3 CSC marker-positive populations of PCa cells are included in the $\mathrm{PSA}^{-/ \mathrm{lo}}$ population (Figure 7; Supplementary Figure 5). The current work, together with our systematic studies published over the past 10 years [6-13] allows us to propose a hypothetical model that unifies most previous PCSC studies (Figure 11). The model posits that untreated prostate tumors contain a spectrum of cancer cells at different stages of differentiation. Undifferentiated $\left(\mathrm{PSA}^{-/ \mathrm{lo}}\right) \mathrm{PCa}$ cells are quiescent and can undergo ACD to generate $\mathrm{PSA}^{+}$cells whereas the $\mathrm{PSA}^{+} \mathrm{PCa}$ cells are highly proliferative but only undergo SCD (Figure 11). The $\mathrm{PSA}^{-/ \mathrm{lo}} \mathrm{PCa}$ cells possess unlimited whereas $\mathrm{PSA}^{+} \mathrm{PCa}$ cells limited tumor-propagating activity [13]. The $\mathrm{PSA}^{-/ \mathrm{lo}} \mathrm{PCa}$ cells are intrinsically more resistant to castration and other therapeutics than $\mathrm{PSA}^{+}$cells [this study; 13]. Importantly, the $\mathrm{PSA}^{-/ l o} \mathrm{PCa}$ cell population is heterogeneous harboring and/or overlapping with other tumorigenic subsets including the SP, holoclones, and $\mathrm{ALDH}^{+}, \mathrm{CD}_{4} 4^{+}, \alpha 2 \beta 1^{+}$, and $\mathrm{ABCG}^{+}$cells $[6-8,10,12$, 13; this study] (Figure 11) and, likely, other subsets such as $\mathrm{CD}_{133^{+}}$[15] and TRA-1-60 $\mathrm{CD}^{+} 151^{+} \mathrm{CD} 166^{+}$cells [19], which are $\mathrm{AR}^{-} \mathrm{PSA}^{-}$.

Our model (Figure 11) also provides a framework for understanding PCa cell heterogeneity and potential cell-oforigin to CRPC. Therefore, untreated primary HPCa, like LNCaP, LAPC9, and LAPC4 xenografts, all contain a major population of $\mathrm{PSA}^{+}$cells but also a minor $\mathrm{PSA}^{-/ l o}$ population, in which tumorigenic subsets differ both quantitatively and qualitatively depending on individual HPCa samples and xenograft models. Due to the nearly homogeneous $\mathrm{AR}$ expression in $\mathrm{PSA}^{+} \mathrm{PCa}$ cells (Supplementary Figure 4A; 13), primary HPCa and AD xenografts respond well to antiandrogens, leading to prominent reduction in tumor burden. On the other hand, the $\mathrm{PSA}^{-/ \mathrm{lo}} \mathrm{PCa}$ cells, being only $\sim 30 \% \mathrm{AR}^{+}$, do not respond well to antiandrogens and will survive ADT leading to the eventual emergence of CRPC. In support, the PSA ${ }^{-/ 10}$ PCa cells from multiple PCa models regenerate AI tumors very efficiently in completely androgen-deficient hosts [13]. Significantly, more tumorigenic subsets can be further purified out from the PSA ${ }^{-/ \mathrm{lo}}$ PCa cell population to establish CRPC [13; Chen et al., manuscript submitted]. These observations implicate the $\mathrm{PSA}^{-1 \mathrm{lo}} \mathrm{PCa}$ cell population, which pre-exists in primary $\mathrm{HPCa}$, as a cell-of-origin for CRPC due to their preferential survival of castration. This conjecture is fully consistent with classical studies performed decades ago reporting that CRPC might result from selective outgrowth of pre-existent AI clones in primary tumors $[69,70]$. In contrast to the untreated HPCa and AD xenografts, the cellular landscape in clinical CRPC and AI xenografts completely changes with the $\mathrm{PSA}^{-/ \mathrm{lo}}$ cells becoming predominant [this study, 13]. The profiles of tumorigenic subsets within the $\mathrm{PSA}^{-/ \mathrm{lo}}$ PCSC pool may also likely to change (Figure 11). Taken together, the current study further highlights the need to develop novel therapeutics that specifically target the $\mathrm{PSA}^{-/ 10}$ population and other PCSC subsets within, which when used in combination with ADT, should help prevent tumor relapse. Many of our ongoing projects are fulfilling this need.

\section{MATERIALS AND METHODS}

\section{Cells and antibodies}

PC3, Du145, PPC-1, LNCaP cells were obtained from ATCC (Manassas, VA) whereas 293FT packaging cells were 


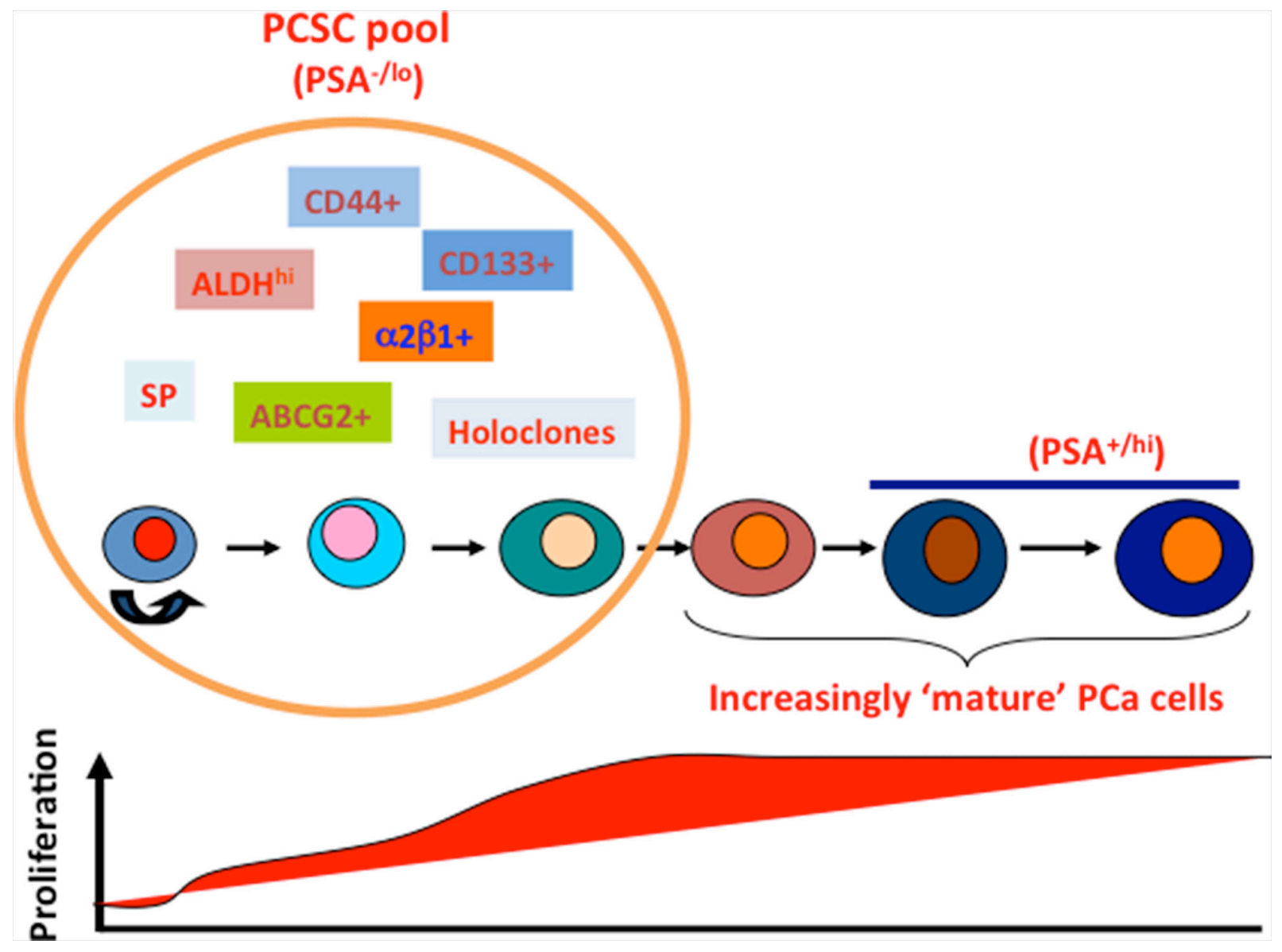

Figure 11: A hypothetical model of tumorigenic heterogeneity of human PCa cells. Untreated (hormone-naïve) PCa contain a spectrum of tumor cells at different stages of differentiation (marked by cells of varying colors and sizes). The PCSC pool in these tumors mainly contains undifferentiated $\left(\mathrm{PSA}^{-/ 10}\right.$ ) PCa cells, which are quiescent (thus low proliferative index; below) and can undergo ACD developing into differentiated cells. The $\mathrm{PSA}^{-/ 10} \mathrm{PCa}$ cells possess long-term tumor-propagating activity. The PSA ${ }^{-/ 10} \mathrm{PCSC}$ pool is heterogeneous harboring and/or overlapping with other tumorigenic subsets that can be prospectively purified out using the marker profiles indicated. The PCSC pool contains the intrinsically castration-resistant cells. In contrast, fully differentiated (PSA ${ }^{+}$) PCa cells, despite being highly proliferative (thus high proliferative index, below), only undergo symmetric cell division and possess more limited tumorpropagating capabilities. The PSA ${ }^{-/ l o}$ PCSC pool is relatively small and preexists in untreated patient tumors but dramatically enriched in CRPC in which the profiles of tumorigenic subsets may likely be very different from those in the untreated tumors. This model is updated from our earlier model (8). See Text for more discussions.

purchased from Invitrogen (Carlsbad, CA), respectively. All these cells were mycoplasma free, STR-authenticated, and routinely maintained in serum- and antibiotic-containing media as suggested by the providers. Synthetic androgen R1881 and androgen antagonist bicalutamide were purchased from PerkinElmer (cat\# NLP005005MG; Waltham, MA) and Toronto Research Chemicals (cat\#B382000; Ontario, Canada), respectively. MDV3100 was bought from Selleck Chemicals (car\# S1250). All other chemicals were obtained from Sigma unless otherwise specified. Antibodies used in the present study included:

mouse $\mathrm{mAb}$ to integrin $\alpha 2 \beta 1$ (cat\# MAB1998Z, clone BHA2.1; Chemicon, Billerica, MA)

mouse $\mathrm{mAb}$ to $\beta$-actin (cat\# 69100, clone C4; ICN, MP Biomedicals, Solon, $\mathrm{OH}$ ) rabbit pAb to ABCG2 (cat\# AV43649; Sigma) mouse mAb to AR (cat\# sc-7305, clone 441; Santa Cruz Biotechnology, Santa Cruz, CA)

mouse mAb to Bcl-2 (clone N-19; Santa Cruz Biotech)

mouse mAb to Bcl-2 (cat\# 610538; BD Biosciences, San Jose, CA)

mouse mAb to BrdU (cat\# B2531, clone BU-33; Sigma, St Louis, MO)

mouse mAb to CD44 (cat\# 550932, clone G44-26; BD Biosciences)

mouse mAb to CD44 (cat\# sc-7297; Santa Cruz Biotech.)

rabbit $\mathrm{pAb}$ to cytokeratin 5 (cat\# PRB-160P; BAbCO, Covance, Princeton, NJ)

mouse $\mathrm{mAb}$ to cytokeratin 18 (cat\# 550511, clone GRE53; BD Biosciences) 
mouse mAb to cytokeratin 18 (cat\# MAB1600, clone DC-10; Chemicon)

rabbit $\mathrm{mAb}$ to GAPDH (cat\# sc-25778, clone FL-

335; Santa Cruz Biotech)

rabbit pAb to GFP (cat\# Ab290; Abcam)

rabbit pAb to Ki-67 (cat\# Ab16667; Abcam)

mouse mAb to P63 (cat\# sc-8431; clone 4A4; Santa

Cruz Biotechnology)

rabbit pAb to PSA (cat\# A0562; Dako, Carpinteria, CA)

mouse mAb to PSA (clone A67-B/E13; Santa Cruz

Biotechnology)

rabbit pAb to Histone $\mathrm{H} 3$ (Cat\# 06-755, Millipore)

rabbit pAb to Histone H3K4, trimethyl (cat\# 07-

473, Millipore)

rabbit pAb to Histone H3K27, trimethyl (cat\# 07-

449, Millipore)

mouse mAb to Histone H3K27, trimethyl (cat\# 61017, Active Motif)

rabbit control IgG, ChIP grade (cat\# ab46540, Abcam)

rabbit pAb to hTERT (cat\# NB 100-141; Novus)

Alexa Flour 405 conjugated streptavidin (S32351, Invitrogen)

Alexa Flour-conjugated secondary antibodies (Invitrogen)

APC-conjugated goat anti-mouse IgG (550826; BD

Biosciences)

Biotin-conjugated $\mathrm{pAb}$ to mouse $\mathrm{H}-2 \mathrm{~K}^{\mathrm{d}}$ (SF1-11; BD Biosciences)

PE-conjugated $\mathrm{mAb}$ to $\mathrm{H}-2 \mathrm{~K}^{\mathrm{d}}$ (clone $\mathrm{SF} 1-1.1$; BD

Biosciences)

PE conjugated mAb CD44 antibody (550932, BD

Bioscience)

\section{Regular immunohistochemical (IHC) staining and double immunofluorescence (IF) staining of AR and PSA in formalin-fixed paraffin- embedded (FFPE) HPCa sample}

Basic IHC protocols have been described $[12,13]$. Paraffin-embedded sections ( $4 \mu \mathrm{m})$ were deparaffinized and hydrated in xylene followed dehydration in graded alcohols to water. Antigen retrieval was performed in $1.0 \mathrm{mM}$ EDTA Buffer ( $\mathrm{pH} 8.0$ ) for $10 \mathrm{~min}$ in a microwave oven followed by a 20 -min cool down. Slides were then incubated with various primary antibodies followed by Envision-plus labeled polymer-conjugated horseradish peroxidase and DAB monitoring staining development (Dako). For IHC analysis of $\mathrm{PSA}^{+}$and $\mathrm{PSA}^{-1 \mathrm{lo}}$ cells in FFPE HPCa sections, we first titrated the primary antibody to PSA (A0526, Dako) and found that at 1:5 dilutions, the antibody reliably differentiated the $\mathrm{PSA}^{+}$and $\mathrm{PSA}^{- \text {lo }}$ PCa cells. We then utilized this antibody concentration to stain FFPE sections [13]. In general we stained at least 3 consecutive sections from each sample for PSA. Twelve fields were chosen from each slide for counting by two individuals in a blind fashion and $\mathrm{PSA}^{+}$and $\mathrm{PSA}^{-/ 10} \mathrm{PCa}$ cells were averaged.

For PSA and AR double IF staining, HPCa sections $(4 \mu \mathrm{m})$ were deparaffinized and dehydrated through graded alcohols. Antigen retrieval was performed by soaking slides in pre-warmed target retrieve agent (S1099, Dakocytomation) in boiling water bath (40 min). Slides were incubated with Background Sniper (BS966H, Biocare Medical) at room temperature for $30 \mathrm{~min}$. For primary antibody staining, slides were incubated at $4^{\circ} \mathrm{C}$ overnight with a mix of mouse monoclonal anti-AR (clone 411, SC-7305, Santa Cruz Technology; 1:50) and rabbit polyclonal anti-PSA (A0526, Carpinteria, CA; 1:5) in PBS containing 0.1\% Triton and 5\% goat serum. After thorough washing, slides were incubated at RT for 60 min with secondary antibodies (Invitrogen), i.e., Alexa Flour 594-conjugated goat anti-mouse $\operatorname{IgG}(1: 500)$ and Alexa Flour 488-conjugated goat anti-rabbit $\operatorname{IgG}(1: 500)$ in PBS plus $0.1 \%$ Triton and $5 \%$ serum, followed by thorough washing. Then slides were incubated with DAPI $(3 \mu \mathrm{M})$ diluted in PBS (RT for $5 \mathrm{~min}$ ). To eliminate autofluorescence, slides were immersed in $70 \%$ ethanol for $5 \mathrm{~min}$, incubated in Autofluorescence Eliminator Reagent (2160, Millipore) for $5 \mathrm{~min}$, and were finally passed through 3 changes of $70 \%$ ethanol for 1 min each. Upon rinsing in PBS, slides were mounted with $10 \mu \mathrm{L}$ Gold Antifade Reagent (936590, Prolong). Images were acquired on an Olympus microscope.

\section{Xenograft tumor processing and purification of human PCa cells from xenografts}

Basic procedures were detailed elsewhere [11]. Briefly, xenograft tumors were harvested from maintenance tumors and minced into $\sim 1 \mathrm{~mm}^{3}$ pieces, which were rinsed once with PBS, digested for 30 min with Accumax (AM105; Innovative Cell Technologies, San Diego, CA) at room temperature, and filtered though $40-\mu \mathrm{m}$ cell strainer. Dead cells and debris were separated from live cells on a discontinuous Percoll gradient. Lineage-positive mouse cells were depleted using either MACS Lineage Cell Depletion Kit (Miltenyi Biotec) or staining for mousespecific MHC using PE or Biotin-conjugated monoclonal anti-H-2K $\mathrm{K}^{\mathrm{d}}$ (SF1-11; BD Biosciences).

\section{Primary prostate tumor (HPCa) processing}

Our lab has so far worked on $>220$ HPCa samples and the present study utilized $>70$ HPCa samples (Supplementary Table 2). All HPCa samples (with the matched normal/benign samples) were obtained with the written informed consent from the patients in accordance with federal and institutional guidelines and with the approved IRB protocols (MDACC LAB04-0498). HPCa processing protocol has been described previously [11-13]. Lineage-positive (i.e., hematopoietic, endothelial, smooth muscle, fibroblast, and other stromal) cells were depleted using the MACS Lin-1 cocktail mix and anti-CD140b-PE (Miltenyi Biotec). Purified HPCa cells 
were used in multiple types of experiments and, in some cases, for infection with the PSAP-GFP lentiviral vector. When necessary, HPCa cells were cultured for a short period time in various media, e.g., serum/androgen-free PrEBM supplemented with insulin, EGF, and bovine pituitary extract.

\section{Tumor experiments and serial tumor transplantation in NOD/SCID mice}

Subcutaneous (s.c) and orthotopic (i.e., dorsal prostate or DP) tumor transplantations were carried out as previously described $[6-8,11-13]$. For serial tumor transplantations in NOD/SCID mice, marker-positive and -negative PCa cells were sorted out by FACS from the first-generation $\left(1^{\circ}\right)$ tumors originally derived from corresponding marker-positive and -negative cells, and implanted s.c or in the DP to generate secondary $\left(2^{\circ}\right)$ tumors. Sequential tumor transplantation was performed using similar strategies. For tumor experiments in castrated mice, male NOD/SCID mice (6-8 weeks) were surgically castrated 1-2 weeks prior to tumor cell injection.

\section{Lentiviral infection of PCa cells}

Lentivirus was produced in 293FT packaging cells and titers determined using GFP positivity in HT1080 cells. PCa cells were infected, generally, at a multiplicity of infection (MOI) of 20 and harvested at 48-72 h post-infection. Infected bulk cells or FACS-purified subpopulation of cells were used in various in vitro and in vivo experiments detailed in each Figure.

\section{Fluorescence-activated cell sorting (FACS)}

PCa cells stained for various markers or after PSAPGFP infection (48-72 h) were dissociated into single-cell suspension and generally $1-10 \times 10^{6}$ cells were used for FACS on a BD FACSAria ${ }^{\mathrm{TM}}$ Fusion cell sorter. Unstained or uninfected cells were used as negative control for gating. Post-sort analysis was routinely performed to guarantee the purity of each population. HPCa cells freshly purified from primary tumors were first infected with PSAP-GFP and sorted 3-7 days later. To purify marker-positive PCa cells from xenograft tumors, we first incubated PCa cells with FcR blocking agent (Miltenyi Biotec) for $15 \mathrm{~min}$ at $4{ }^{\circ} \mathrm{C}$ and then stained them with various primary antibodies. For double or triple marker populations, we would incubate cells with anti- $\alpha 2 \beta 1$ (MAB1998Z; Chemicon) for $30 \mathrm{~min}$ on ice followed by staining with APC-conjugated goat anti-mouse IgG (550826; BD Biosciences) for $15 \mathrm{~min}$ on ice. Cells were then washed $(3 \mathrm{x})$ and stained with $\mathrm{PE}$-conjugated antiCD44 antibody (550932, BD Bioscience) and biotinylated mouse H2-Kd (553564, BD Pharmingen) for $20 \mathrm{~min}$. After washing, cells were incubated with Alexa Flour 405-conjugated streptavidin for $10 \mathrm{~min}$ at $4^{\circ} \mathrm{C}$. Cells were incubated in solution containing $1 \% \mathrm{BSA}$ and $2.5 \mu \mathrm{g} /$ $\mathrm{ml}$ insulin (I-6634, Sigma). PCa cells were suspended in ALDEFLUOR assay buffer containing ALDH substrate $\left(1 \mu \mathrm{M}\right.$ per $1 \times 10^{6}$ cells, the ALDEFLUOR kit; StemCell Technologies, Vancouver, Canada) and incubated for 40 min at $37^{\circ} \mathrm{C}$ and sorted by FACS. As negative control, we added $50 \mathrm{nmol} / 1$ diethylaminobenzaldehyde (DEAB) to the cell suspension.

\section{Clonal and clonogenic sphere-formation assays}

Holoclone and sphere-formation assays were conducted as previously described $[10,11]$ and stringent conditions were employed to ensure that clones, colonies, and spheres were all derived from single cells [12]. Briefly, we performed clonal analysis using purified and/or sorted PCa cells plated at 100 cells/10-cm plate or 100 cells/well in a six-well culture dish. Clones with $\geq 50$ cells were scored $\sim 2$ weeks after plating. We performed LAPC9 clonal analysis on mitomycin C (M0530, Sigma) treated Swiss 3 T3 cells. The results were expressed as cloning efficiency (\%). In some clonal assays, cells were directly sorted into 96-well plates at $1 \mathrm{cell} /$ well and clonal type and size were monitored and scored under a (fluorescence) microscope $[10,11]$. For clonogenic sphere-formation assays in xenograft and HPCa cells, cells were plated at 5,000-10,000 cells/well in six-well culture dishes coated with a thin layer of $1 \%$ solidified agar or $50 \%$ Matrigel or plated in 6-well ultra-low attachment (ULA) plates. Spheres that arose within 1-2 weeks were presented as clonogenicity (\%). For serial sphere-formation assays, the first-generation spheres were harvested, disaggregated with $0.025 \%$ trypsin/EDTA, triturated with a $27-\mathrm{G}$ needle, filtered through $40-\mu \mathrm{m}$ mesh, and replated as above. This process was repeated for up to 4-5 generations. We sometimes performed serial clonogenic assays in a different way. Briefly, cells were first resuspended in DMEM/F12 supplemented with B27 (17504-044, Invitrogen) and N2 (17502-048, Invitrogen) and mixed (7:4) thoroughly with methylcellulose (04100, Stem Cell Technology) and plated $(600 \mu \mathrm{l})$ in 24-well ULA plates at 2, 000 cells/wells. Primary spheres were scored in $\sim 2$ weeks. For secondary sphere assays, the first-generation spheres were individually picked up with a transfer pipette under a dissection microscope and dissociated with $0.05 \%$ trypsin/EDTA. All the cells derived from individual spheres were mixed with methylcellulose and plated back to one well of a 96-well ULA plate.

\section{Clonogenic assays in $\mathrm{CD}_{4}^{+} \mathrm{PCa}$ cells treated with FGFR inhibitor or with gene knockdowns}

Du145 and LAPC9 cells were incubated with PEconjugated anti-CD44 (BD Biosciences; 1:10 dilution) for $1 \mathrm{~h}$ at $4^{\circ} \mathrm{C}$. Cells were washed and resuspended in sorting buffer, and the $\mathrm{CD}_{4} 4^{+}$(top 20\%) population was sorted out by FACS (see above). For shRNA (CD44, integrin $\alpha 2$, and $A B C G 2)$ infection, $1 \times 10^{5}$ sorted cells were plated in a 12-well plate in PrEBM media supplemented with B27, 
$10 \mu \mathrm{M}$ EGF, $10 \mu \mathrm{M}$ FGF, $8 \mu \mathrm{g}$ polybrene and infected with individual shRNA lentiviral vectors (MOI 20). After $48 \mathrm{~h}$, $2 \times 10^{3}$ cells were plated per well in a 6 -well ULA plate in complete PrEBM media and incubated for 2 weeks before scoring. Alternatively, cells were resuspended in a 1:1 ratio of Matrigel:PrEBM media mix and $3 \times 10^{3}$ cells per well were plated around the rim in a 12-well plate. After the Matrigel solidified, $2 \mathrm{ml}$ of complete PrEBM media was added to wells and cells were incubated for 2 weeks before scoring. For treatment with the FGFR inhibitor SU5402, CD44 ${ }^{+}$cells were plated in both Matrigel and ULA plates immediately after sorting as described above with the indicated SU5402 concentrations.

\section{Immunofluorescence (IF) microscopy}

Basic IF procedures have been described [6-8]. To correlate GFP and AR expression in $\mathrm{LNCaP}$ cells, $\mathrm{GFP}^{+}$ and $\mathrm{GFP}^{-/ l o}$ cells were sorted out by FACS and plated on the glass coverslips overnight. Cells were stained using a monoclonal antibody to AR (clone 441) followed by goat anti-mouse IgG conjugated to Alexa Fluor 594. For Ki-67 staining, cells were sorted out via FACS and plated on the glass coverslips for $8 \mathrm{~h}$. Cells were then incubated with the rabbit $\mathrm{mAb}$ to $\mathrm{Ki}-67$ (Abcam; 1:1000) for $60 \mathrm{~min}$ at room temperature. Following thorough washing for 3 times with $\mathrm{PBS}$, the coverslips were incubated for $60 \mathrm{~min}$ at room temperature with Alexa Fluor 594-conjugated goat antirabbit IgG (1:1000). In some experiments, freshly purified CD44+ HPCa cells were plated on collagen-coated glass coverslips and cultured in PrEBM media supplemented with B27, $10 \mu \mathrm{M}$ EGF, $10 \mu \mathrm{M}$ FGF, and BPE overnight followed by IF labeling for CD $44, \alpha 2 \beta 1$, AR, PSA, and hTERT.

\section{Cell cycle and cell death analyses}

To determine the cell-cycle profiles, regular PCa cells or PSAP-GFP infected cells were plated in 3.5-cm culture dish at $30 \%$ confluence and harvested at $\sim 60 \%$ confluence, fixed in $0.5 \%$ PFA for $1 \mathrm{~h}$ at $4^{\circ} \mathrm{C}$, and then permeabilized in $70 \%$ cold ethanol at $4^{\circ} \mathrm{C}$ for $3 \mathrm{~h}$. Cells were incubated in propidium iodide (PI) working solution (40 $\mu \mathrm{g} / \mathrm{ml}, \mathrm{P} 4170$; Sigma) at $37^{\circ} \mathrm{C}$ for $30 \mathrm{~min}$ and analyzed by FACS for cellcycle profiles $[11,13]$. To determine differential sensitivities of the $\mathrm{PSA}^{-/ \mathrm{lo}}$ and $\mathrm{PSA}^{+} \mathrm{PCa}$ cell populations to various drug treatments, we performed FACS analysis using the Vybrant Apoptosis Kit (catalog \#V23200; Molecular Probes, Invitrogen) according to the manufacturern's instructions. The kit contained biotin-Annexin V, Alexa Fluor 350 (similar spectrum to DAPI) streptavidin, and PI. Briefly, LNCaP cells infected with the PSAP-GFP reporter construct were plated in 10-cm cell culture plates at 500, 000 cells per plate. Cells were treated with DMSO (vehicle control), etoposide $(25 \mu \mathrm{M})$, paclitaxel $(10 \mathrm{nM})$, CDSS plus bicalutamide (20 $\mu \mathrm{M})$ or $\mathrm{H}_{2} \mathrm{O}_{2}(10 \mu \mathrm{M})$ for various time intervals with fresh drugs added every 1-2 days. Treated cells and controls were analyzed by FACS at 2-5 days after the initiation of treatments. Healthy live cells were identified as Annexin V dim and PI negative; apoptotic cells Annexin V positive and PI low/-; and necrotic cells Annexin V bright and PI bright.

\section{Quantitative RT-PCR (qRT-PCR)}

Basic protocols for qRT-PCR have been described $[12,13]$. In brief, qRT-PCR was performed using an ABI Prism 7900HT and the TaqMan system (ABI; Applied Biosystems, Foster City, CA; http://www. appliedbiosystems.com). The primers, probes, and assay conditions for other molecules were designed by ABI with the following information: PSA (Hs03063374_m1; assay number), AR (Hs00907244_m1), $\beta$-actin (Hs99999903 $\mathrm{ml}$ ), CD44 (Hs00153304_m1), $\alpha 2$ integrin (Hs00158148_ $\mathrm{m} 1)$, and GAPDH (4326317E).

\section{Time-lapse videomicroscopy and estimate of cell-cycle transit time}

Purified $\mathrm{GFP}^{+}$and $\mathrm{GFP}^{-} \mathrm{LNCaP}$ cells were plated on special glass-bottom dishes, placed on the incubator stage of Nikon Biostation Timelapse system [13], and maintained at $37^{\circ} \mathrm{C}, 5 \% \mathrm{CO} 2$ and $>95 \%$ humidity in the RPMI medium supplemented with 7\% FBS. Phase and GFP images were collected continuously with a $20 \mathrm{X}$ objective lens at a 1-h interval for up to $\sim 1$ week. Data analysis was performed using Nikon NIS-Elements software. Several dozens of recorded $\mathrm{GFP}^{+}$and $\mathrm{GFP}^{-}$ images were analyzed in detail for cell-cycle transit times using the first cell division as the starting point.

\section{Correlating PSA mRNA levels with clinical outcomes of PCa patients in Oncomine}

A total of 27 Oncomine PCa data sets containing KLK3 mRNA expression data (Supplementary Table 2) were analyzed in detail for correlations with available patient parameters including survival, recurrence, metastasis, Gleason score, serum PSA levels, and LN status. Significance of PSA mRNA between conditions was determined by Student's $t$-test, and $P$ values less than 0.05 were considered statistically significant. Box plot data presentations and statistical analyses were generated using program R. We also performed survival analysis and generated Kaplan-Meier survival plots using the survival package in R. Briefly, we first input the individual normalized gene expression data from patients with both survival time and survival status from Oncomine and ranked the data according to $P S A$ mRNA expression. We then assigned the samples with rankings from the first quartile to the third quartile into two groups and compared the $P$-value between these two groups along with different cutoffs. Finally, we set the ultimate cutoff with the smallest $P$-value and plotted a Kaplan-Meier survival curve. 


\section{Determination and GO analysis of genes commonly upregulated in both LNCaP and LAPC9 cDNA microarrays}

We previously performed cDNA microarrays in PSA $^{-1 / 0}$ versus PSA ${ }^{+}$LNCaP and LAPC9 cells [13] and all microarray data have been deposited in the NCBI GEO database (www.ncbi.nlm.nih.gov/geo/query) under the accession number GSE15411 and GSE30114. To determine commonly changed genes, we first selected the genes (by Agilent's Probe ID) either up-regulated or down-regulated using a 1.4FC cutoff from both LAPC9 and LNCaP gene lists (from raw data file) and used these genes for Venn diagram analysis. This analysis identified 3,949 and 3,338 upregulated probe ID's in $\mathrm{PSA}^{-1 / 0} \mathrm{LAPC} 9$ and $\mathrm{LNCaP}$ cells, respectively, over the corresponding $\mathrm{PSA}^{+}$cells, of which 570 probe ID's were shared (see Supplementary Figure 4B). The probe ID's were then converted into official gene names (symbols) using the ID conversion tool available in DAVID, which identified a total 337 genes commonly upregulated in both LNCaP and LAPC9 PSA $^{-10}$ populations. We performed Gene Ontology (GO) analysis of 337 commonly upregulated genes using functional annotation tool in DAVID.

\section{ChIP and re-ChIP assays}

To determine if $\mathrm{PSA}^{-10}$ and $\mathrm{PSA}^{+}$tumor cells differed in chromatin composition and stem-cell associated bivalent domains, ChIP and re-ChIP assays [30] were performed using chromatin from prospectively purified $\mathrm{PSA}^{-1 \mathrm{lo}}$ and $\mathrm{PSA}^{+}$LAPC9 and LNCaP cells. Freshly sorted PSA ${ }^{-10}$ and $\mathrm{PSA}^{+}$cells were fixed for $15 \mathrm{~min}$ at RT by addition of freshly prepared neutral buffered formalin to their respective media at a final concentration of $0.75 \%$, with gentle rocking. Formalin was quenched by the addition of $2 \mathrm{M}$ glycine to a final concentration of $0.125 \mathrm{M}$ and incubation for $5 \mathrm{~min}$ at RT with gentle rocking. Cells were then pelleted and resuspended in $750 \mu$ of ChIP lysis buffer ( $50 \mathrm{mM}$ HEPES$\mathrm{KOH}, 140 \mathrm{mM} \mathrm{NaCl}, 1 \mathrm{mM}$ EDTA, pH 8.0, 1\% Triton X100, $0.1 \%$ sodium deoxycholate, and Roche complete protease inhibitor cocktail) for every million cells, and sonicated on ice until the majority of the chromatin had been sheared into $500-1000$ bp fragments. $50 \mu \mathrm{l}$ was removed for use as input, and the remaining chromatin was divided into aliquots for immunoprecipitation (IP) and diluted 10x with dilution buffer (1\% Triton X-100, 2 mM EDTA, $150 \mathrm{mM} \mathrm{NaCl}, 20 \mathrm{mM}$ Tris-HCl, $\mathrm{pH}$ 8.0, and Roche protease inhibitor cocktail).

In all immunoprecipitations, $5 \mu \mathrm{g}$ of primary antibody or control IgG was used for the initial ChIP as well as re-ChIPs performed. Antibodies used in the initial ChIP were ChIP-grade rabbit control IgG, anti-Histone $\mathrm{H} 3$, anti-Histone H3K4 (trimethyl), and anti-Histone H3K27 (trimethyl). For the re-ChIP, a mouse monoclonal antibody raised against histone H3K27 (trimethyl) was used. For each ChIP antibody, $60 \mu \mathrm{l}$ of Invitrogen Dynal beads were washed and blocked in PBS- $0.1 \%$ BSA. Half of the beads were incubated overnight with the chromatin samples without antibody, as a pre-clearing step to reduce background due to non-specific chromatin interaction with the beads. Beads used for pre-clearing were then discarded. The other half of the beads were incubated with antibodies for ChIP while pre-clearing was ongoing. The following day, IP's were performed by combining pre-cleared chromatin samples with antibodybead complexes and incubating overnight at $4^{\circ} \mathrm{C}$ with gentle rocking. The next day, the beads were washed $3 \times 5$ min. with ChIP wash buffer $(0.1 \%$ SDS $1 \%$ Triton X-100 2 mM EDTA $150 \mathrm{mM} \mathrm{NaCl} 20 \mathrm{mM}$ Tris-HCl, pH8) and the bound chromatin eluted by incubating the beads with $450 \mu \mathrm{l}$ of $100 \mathrm{mM}$ sodium bicarbonate, 20 mM DTT for 15 min. at RT. $50 \mu \mathrm{l}$ of each ChIP was removed for use as input before incubating the IP eluate with the re-ChIP antibody. Re-ChIPs were performed by incubating the eluted chromatin from the first round of ChIP with the H3K27 (trimethyl) mAb/bead mixture overnight at $4{ }^{\circ} \mathrm{C}$ with gentle rocking. The re-ChIP'ed chromatin was washed $3 \times$ for $5 \mathrm{~min}$. in ChIP wash buffer and then eluted by incubation with $450 \mu \mathrm{l}$ of $100 \mathrm{mM}$ sodium bicarbonate, $1 \% \mathrm{SDS}$ for $15 \mathrm{~min}$ at RT. Prior to use in PCR reactions to detect the immunoprecipitated DNA, all samples and inputs were subjected to cross-link reversal by addition of $5 \mu \mathrm{l}$ of $20 \mathrm{mg} / \mathrm{ml}$ proteinase $\mathrm{K}$ and incubation at $60^{\circ} \mathrm{C}$ overnight. Protein was removed from ChIP samples and inputs by phenol-chloroform extraction and alcohol precipitation, and inputs were resuspended in $100 \mu \mathrm{l}$ of ddH2O while samples were resuspended in $30 \mu \mathrm{lddH} 2 \mathrm{O}$. PCR was typically performed for 33 cycles with $1 \mathrm{~min}$. for extension and 30 seconds for denaturing and annealing steps with a 5-minute final extension. Promega GoTaq $2 X$ master mix was used for all reactions. ChIP primers were targeted to sequences approximately $1000 \mathrm{bp}$ from the TSS (transcription start site) and were as follows:

$\begin{array}{ll}\text { AR } & \text { Forward: 5'-GGGTGATTTTGCCTTTG } \\ & \text { AGA-3' } \\ & \text { Reverse: 5'-GGCTTTGGAGAAACAA } \\ & \text { GTGC-3' } \\ \text { ASCL1 } & \text { Forward: 5'-TTCACCCCAAGTCTTTC } \\ & \text { CAC -3' } \\ & \text { Reverse 5'-ACTAAGGCTGCGCTCTC } \\ & \text { TTG-3' } \\ \text { BCL2 } & \text { Forward: } \\ & \text { 5'-GTCTGGGAATCGATCTGGAA-3' } \\ & \text { Reverse: 5'-GCGGAACACTTGATTCT } \\ & \text { GGT-3' } \\ \text { CD61 } & \text { Forward: 5'-CACACACACATGCAAA } \\ & \text { CGAG-3' } \\ & \text { Reverse: 5'-CACCCTCCCAAACACT } \\ \text { AGGA-3' } & \text { Forward: 5'-GCGGGAGGAATAGGAG } \\ \text { CDH2 } & \text { AGG-3' } \\ & \text { Reverse 5'-ATGTGGAGGTGGAAGTG } \\ & \text { GAG-3' }\end{array}$


FGF5

Forward: 5'-CAATCATCCTCCCCAG AAGA-3'

Reverse: 5'-TTGCATGCTTGGAATG TTTC-3'

NKX3-1 Forward: 5'-ACTCACTGCAGCCTCG ATTT-3'

Reverse: 5'-CCCGTTGCACAGGTAG TTTT-3'

PPP2R4 Forward: 5'-CCTGTCCCCACATGTC TTCT-3'

Reverse: 5'-CCTCTCGCCTTTCACT CTTG-3'

Quantification of relative binding in ChIP assays was performed using NIH ImageJ software (http://stanxterm. aecom.yu.edu/wiki/index.php?page=Using_ImageJ), and each gene promoter was analyzed in 3 independent immunoprecipitations. Arbitrary optical density values obtained through ImageJ were scaled for each ChIP by setting the pan-Histone $\mathrm{H} 3$ band to 1 .

\section{Statistics}

In general, unpaired two-tailed Student's $t$-test was used to compare differences in cell numbers, cell-cycle transit time, cloning and sphere-forming efficiency, tumor weights, and many other parameters. Fisher's Exact Test and $\chi^{2}$ test were used to compare incidence and latency. Log-Rank test was employed to analyze the survival curves and ANOVA (F-test) was used to compare multiple groups. In all these analyses, a $P<0.05$ was considered statistically significant.

\section{ACKNOWLEDGMENTS}

We thank the Histology Core for assistance in IHC, Drs. D. Cuellar, R. Fagin, and E. Giesler and their Associates for providing HPCa samples, J. Repass for help in qPCR analysis, Drs. B. Bhatia and L. Patrawala for some earlier studies, and the rest of the Tang lab members for insightful discussions. We apologize to the colleagues whose work was not cited due to space constraint.

\section{FUNDING}

This project was supported, in part, grants from NIH (NCI R01-CA155693), DOD (W81XWH-13-1-0352 and W81XWH-14-1-0575), CPRIT (RP120380), and MDACC Center for Cancer Epigenetics (all to D.G.T). This study also made use of the Science Park NGS Core, supported by CPRIT Core Facility Support Grant RP120348 (to J.S). C. J was supported in part by CPRIT (RP120394). X. Chen and C. Liu were supported, in part, by DOD postdoc fellowships PC141581 and PC121553, respectively.

\section{CONFLICTS OF INTEREST}

The authors claim no conflict of interests.

\section{REFERENCES}

1. Tang DG. Understanding cancer stem cell heterogeneity and plasticity. Cell Res. 2012; 22:457-472.

2. Kreso A, Dick JE. Evolution of the cancer stem cell model. Cell Stem Cell. 2014; 14:275-291.

3. Wicha MS. Targeting self-renewal, an Achilles' heel of cancer stem cells. Nat Med. 2014; 20:14-15.

4. Kreso A, van Galen P, Pedley NM, Lima-Fernandes E, Frelin C, Davis T, Cao L, Baiazitov R, Du W, Sydorenko N, Moon YC, Gibson L, Wang Y, et al. Self-renewal as a therapeutic target in human colorectal cancer. Nat Med. 2014; 20:29-36.

5. Jeter CR, Yang T, Wang J, Chao H, Tang DG. Nanog in cancer stem cells and tumor development: An update and outstanding questions. Stem Cells. 2015. In press.

6. Patrawala L, Calhoun T, Schneider-Broussard R, Zhou J, Claypool K, Tang DG. Side population (SP) is enriched in tumorigenic, stem-like cancer cells whereas $\mathrm{ABCG} 2^{+}$and $\mathrm{ABCG}^{-}$cancer cells are similarly tumorigenic. Cancer Res. 2005; 65:6207-6219.

7. Patrawala L, Calhoun $\mathrm{T}$, Schneider-Broussard R, Li H, Bhatia B, Tang S, Reilly JG, Chandra D, Zhou J, Claypool K, Coghlan L, Tang DG. Highly purified CD44 prostate cancer cells from xenograft human tumors are enriched in tumorigenic and metastatic progenitor cells. Oncogene. 2006; 25:1696-1708.

8. Patrawala L, Calhoun-Davis T, Schneider-Broussard R, Tang DG. Hierarchical organization of prostate cancer cells in xenograft tumors: The $\mathrm{CD}_{4} 4^{+} \alpha 2 \beta 1^{+}$cell population is enriched in tumor-initiating cells. Cancer Res. 2007; 67:6796-6805.

9. Tang DG, Patrawala L, Calhoun T, Bhatia B, Choy G, Schneider-Broussard R, Jeter C. Prostate cancer stem/progenitor cells: Identification, characterization, and implications. Mol Carcinogenesis. 2007; 46:1-14.

10. Li HW, Chen X, Calhoun-Davis T, Claypool K, Tang DG. PC3 Human prostate carcinoma cell holoclones contain self-renewing tumor-initiating cells. Cancer Res. 2008; 68:1820-1825.

11. Li HW, Jiang M, Honorio S, Patrawala L, Jeter CR, Calhoun-Davis T, Hayward SW, Tang DG. Methodologies in assaying prostate cancer stem cells. Methods Mol Biol 2009; 569:85-138.

12. Liu C, Kelnar K, Liu B, Chen X, Calhoun-Davis T, Li H, Patrawala L, Yan H, Jeter C, Honorio S, Wiggins JF, Baders AG, Fagin R, et al. The microRNA miR-34a inhibits prostate cancer stem cells and metastasis by directly repressing CD44. Nature Med. 2011; 17:211-215. 
13. Qin J, Liu X, Laffin B, Chen X, Choy G, Jeter CR, CalhounDavis T, Li H, Palapattu GS, Pang S, Lin K, Huang J, Ivanov I, et al. The $\mathrm{PSA}^{-/ 10}$ prostate cancer cell population harbors self-renewing long-term tumor-propagating cells that resist castration. Cell Stem Cell. 2012; 10:556-569.

14. Huss WJ, Gray DR, Greenberg NM, Mohler JL, Smith GJ. Breast cancer resistance protein-mediated efflux of androgen in putative benign and malignant prostate stem cells. Cancer Res. 2005; 65:6640-6650.

15. Collins AT, Berry PA, Hyde C, Stower MJ, Maitland NJ. Prospective identification of tumorigenic prostate cancer stem cells. Cancer Res. 2005; 65:10946-10951.

16. Gu G, Yuan J, Wills M, Kasper S. Prostate cancer cells with stem cell characteristics reconstitute the original human tumor in vivo. Cancer Res. 2007; 67:4807-4815.

17. Li T, Su Y, Mei Y, Leng Q, Leng B, Liu Z, Stass SA, Jiang F. ALDH1A1 is a marker for malignant prostate stem cells and predictor of prostate cancer patients' outcome. Lab Invest. 2010; 90:234-244.

18. van den Hoogen C, van der Horst G, Cheung H, Buijs JT, Lippitt JM, Guzman-Ramirez N, Hamdy FC, Eaton CL, Thalmann GN, Cecchini MG, Pelger RC, van der Pluijm G. High aldehyde dehydrogenase activity identifies tumorinitiating and metastasis-initiating cells in human prostate cancer. Cancer Res. 2010; 70:5163-5173.

19. Rajasekhar VK, Studer L, Gerald W, Socci ND, Scher HI. Tumour-initiating stem-like cells in human prostate cancer exhibit increased NF- $\mathrm{KB}$ signalling. Nat Commun. 2011; 2:162.

20. Mulholland DJ, Kobayashi N, Ruscetti M, Zhi A, Tran LM, Huang J, Gleave M, Wu H. Pten loss and RAS/MAPK activation cooperate to promote EMT and metastasis initiated from prostate cancer stem/progenitor cells. Cancer Res. 2012; 72:1878-1889.

21. Cai H, Memarzadeh S, Stoyanova T, Beharry Z, Kraft AS, Witte ON. Collaboration of Kras and androgen receptor signaling stimulates EZH2 expression and tumor-propagating cells in prostate cancer. Cancer Res. 2012; 72:4672-4681.

22. Domingo-Domenech J, Vidal SJ, Rodriguez-Bravo V, Castillo-Martin M, Quinn SA, Rodriguez-Barrueco R, Bonal DM, Charytonowicz E, Gladoun N, de la IglesiaVicente J, Petrylak DP, Benson MC, Silva JM, et al. Suppression of acquired docetaxel resistance in prostate cancer through depletion of notch- and hedgehog-dependent tumor-initiating cells. Cancer Cell. 2012; 22:373-388.

23. Yoshioka T, Otero J, Chen Y, Kim YM, Koutcher JA, Satagopan J, Reuter V, Carver B, de Stanchina E, Enomoto K, Greenberg NM, Scardino PT, Scher HI, et al. $\beta 4$ Integrin signaling induces expansion of prostate tumor progenitors. J Clin Invest. 2013; 123:682-699.

24. Li X, Liu Y, Chen W, Fang Y, Xu H, Zhu HH, Chu M, Li W, Zhuang G, Gao WQ. TOP2Ahigh is the phenotype of recurrence and metastasis whereas TOP2Aneg cells represent cancer stem cells in prostate cancer. Oncotarget. 2014; 5:9498-513.
25. Culig Z, Hoffman J, Erdel M, Eder IE, Hobisch A, Hittmair A, Bartsch G, Utermann G, Schneider MR, Parczyk K, Klocker H. Switch from antagonist to agonist of the androgen receptor bicalutamide is associated with prostate tumour progression in a new model system. Br J Cancer. 1999; 81:242-51.

26. Souers AJ, Leverson JD, Boghaert ER, Ackler SL, Catron ND, Chen J, Dayton BD, Ding H, Enschede SH, Fairbrother WJ, Huang DC, Hymowitz SG, Jin S, et al. ABT-199, a potent and selective BCL-2 inhibitor, achieves antitumor activity while sparing platelets. Nat Med. 2013; 19:202-208.

27. Vaillant F, Merino D, Lee L, Breslin K, Pal B, Ritchie ME, Smyth GK, Christie M, Phillipson LJ, Burns CJ, Mann GB, Visvader JE, Lindeman GJ. Targeting BCL-2 with the BH3 mimetic ABT-199 in estrogen receptor-positive breast cancer. Cancer Cell. 2013; 4:120-129.

28. Garcia-Echeverria C, Pearson MA, Marti A, Meyer T, Mestan J, Zimmermann J, Gao J, Brueggan J, Capraro HG, Cozens R, Evans DB, Fabbro D, Furet P, et al. In vivo antitumor activity of NVP-AEW541-A novel, potent, and selective inhibitor of the IGF-IR kinase. Cancer Cell. 2004; 5:231-239.

29. Sharov AA, Ko MSH. Human ES cell profiling broadens the reach of bivalent domains. Cell Stem Cell. 2007; 1:237-238.

30. Bernstein BE, Mikkelsen TS, Xie X, Kamal M, Huebert DJ, Cuff J, Fry B, Meissner A, Wernig M, Plath K, Jaenisch R, Wagschal A, Feil R, et al. A bivalent chromatin structure marks key developmental genes in embryonic stem cells. Cell. 2006; 125:315-326.

31. Chen X, Liu B, Li Q, Honorio S, Liu X, Liu C, Multani AS, Calhoun-Davis T, Tang DG. Dissociated primary human prostate cancer cells coinjected with the immortalized Hs5 bone marrow stromal cells generate undifferentiated tumors in NOD/SCID- $\gamma$ mice. PLoS One. 2013; 8:e56903.

32. Ho ME, Quek SI, True LD, Morrissey C, Corey E, Vessella RL, Dumpit R, Nelson PS, Maresh EL, Mah V, Alavi M, Kim SR, Bagryanova L, et al. Prostate cancer cell phenotypes based on AGR2 and CD10 expression. Mod Pathol. 2013; 26:849-859.

33. Dudley AC, Khan ZA, Shih SC, Kang SY, Zwaans BM, Bischoff J, Klagsbrun M. Calcification of multipotent prostate tumor endothelium. Cancer Cell. 2008; 14:201-218.

34. Wang J, Zhu HH, Chu M, Liu Y, Zhang C, Liu G, Yang X, Yang R, Gao WQ. Symmetrical and asymmetrical division analysis provides evidence for a hierarchy of prostate epithelial cell lineages. Nat Commun. 2014; 5:4758.

35. Cojoc M, Peitzsch C, Kurth I, Trautmann F, KunzSchughart LA, Telegeev GD, Stakhovsky EA, Walker JR, Simin K, Lyle S, Fuessel S, Erdmann K, Wirth MP, et al. Aldehyde dehydrogenase is regulated by Beta-catenin/TCF and promotes radioresistance in prostate cancer progenitor cells. Cancer Res. 2015; Feb 10;. pii: canres.1924.2014 [Epub ahead of print]. 
36. Wan X, Corn PG, Yang J, Palanisamy N, Starbuck MW, Efstathiou E, Tapia EM, Zurita AJ, Aparicio A, Ravoori MK, Vazquez ES, Robinson DR, Wu YM, et al. Prostate cancer cell-stromal cell crosstalk via FGFR1 mediates antitumor activity of dovitinib in bone metastases. Sci Transl Med. 2014; 6, 252ra122.

37. Bhatia B, Tang S, Yang P, Doll A, Aumueller G, Newman RA, Tang DG. Cell-autonomous induction of functional tumor suppressor 15-lipoxygenase 2 (15-LOX2) contributes to replicative senescence of human prostate progenitor cells. Oncogene. 2005; 24:3583-3595.

38. Bhatia B, Jiang M, Suraneni M, Patrawala L, Badeaux M, Schneider-Broussard R, Multani AS, Jeter CR, CalhounDavis T, Hu L, Hu J, Tsavachidis S, Zhang W, et al. Critical and distinct roles of p16 and telomerase in regulating the proliferative lifespan of normal human prostate epithelial progenitor cells. J Biol Chem 2008; 283:27957-27972.

39. Purnell DM, Heatfield BM, Trump BF. Immunocytochemical evaluation of human prostatic carcinomas for carcinoembryonic antigen, nonspecific cross-reacting antigen, beta-chorionic gonadotrophin, and prostate-specific antigen. Cancer Res. 2984; 44:285-292.

40. Stein BS, Vangore S, Petersen RO. Immunoperoxidase localization of prostatic antigens. Comparison of primary and metastatic sites. Urol. 1984; 24:146-152.

41. Feiner HD, Gonzalez R. Carcinoma of the prostate with atypical immunohistological features. Clinical and histologic correlates. Am J Surg Pathol. 1986; 10:765-770.

42. Abrahamsson PA, Lilja H, Falkmer S, Wadström LB. Immunohistochemical distribution of the three predominant secretory proteins in the parenchyma of hyperplastic and neoplastic prostate glands. Prostate. 1988; 12:39-46.

43. Gallee MP, Visser-de Jong E, van der Korput JA, van der Kwast TH, ten Kate FJ, Schroeder FH, Trapman J. Variation of prostate-specific antigen expression in different tumour growth patterns present in prostatectomy specimens. Urol Res. 1990; 18:181-187.

44. de Winter JA, Trapman J, Brinkmann AO, Boersma WJ, Mulder E, Schroeder FH, Claassen E, van der Kwast TH. Androgen receptor heterogeneity in human prostatic carcinomas visualized by immunohistochemistry. J Pathol. 1990; 160:329-332.

45. Masai M, Sumiya H, Akimoto S, Yantani R, Chang CS, Liao SS, Shimazaki J. Immunohistochemical study of androgen receptor in benign hyperplastic and cancerous human prostates. Prostate. 1990; 17:293-300.

46. van der Kwast TH, Schalken J, Ruizeveld de Winter JA, van Vroonhoven CC, Mulder E, Boersma W, Trapman J. Androgen receptors in endocrine-therapy-resistant human prostate cancer. Int J Cancer. 1991; 48:189-193.

47. Oesterling JE. Prostate specific antigen: a critical assessment of the most useful tumor marker for adenocarcinoma of the prostate. J Urol. 1991; 145:907-923.

48. Sadi MV, Walsh PC, Barrack ER. Immunohistochemical study of androgen receptors in metastatic prostate cancer.
Comparison of receptor content and response to hormonal therapy. Cancer. 1991; 67:3057-3064.

49. Chodak GW, Kranc DM, Puy LA, Takeda H, Johnson K, Chang C. Nuclear localization of androgen receptor in heterogeneous samples of normal, hyperplastic and neoplastic human prostate. J Urol. 1992; 147:798-803.

50. Sadi MV, Barrack ER. Image analysis of androgen receptor immunostaining in metastatic prostate cancer. Heterogeneity as a predictor of response to hormonal therapy. Cancer. 1993; 71:2574-2580.

51. Ruizeveld de Winter JA, Janssen PJ, Sleddens HM, Verleun-Mooijman MC, Trapman J, Brinkmann AO, Santerse AB, Schroder FH, van der Kwast TH. Androgen receptor status in localized and locally progressive hormone refractory human prostate cancer. Am J Pathol. 1994; 144:735-746.

52. Aihara M, Lebovitz RM, Wheeler TM, Kinner BM, Ohori M, Scardino PT. Prostate specific antigen and gleason grade: an immunohistochemical study of prostate cancer. J Urol. 1994; 151:1558-1564.

53. Tilley WD, Lim-Tio SS, Horsfall DJ, Aspinall JO, Marshall VR, Skinner JM. Detection of discrete androgen receptor epitopes in prostate cancer by immunostaining: Measurement by color video image analysis. Cancer Res. 1994; 54:4096-4102.

54. Pertschuk LP, Macchia RJ, Feldman JG, Brady KA, Levine M, Kim DS, Eisenberg KB, Rainford E, Prins GS, Greene GL. Immunocytochemical assay for androgen receptors in prostate cancer: a prospective study of 63 cases with long-term follow-up. Ann Surg Oncol. 1994; 1:495-503.

55. Hobisch A, Culig Z, Radmayr C, Bartsch G, Klocker H, Hittmair A. Distant metastases from prostatic carcinoma express androgen receptor protein. Cancer Res. 1995; 55:3068-3072.

56. Roudier MP, True LD, Higano CS, Vesselle H, Ellis W, Lange P, Vessella RL. Phenotypic heterogeneity of endstage prostate carcinoma metastatic to bone. Hum Pathol. 2003; 34:646-653.

57. Shah RB, Mehra R, Chinnaiyan AM, Shen R, Ghosh D, Zhou M, Macvicar GR, Varambally S, Harwood J, Bismar TA, Kim R, Rubin MA, Pienta KJ. Androgenindependent prostate cancer is a heterogeneous group of diseases: lessons from a rapid autopsy program. Cancer Res. 2004; 64:9209-9216.

58. Birtle AJ, Freeman A, Masters JR, Payne HA, Harland SJ. Tumour markers for managing men who present with metastatic prostate cancer and serum prostate-specific antigen levels of $<10 \mathrm{ng} / \mathrm{mL}$. BJU Int. 2005; 96:303-307.

59. Davis JN, Wojno KJ, Daignault S, Hofer MD, Kuefer R, Rubin MA, Day ML. Elevated E2F1 inhibits transcription of the androgen receptor in metastatic hormone-resistant prostate cancer. Cancer Res. 2006; 66:11897-11906.

60. Mostaghel EA, Page ST, Lin DW, Fazil L, Coleman IM, True LD, Knudsen B, Hess D1, Nelson CC, Matsumoto AM, 
Bremner WJ, Gleave ME, Nelson PS. Intraprostatic androgens and androgen-regulated gene expression persist after testosterone suppression: therapeutic implications for castrationresistant prostate cancer. Cancer Res. 2007; 67:5033-5041.

61. Tamburrino L, Salvianti F, Marchiani S, Pinzani P, Nesi G, Serni S, Forti G, Baldi E. Androgen receptor (AR) expression in prostate cancer and progression of the tumor: Lessons from cell lines, animal models and human specimens. Steroids. 2012; 77:996-1001.

62. Ginestier C, Hur MH, Charafe-Jauffret E, Monville F, Dutcher J, Brown M, Jacquemier J, Viens P, Kleer CG, Liu S, Schott A, Hayes D, Birnbaum D, et al. ALDH1 is a marker of normal and malignant human mammary stem cells and a predictor of poor clinical outcome. Cell Stem Cell. 2007; 1:555-567.

63. Liu S, Cong Y, Wang D, Sun Y, Deng L, Liu Y, MartinTrevino R, Shang L, McDermott SP, Landis MD, Hong S, Adams A, D'Angelo R, et al. Breast cancer stem cells transition between epithelial and mesenchymal states reflective of their normal counterparts. Stem Cell Reports. 2013; 2:78-91.

64. Dieter SM, Ball CR, Hoffmann CM, Nowrouzi A, Herbst F, Zavidij O, Abel U, Arens A, Weichert W, Brand K, Koch M, Weitz J, Schmidt M, et al. Distinct types of tumorinitiating cells form human colon cancer tumors and metastases. Cell Stem Cell. 2011; 9:357-365.

65. Hermann PC, Huber SL, Herrler T, Aicher A, Ellwart JW, Guba M, Bruns CJ, Heeschen C. Distinct populations of cancer stem cells determine tumor growth and metastatic activity in human pancreatic cancer. Cell Stem Cell. 2007; $1: 313-323$.

66. Sarry JE1, Murphy K, Perry R, Sanchez PV, Secreto A, Keefer C, Swider CR, Strzelecki AC, Cavelier C, Récher C, Mansat-De Mas V, Delabesse E, Danet-Desnoyers G, et al. Human acute myelogenous leukemia stem cells are rare and heterogeneous when assayed in NOD/SCID/IL2Rgammacdeficient mice. J Clin Invest. 2011; 121:384-395.

67. Chen R, Nishimura MC, Bumbaca SM, Kharbanda S, Forrest WF, Kasman IM, Greve JM, Soriano RH, Gilmour LL, Rivers CS, Modrusan Z, Nacu S, Guerrero S, et al. A hierarchy of self-renewing tumor-initiating cell types in glioblastoma. Cancer Cell. 2010; 17:362-375.

68. Liu AY, Roudier MP, True LD. Heterogeneity in primary and metastatic prostate cancer as defined by cell surface CD profile. Am J Pathol. 2004; 165:1543-1556.

69. Issacs JT, Coffey DS. Adaptation versus selection as the mechanism responsible for the relapse of prostatic cancer to androgen ablation therapy as studied in the Dunning R-3327-H adenocarcinoma. Cancer Res. 1981; 41:5070-5075.

70. Craft N, Chhor C, Tran C, Belldegrun A, DeKernion J, Witte ON, Said J, Reiter RE, Sawyers CL. Evidence for clonal outgrowth of androgen-independent prostate cancer cells from androgen-dependent tumors through a two-step process. Cancer Res. 2009; 59:5030-5036. 